\title{
Deciphering Biochemical Responses, Metabolome Analysis and Key Genes Controlling Sorghum [Sorghum Bicolor (L.) Moench] Ion Transport in Responses to Salt Stress
}

Himani Punia ( $\nabla$ puniahimani@hau.ac.in )

Chaudhary Charan Singh Haryana Agricultural University

Jayanti Tokas

Chaudhary Charan Singh Haryana Agricultural University

Anurag Malik

Chaudhary Charan Singh Haryana Agricultural University

Satpal

Chaudhary Charan Singh Haryana Agricultural University

Neeraj Kharor

Chaudhary Charan Singh Haryana Agricultural University

Shikha Yashveer

Chaudhary Charan Singh Haryana Agricultural University

\section{Research Article}

Keywords: antioxidants, ion transporters, oxidative stress, proline, reactive oxygen species (ROS), salinity, sorghum

Posted Date: June 10th, 2021

DOl: https://doi.org/10.21203/rs.3.rs-576430/v1

License: (c) (i) This work is licensed under a Creative Commons Attribution 4.0 International License. Read Full License 
Deciphering biochemical responses, metabolome analysis and key genes controlling sorghum [Sorghum bicolor (L.) Moench] ion transport in responses to salt stress

\author{
Himani Punia ${ }^{1 *}$, Jayanti Tokas ${ }^{1}$, Anurag Malik$^{2}$, Satpal ${ }^{3}$, Neeraj Kharor ${ }^{1} \&$ Shikha Yashveer ${ }^{4}$ \\ ${ }^{1}$ Department of Biochemistry, College of Basic Sciences \& Humanities, CCS Haryana Agricultural \\ University, Hisar-125 004, Haryana, India \\ 2 Department of Seed Science \& Technology, College of Agriculture, CCS Haryana Agricultural University, \\ Hisar-125 004, Haryana, India \\ 3 Forage Section, Department of Genetics \& Plant Breeding, College of Agriculture, CCS Haryana \\ Agricultural University, Hisar-125 004, Haryana, India \\ 4 Department of Molecular Biology, Biotechnology \& Bioinformatics, College of Basic Sciences \& \\ Humanities, CCS Haryana Agricultural University, Hisar-125 004, Haryana, India \\ *email: puniahimani@hau.ac.in
}

Background: Crops usually encounter several abiotic stresses, and salt stress is one of the major constraints affecting plant growth and agricultural productivity globally. Sorghum is not only a valuable source of food but also a potential model for studying and better understanding the salt stress mechanics in the cereals and obtain a better knowledge of their cellular mechanism. Herein, we examined the effects of salt stress on physio-biochemical and molecular responses of sorghum genotypes to determine their tolerance.

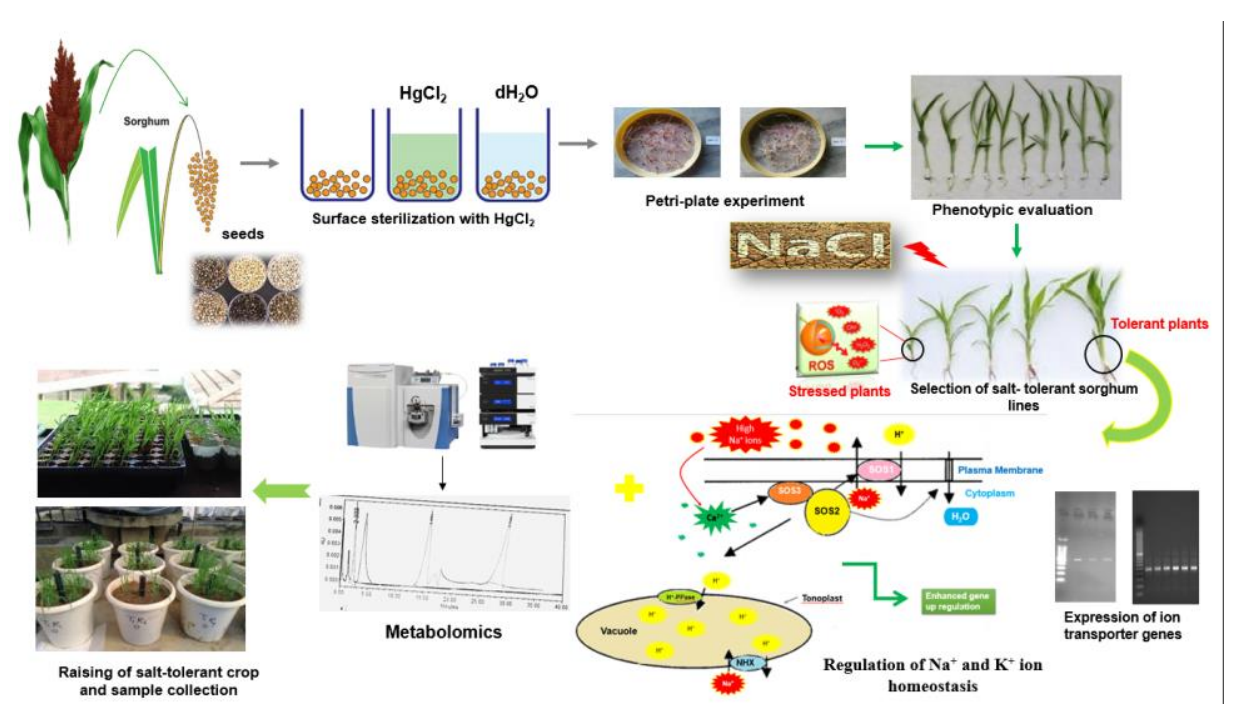

Summary: A pot experiment was conducted in a climate-controlled greenhouse with different salt stress treatments $(60,80,100$, and $120 \mathrm{mM} \mathrm{NaCl})$. The results indicated that exposure to $\mathrm{NaCl}-$ induced salinity reduces growth of sorghum cultivars by damaging chlorophyll pigment and chloroplast, particularly at a higher stress level. SSG 59-3 alleviated adverse effects of salinity by suppressing oxidative stress $\left(\mathrm{H}_{2} \mathrm{O}_{2}\right)$ and stimulating enzymatic and non-enzymatic antioxidant activities (SOD, APX, CAT, POD, GR, GST, DHAR, MDHAR, GSH, ASC, proline, GB), as well as protecting cell membrane integrity (MDA, electrolyte leakage). Salinity also influenced $\mathrm{Na}^{+}$ion efflux and maintained a lower cytosolic $\mathrm{Na}^{+} / \mathrm{K}^{+}$ratio via concomitant upregulation of $\mathrm{SbSOS}_{1}, \mathrm{SbSOS}_{2}$, and $\mathrm{SbNHX}$ ion transporter genes in sorghum genotypes. Overall, these results suggest that $\mathrm{Na}^{+}$ions are retained and detoxified and less stress impact was observed in mature and younger leaves. Based on the above, we deciphered that SSG 59-3 performed better by retaining higher plant water 
status, photosynthetic rate and antioxidant potential and upregulation of ion transporter genes, thereby alleviating stress, which may be augmented as genetic resources to establish sorghum cultivars with improved quality in saline soils.

Keywords: antioxidants; ion transporters; oxidative stress; proline; reactive oxygen species (ROS); salinity; sorghum

\section{Introduction}

Salt stress is one of the major abiotic stresses, drastically affecting global agricultural productivity 1,2 . Salt-affected soils are estimated to comprise $23 \%$ of the cultivated land, approximately 3.5108 ha, the global extent of saline soils to be $412 \mathrm{Mha}$, which closely agrees with the FAO ${ }^{3}$. The annual loss caused by soil salinization in agricultural productivity is estimated to be US\$31 million, and the production potential of up to 46 million ha per year. Soil salinization alone has rendered significant chunks of land unproductive or less productive ${ }^{4}$. It is especially worrisome as urban expansion drives farming into more or less dry land, $30 \%$ of the cultivable soils will become unusable due to salt stress, and global food needs expecting to rise by $70 \%$ to feed over 9.7 billion people by 2050 (http://www.fao.org/wsfs/world-summit/en), requiring agricultural productivity gains on smaller land areas and lower water resources ${ }^{5}$.

Salinity causes multiple responses in plants, particularly physiological, morphological, biochemical and molecular alterations ${ }^{6}$. It induces ion imbalance, leading to ion toxicity, osmotic stress and generation of reactive oxygen production (ROS), cellular damage, oxidative damage of membrane lipids, proteins and nucleic acids ${ }^{7}$. The retention of excess of sodium ions in proteins competes with potassium ions, inhibiting synthesis of metabolic enzymes and thereby protein synthesis ${ }^{8}$. Concentrations of $\mathrm{NaCl}$ higher outside the roots impede water absorption, make water extraction more difficult for plants leading to the osmotic stress 9. High levels of salt in the leaves induce stomata shutting, electron transport impairment and photosynthesis contributing to reduced photosynthetic activity and productivity ${ }^{10-12}$.

Sorghum [Sorghum bicolor (L.) Moench] belongs to the family Poaceae and physiologically classified as $\mathrm{C}_{4}$ plants and ranked fifth among the top five economically valuable cereal crops globally ${ }^{13}$. It is grown worldwide in over 41.14 million hectares of area and accounts for 58.72 million metric tonnes of grains with an average yield of 1.43 metric tonnes per hectare ${ }^{14}$. Sorghum plays a vital role in global food production and is a dietary staple for more than 500 million people from several rural communities and food-insecure people in many parts of the world ${ }^{15}$. It is well known for its adaptability in arid and semi-arid regimes, moderately drought tolerant, and highly biomass productive ${ }^{16,17}$. In the current global climate change scenario, the crop is likely to become more critical due to its more extensive adaptability to high temperature, water scarcity, and saline conditions, making it a valuable feed resource ${ }^{13}$. Sorghum possesses a diverse range of morphological, anatomical and physiological, characteristics that enables it to survive under stress conditions.

Plants emerging in saline soils regulate ion accumulation so that ion toxicity is avoided and appropriate osmotic solutes are retained ${ }^{18}$. This osmotic adjustment retains the volume and turgor pressure of the cells and organelles of the growing plant. The roots of the constantly transpiring plants must exclude the excess of cations and anions in saline soils that also depends on the type of root and plant species to avoid the ion toxicity ${ }^{19}$. Plants respond to the effects of salt stress via a complex network of mechanisms aimed at sustaining cellular metabolism under the prevailing conditions ${ }^{20}$. To scavenge high ROS levels, an efficient system of and enzymatic and non-enzymatic antioxidants is involved ${ }^{17}$. The enzymatic antioxidants include superoxide dismutase (SOD), peroxidase (POX), catalase (CAT), as well as the enzymes of theascorbate (ASC)-glutathione (GSH) cycle [GSH reductase (GR), ASC peroxidase (APX), monodehydroascorbate dehydrogenase (MDHAR), and dehydroascorbate reductase (DHAR)] that 
detoxify ROS ${ }^{7,21}$, while non-enzymatic antioxidants include phenolics, flavonoids, tocopherols, ascorbic acid and glutathione ${ }^{22,23}$ whose up-regulation suggested a pertinent role of theses antioxidants in alleviating salt stress-induced oxidative damage. For example, the intake, partitioning or removal of ions from specialized cells under salinity is necessary for normal growth and development ${ }^{22}$.

Roots are the first organs experiencing high $\mathrm{Na}^{+}$ions which display a greater reduction in growth than shoots. Interestingly, age- related differences in responses in plant cells, tissues and organs have been observed ${ }^{24}$. Variations were however considerably less studied in oxidative stress and antioxidant protection in the different organs and stages of development. Sorghum is an economically important climate resilient cereal crop with wider ecological adaptability. In the current global climate change scenario, the crop is likely to become more critical due to its more extensive adaptability to high temperature, water scarcity, and saline conditions, making it a valuable feed resource. Therefore, this work aims to elucidate the effects of salinity on antioxidant potential, oxidative stress, and expression of stress-inducible genes in roots, young and mature leaves harvested from vegetative and physiological maturity in salt-treated and non-treated sorghum genotypes.

\section{Results}

Biomass accumulation. To assess the effect of high salinity $(\mathrm{NaCl})$ on sorghum growth, biomass (fresh and dry weight) of plants, under different salt concentrations was measured. With the increasing levels of salt stress from control to $120 \mathrm{mM} \mathrm{NaCl}$, a significant reduction in plant fresh and weight was observed among all the genotypes at $\mathrm{p}<0.05$ (Fig. $1 \mathrm{~A}$ and $1 \mathrm{~B}$ ). At $35 \mathrm{DAS}, \mathrm{PC}-5$ had maximum reduction $(79.6 \%)$ in fresh weight while minimum in SSG $59-3(29.9 \%)$ at $100 \mathrm{mM} \mathrm{NaCl}$, while at $120 \mathrm{mM}$, the decline was more, 87.6 $\%$ in PC-5 and $41.9 \%$ in SSG 59-3. At two sampling stages, SSG 59-3 had more biomass production over PC-5. Root length decreased significantly with increasing concentration of $\mathrm{NaCl}$ in all the genotypes at 35 and 95 DAS (Fig. 1C). At 35 DAS, minimum percent reduction of plant height was observed in SSG 59-3 (26\%), and a higher reduction in PC-5 (69\%) at $100 \mathrm{mM} \mathrm{NaCl}$. While at $120 \mathrm{mM}$, the percent decrease was more, PC-5 had a maximum reduction of $78 \%$, while SSG 59-3 had only $36 \%$ reduction over their respective controls. A similar trend was noticed for shoot length (Fig. 1D). SSG 59-3 $(108.6 \mathrm{~cm})$ acquired maximum shoot length compared to PC-5 $(48.3 \mathrm{~cm})$. A significant interaction was found at both sampling stages, i.e., 35 and 95 DAS.

Morpho-physiological analysis. RWC of leaves was relatively low under salt stress as compared to control conditions in all the sorghum genotypes (Fig. 2A). At 35 DAS, the reduction in RWC under salt stress was much higher in PC-5 (5.2\%) as compared to SSG 59-3 (17\%) at $100 \mathrm{mM} \mathrm{NaCl}$. SSG 59-3 maintained RWC under increasing salt concentrations. The osmotic potential of leaves was measured in terms of $\mathrm{MPa}$ at two developmental stages (Fig. 2B). The osmotic potential of leaf declined progressively with the increasing level of salt from 0 to $120 \mathrm{mM} \mathrm{NaCl}$. At $35 \mathrm{DAS}$, values of osmotic potential became more negative in PC-5 than SSG 59-3, i.e.,-1.13 MPa and -0.71 MPa, respectively, at $120 \mathrm{mM} \mathrm{NaCl}$. At $95 \mathrm{DAS}$, trends were similar at 35 DAS.

A significant difference in chlorophyll fluorescence/photochemical quantum yield was observed within the genotypes and treatments (Fig. 2C). At 35 DAS, SSG 59-3 showed more quantum yield than PC5. Percent reduction was higher in PC-5, i.e., $54 \%$ and $62 \%$, and lower in SSG 59-3, i.e., $20 \%$ and $28 \%$ at 100 and $120 \mathrm{mM} \mathrm{NaCl}$, respectively. Up to $100 \mathrm{mM}$, both sorghum genotypes performed better, but at $120 \mathrm{mM}$, the reduction was more, which drastically reduced the photosynthetic rate, and conferred that 100 $\mathrm{mM}$ was under the physiological tolerance range of the crop. After attaining physiological maturity (95 DAS), the quantum yield reduced significantly. Salt stress significantly reduced the chlorophyll stability index (CSI) (\%) of sorghum genotypes at $\mathrm{p}<0.05$ (Fig. 2D). At $35 \mathrm{DAS}$, the reduction was more eminent in genotype PC-5 (65.3\%) trailed by genotype SSG 59-3 (22.9\%). The decline in chlorophyll stability in terms of loss 
of chlorophyll was higher in PC-5 (85.3\%) and lower in SSG 59-3 (30.2\%) at $120 \mathrm{mM} \mathrm{NaCl}$, suggesting the tolerance behavior of SSG 59-3 genotype. At physiological maturity, PC-5 exhibited the highest percent reduction $(81.3 \%)$ at $120 \mathrm{mM} \mathrm{NaCl}$, indicating its susceptibility towards salinity due to severe loss in chlorophyll content, while SSG 59-3 had 46.8 percent reduction, indicating its stability towards chlorophyll content

A
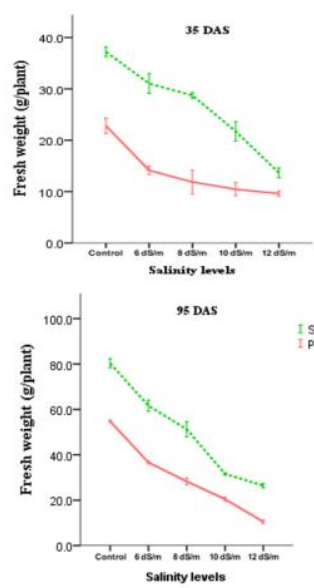

B

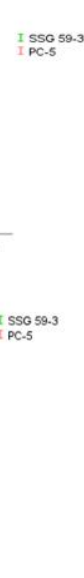

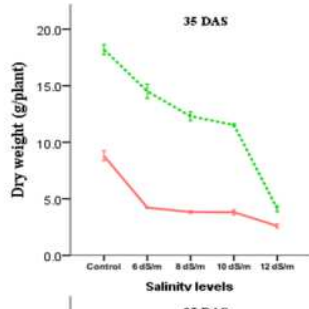

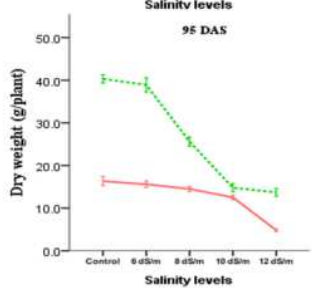

$\mathrm{C}$

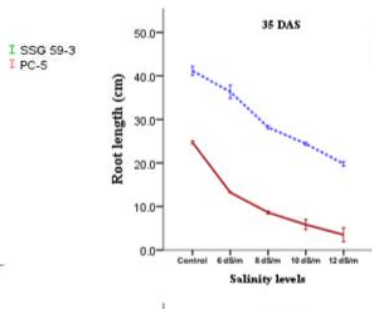

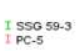

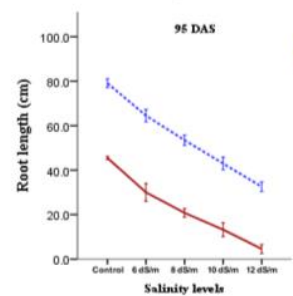

$\mathrm{D}$

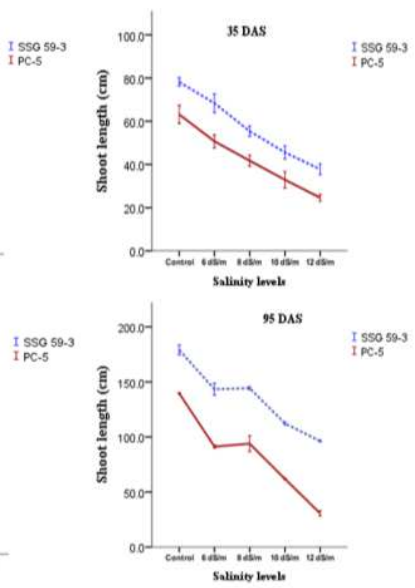

Figure 1 Effect of salt stress on fresh weight (A), dry weight (B), Root length (C), and shoot length (D) of sorghum genotypes at 35 and 95 DAS. Values are means of at least three replicates and significant differences between means, as determined by Tuckey's test $(P<0.05)$.

A
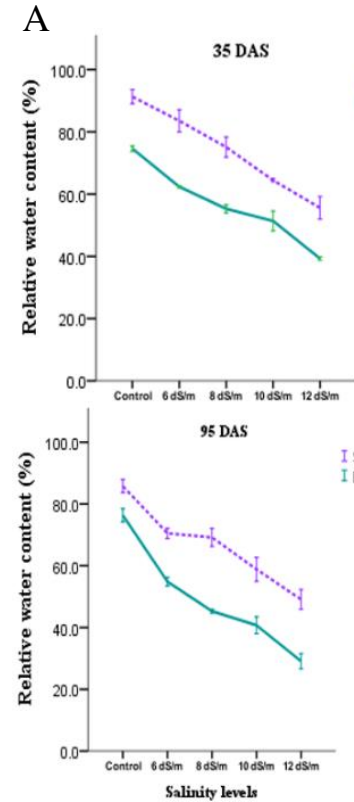

B
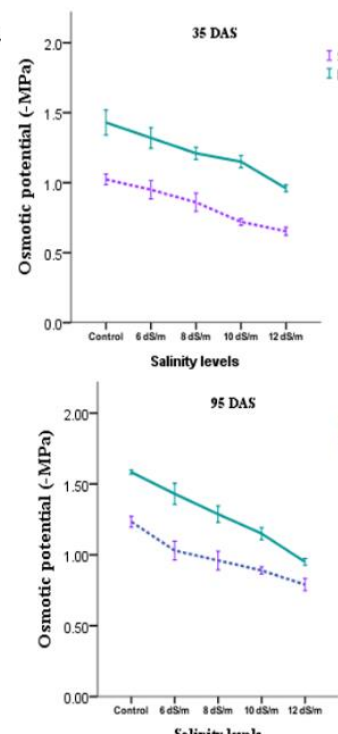

Salinity levele
$\mathrm{C}$
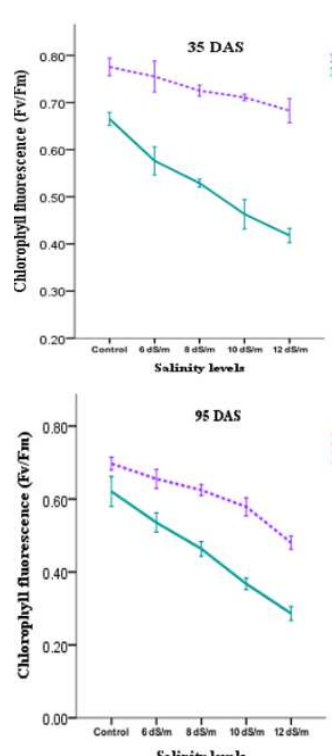

$\mathrm{D}$

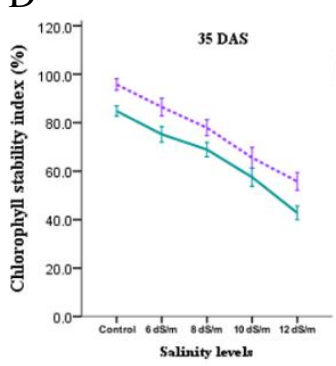

SSG 59-3

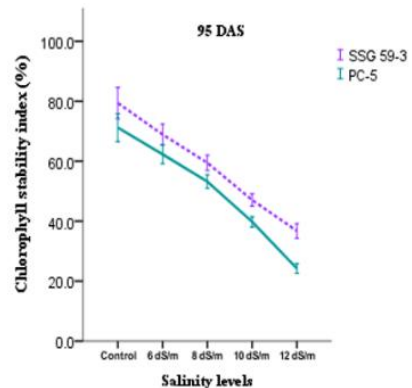

Figure 2 Effect of salt stress on relative water content (A), osmotic potential (B), chlorophyll fluorescence (C), and chlorophyll stability index (D) of sorghum genotypes at 35 and 95 DAS. Values are means of at least three replicates and significant differences between means, as determined by Tuckey's test $(P<0.05)$.

During the vegetative stage, the photosynthetic rate was low and hence, PC-5 (52.5\%) had a decrease in chlorophyll a content as compared to SSG 59-3 (22.5\%) at $100 \mathrm{mM}$ (Fig. 3A). The analysis of 
Fig. 3B demonstrates that as the level of $\mathrm{NaCl}$ decreased from control to $120 \mathrm{mM} \mathrm{NaCl}$, a parallel reduction was recorded in the chlorophyll b content. A considerable difference was observed within the genotypes and treatments. Total chlorophyll content followed the similar pattern (Fig. 3C). The overall mean value of chlorophyll a, chlorophyll b, and total chlorophyll content was maximum at 35 DAS compared to 95 DAS.

A
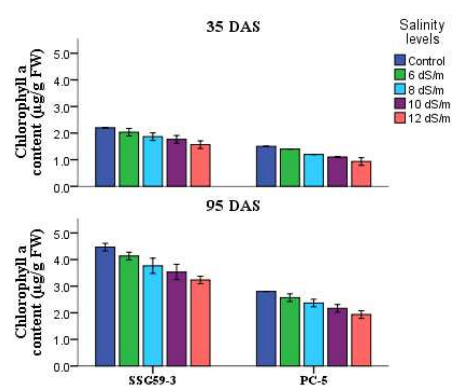
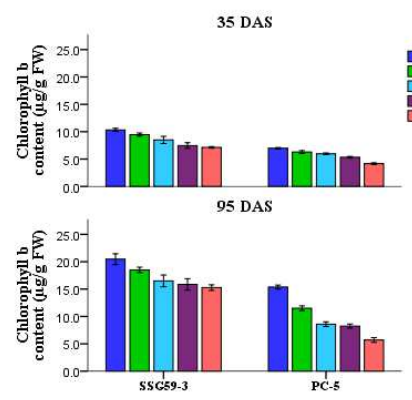

$\mathrm{C}$
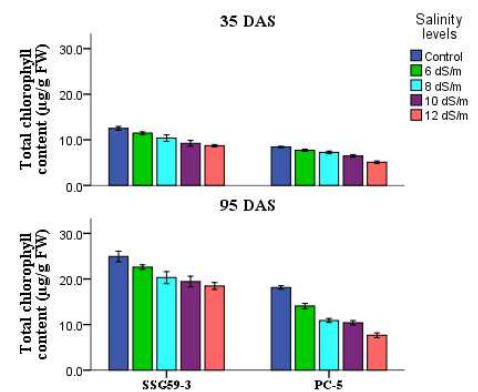

Figure 3 Effect of salt stress on chlorophyll a (A), chlorophyll B (B), and total chlorophyll (C) of sorghum genotypes at 35 and 95 DAS. Values are means of at least three replicates and significant differences between means, as determined by Tuckey's test $(P<0.05)$.

\section{$\mathrm{Na}^{+}: \mathrm{K}^{+}$and $\mathrm{Cl}^{-}$Content}

High soil salinity causes over-accumulation of $\mathrm{Na}^{+}$inside the cell, which may result in ionic imbalances and metabolic toxicity. $\mathrm{Na}^{+}$: $\mathrm{K}^{+}$ratio (Fig. $4 \mathrm{~A}$ ) increased significantly with the increase of applied $\mathrm{NaCl}$ concentration in leaves and in roots, $\mathrm{Na}^{+}$accumulation was more significant in roots only under $120 \mathrm{mM}$ treatment (Fig. 4B). As with the effect of salt on biomass, there was an apparent gradient, with highest $\mathrm{Na}^{+}$ accumulation in roots. SSG 59-3 maintained lower $\mathrm{Na}^{+}$ions. It imported more $\mathrm{K}^{+}$ions, so had a lower $\mathrm{Na}^{+} / \mathrm{K}^{+}$ ratio, while PC-5 excluded fewer $\mathrm{Na}^{+}$ions and had a higher $\mathrm{Na}^{+} / \mathrm{K}^{+}$ratio as $\mathrm{Na}^{+}$competes with $\mathrm{K}^{+}$for uptake through a common transport system. In accord with trends observed in the $\mathrm{Na}^{+}$content in roots, the $\mathrm{Na}^{+}$in leaves also increased, and $\mathrm{K}^{+}$content decreased with increasing salt stress levels.
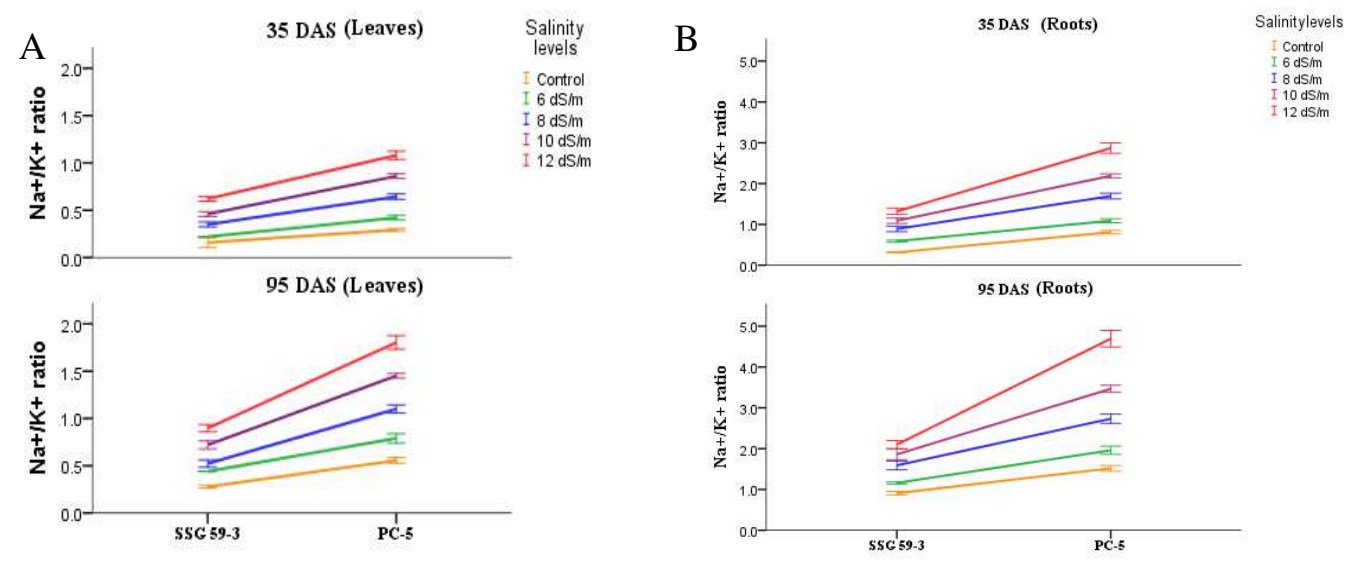

Figure 4 Effect of salt stress on $\mathrm{Na}^{+}: \mathrm{K}^{+}$in leaves $(\mathrm{A})$, and $\mathrm{Na}^{+}: \mathrm{K}^{+}$in roots $(\mathrm{B})$ of sorghum genotypes at 35 and 95 DAS. Values are means of at least three replicates and significant differences between means, as determined by Tuckey's test $(P<0.05)$. 
ASC/GSH cycle components. Mild or severe salinity stress increased SOD activity in I eaves and rootin a concentration independent manner (Fig. 5A). At 35 DAS, the percent increase in SOD activity in leaves was maximum in SSG 59-3 (51\%) considering it as salt-tolerant genotype. In contrast, the increase was less in PC-5 (19\%), suggesting it as salt-susceptible genotype at $100 \mathrm{mM}$. A similar trend was found in roots in all the genotypes; however, SOD activity in roots was lower than leaf tissue at both the growth stages. Differential response of CAT activity (Units $\mathrm{mg}^{-1}$ protein) in leaves and roots is shown in Fig. 5B. At vegetative stage, a significant increase in CAT activity was observed in the leaves of SSG 59-3 (46\%) with a higher decrease in PC-5 (22\%). A similar trend was observed in roots of all the genotypes; however, CAT activity in roots was lower than leaf tissue at both growth stages. A significant increase in POX activity was observed in all the sorghum genotypes (Fig. 5C). In SSG 59-3, the increase in activity was $38 \%$ and $44 \%$ at $100 \mathrm{mM}$ and $120 \mathrm{mM} \mathrm{NaCl}$, whereas PC-5 had lower POX activity (22\% and $29 \%$ ). Roots also had a similar basal level of POX activity as observed in the leaves at both developmental stages.

APX activity increased significantly in SSG 59-3 (55\%), whereas its activity declined in PC-5 (26 $\%)$ at $100 \mathrm{mM} \mathrm{NaCl}$ (Fig. 5D). Further increase in salt concentration enhanced the APX activity, more in SSG 59-3 (65 \%) and less in PC-5 (33\%). The same trend was observed in roots. Differential response of GPX activity (Units $\mathrm{mg}^{-1}$ protein) showed a significant increase, SSG 59-3 (45\%), with decrease in the leaves of salt-sensitive genotype PC-5 (24\%) (Fig. 6A). Salt stress increased the GR activity in both the tolerant and susceptible sorghum genotypes (Fig. 6B). However, the increase was found to be higher in tolerant genotypes. MDHAR activity increased significantly at 35 DAS in the sorghum genotypes under salt stress (Fig. 6C). At 35 DAS, the activity increased by $53 \%$ in SSG $9-3$ while it reduced in PC-5 by $28 \%$ at $100 \mathrm{mM} \mathrm{NaCl}$. Among the studied genotypes, PC-5 showed the lower, while SSG 59-3 had the higher DHAR activity under salinity conditions (Fig. 6D).

A
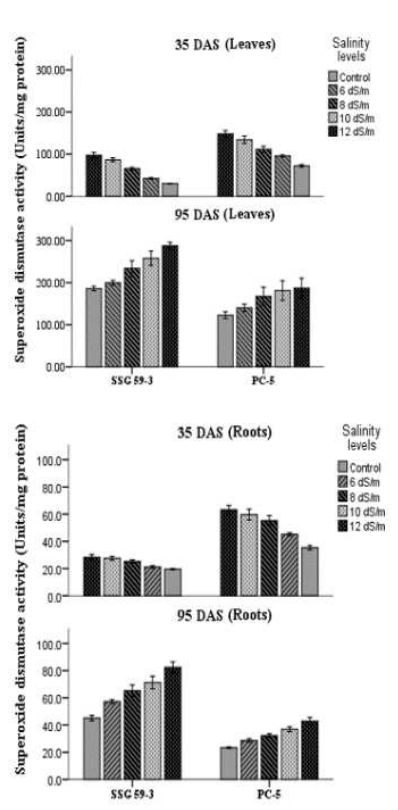

B
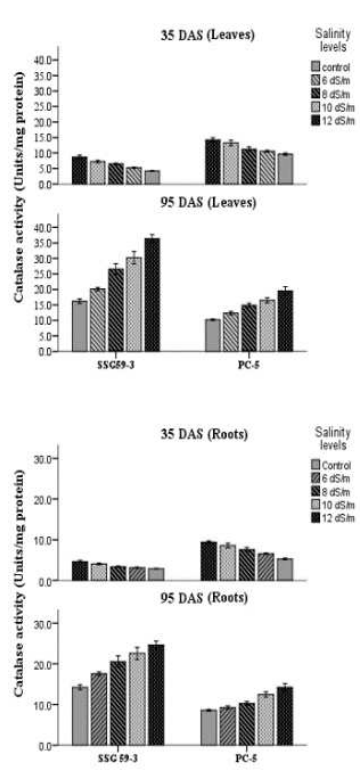

$\mathrm{C}$
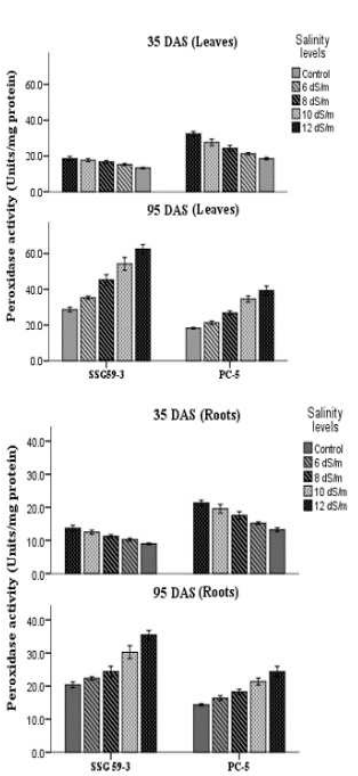

$\mathrm{D}$
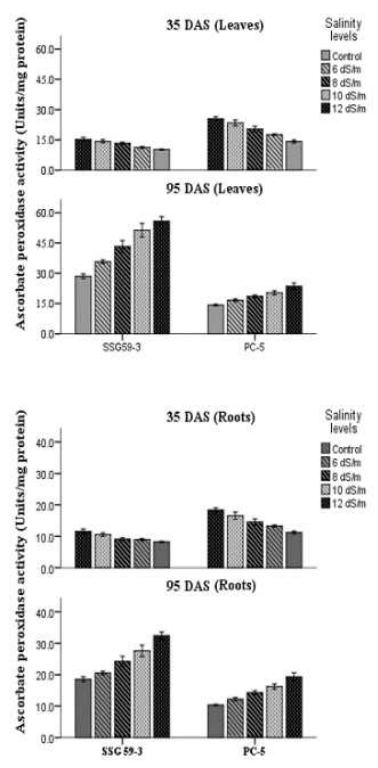

Figure 5 Effect of salt stress on superoxide dismutase (SOD, A), catalase (CAT, B), peroxidase (POX, C), and ascorbate peroxidase (APX, D) of sorghum genotypes at 35 and 95 DAS. Values are means of at least three replicates and significant differences between means, as determined by Tuckey's test $(P<0.05)$. 

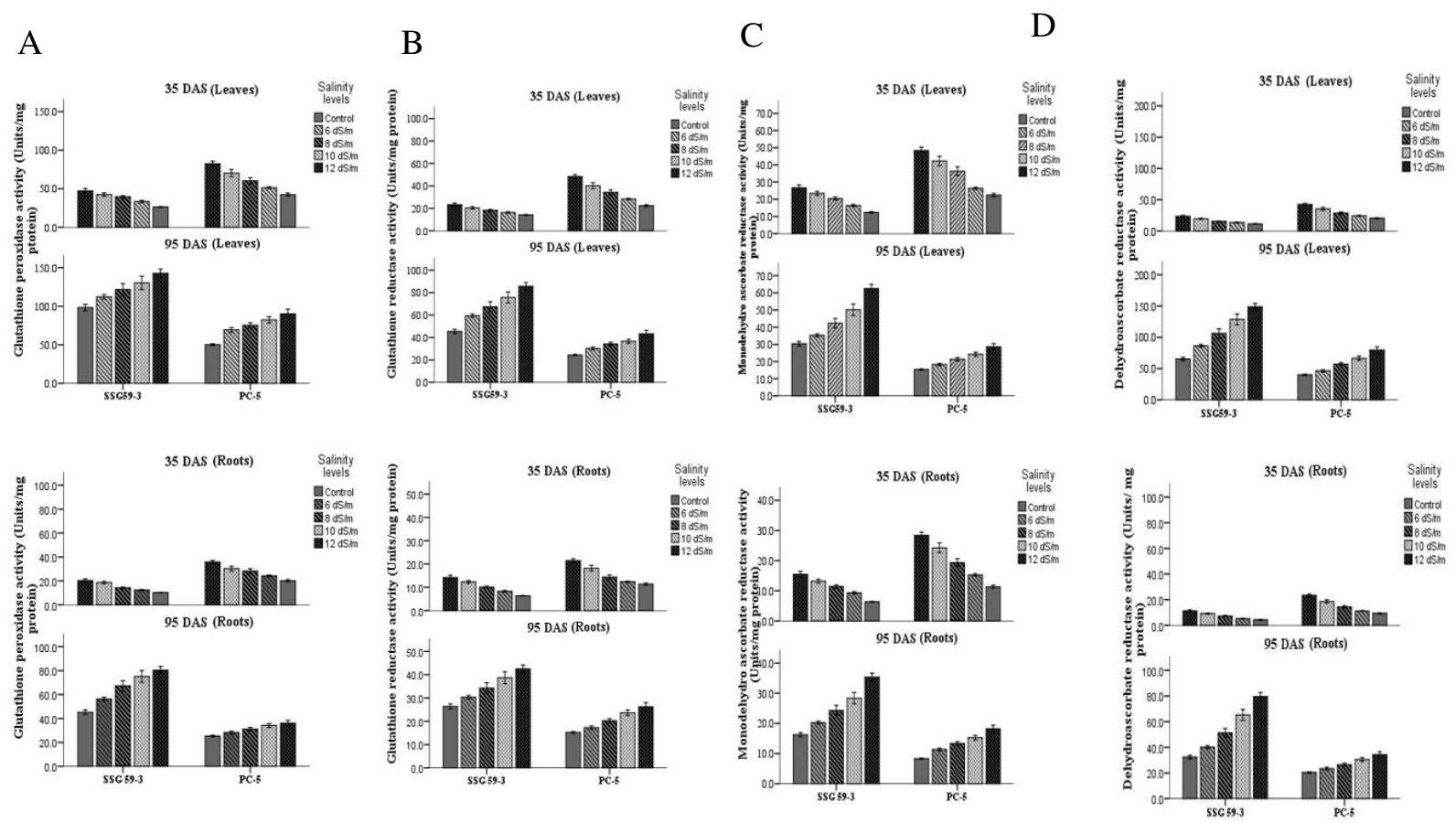

Figure 6 Effect of salt stress on glutathione peroxidase (GPX, A), glutathione reductase (GR, B), monodehydroascorbate reductase (MDHAR, C), and dehydroascorbate reductase (DHAR, D) of sorghum genotypes at 35 and 95 DAS. Values are means of at least three replicates and significant differences between means, as determined by Tuckey's test $(P<0.05)$.

Enzymatic antioxidants. Salt stress resulted in a significant increase in total glutathione content in leaves at both stages (Fig. 7A). At 100 mM, total glutathione content in SSG 59-3 was $54 \%$ as compared to PC5 , where the percent increase was only $21 \%$. A higher concentration of $\mathrm{Na}^{+}$ions had a pronounced effect on total glutathione content, which further increased the glutathione content by $69 \%$ in SSG 59-3 and 32 $\%$ in PC-5. A higher concentration of $\mathrm{Na}^{+}$ions has a pronounced effect on total glutathione content, further increased the GSH content (Fig. 7B) by $56 \%$ in SSG 59-3 and $31 \%$ in PC-5. In oxidized glutathione (GSSG), the percent increase was more in the case of SSG 59-3 (52\%) than PC-5 (27\%) (Fig. 7C). In roots, the values of total glutathione, GSSG, and GSH were not higher as compared to leaves.

In all plant parts, there was a significant increase of ascorbic acid (ASC) under salinity stress (Fig. 8A and 8B). At 35 DAS, ASC content increased by $52.51 \%$ in SSG $59-3$ as compared to PC-5 where percent increase was only $23 \%$ at $100 \mathrm{mM} \mathrm{NaCl}$. A significant decline in carotenoid content of all the genotypes under stress conditions was observed with more decrease in salt susceptible genotype (PC-5) as compared to the tolerant one (SSG 59-3) at both the developmental stages (Fig. 8C). Higher percent reduction was recorded in PC-5, i.e., $40 \%$ and $52 \%$, and lower percent reduction in SSG 59-3, i.e., $18 \%$ and $24 \%$ at $100 \mathrm{mM}$ and $120 \mathrm{mM} \mathrm{NaCl}$, respectively.

Antioxidant capacity and polyphenolic compounds. Antioxidant activities viz. FRAP, DPPH and ABTS were evaluated to exploit the antioxidant potential of two sorghum genotypes at $p<0.05$ (Table 1). The red coloured SSG 59-3 grains showed high FRAP and DPPH activities as compared to the PC-5. In ABTS assay, SSG $59-3$ exhibited highest antioxidant activity at $43.76 \pm 0.23 \mathrm{mg} / 100 \mathrm{~g}$ and lowest was exhibited by white PC- 5 grains at $20.24 \pm 0.15 \mathrm{mg} / 100 \mathrm{~g}$. In the FRAP assay, SSG 59-3 exhibited highest antioxidant activity at $16.64 \pm 0.10 \mathrm{mg} / \mathrm{g}$ TE, while lower was showed by white grains PC-5. A significant difference in total phenolic content was observed between different sorghum varieties. The red pericarp SSG 59-3 had 
the highest TPC $940.73 \pm 6.7 \mathrm{mg} / 100 \mathrm{~g}$ GAE. The TPC over $291.18 \pm 3.87 \mathrm{mg} / 100 \mathrm{~g}$ GAE was less in white pigmented PC-5. Similar results were observed for flavanols and o-hydroxy phenols.
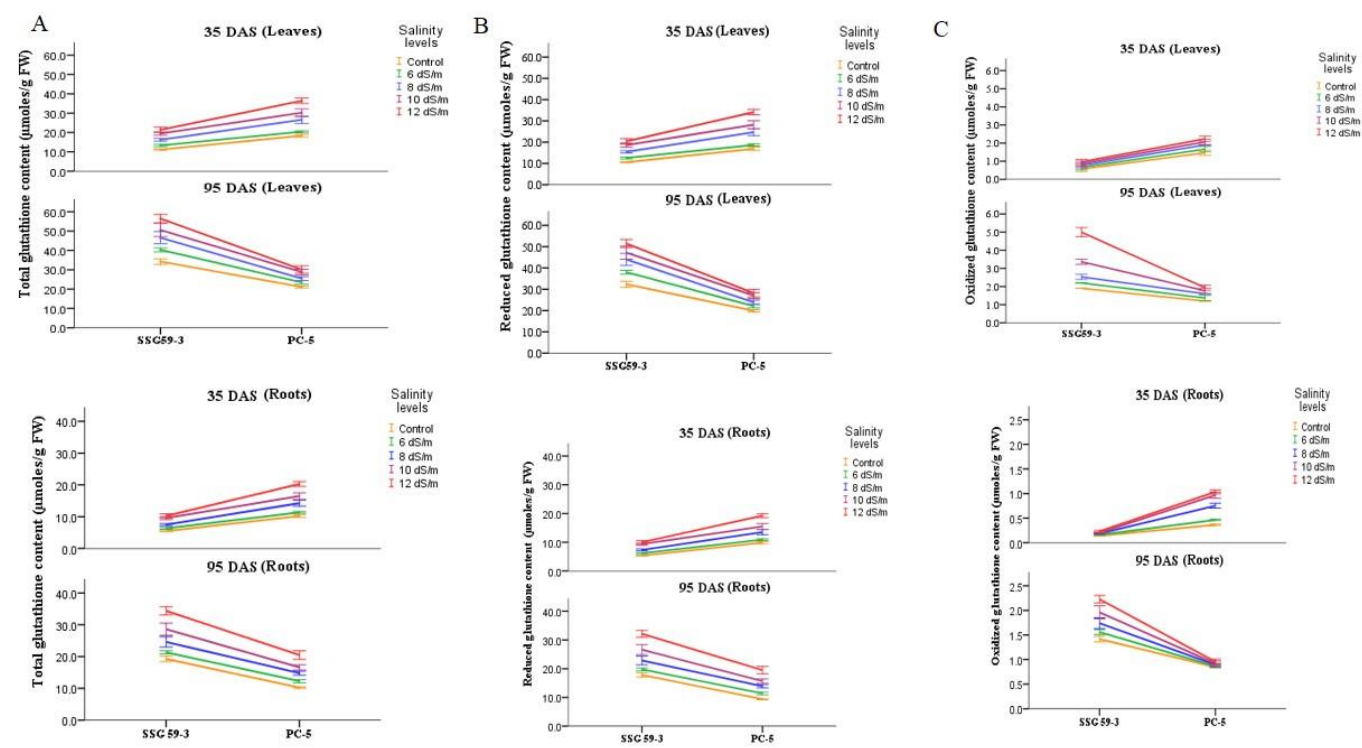

Figure 7 Effect of salt stress on total glutathione (A), reduced glutathione (GSH, B), and oxidized glutathione (GSSG, C) of sorghum genotypes at 35 and 95 DAS. Values are means of at least three replicates and significant differences between means, as determined by Tuckey's test $(P<0.05)$.
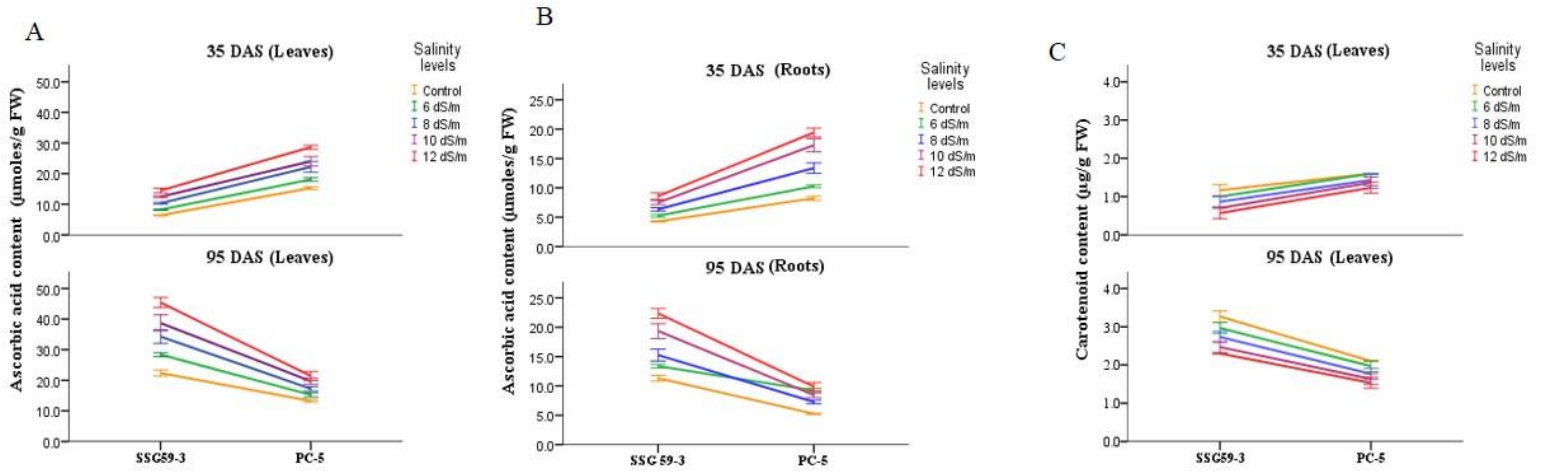

Figure 8 Effect of salt stress on ascorbic acid (ASC, A and B) and carotenoids (B) of sorghum genotypes at 35 and 95 DAS. Values are means of at least three replicates and significant differences between means, as determined by Tuckey's test $(P<0.05)$.

Table 1. Antioxidant activity and polyphenolic composition of sorghum grains

\begin{tabular}{lllllllll}
\hline Variety & $\begin{array}{l}\text { DPPH } \\
\text { TE/100g }\end{array}$ & $\begin{array}{l}\text { FRAP } \\
\text { TE/100g }\end{array}$ & $\begin{array}{l}\text { ABTS } \\
\mathbf{m g} / \mathbf{1 0 0 g}\end{array}$ & $\begin{array}{l}\text { TPC } \mathbf{m g} \text { GAE } \\
/ \mathbf{1 0 0 g}\end{array}$ & $\begin{array}{l}\text { TFC } \\
\text { RE/100g }\end{array}$ & $\begin{array}{l}\text { Flavanols } \\
\mathbf{m g} / \mathbf{1 0 0 g} \text { DW }\end{array}$ & $\begin{array}{l}\text { O- } \\
\text { Hydoxyphenols } \\
\mathbf{m g} / \mathbf{1 0 0 g} \text { DW }\end{array}$ \\
\hline $\begin{array}{l}\text { SSG 59- } \\
3\end{array}$ & $22.35 \pm 0.11^{\mathrm{a}}$ & $16.44 \pm 0.10^{\mathrm{a}}$ & $43.76 \pm 0.23^{\mathrm{a}}$ & $940.73 \pm 6.79^{\mathrm{a}}$ & $45.34 \pm 0.35^{\mathrm{a}}$ & $0.292 \pm 0.005^{\mathrm{a}}$ & $0.924 \pm 0.021^{\mathrm{a}}$ \\
\hline PC-5 & $9.67 \pm 0.07^{\mathrm{d}}$ & $7.13 \pm 0.25^{\mathrm{c}}$ & $20.24 \pm 0.08^{\mathrm{d}}$ & $291.18 \pm 3.87^{\mathrm{e}}$ & $17.23 \pm 0.11^{\mathrm{c}}$ & $0.117 \pm 0.003^{\mathrm{d}}$ & $0.243 \pm 0.005^{\mathrm{b}}$ \\
\hline
\end{tabular}


a-b Values with different superscripts in the same row are significantly different at $p<0.05$. DW (Dry weight basis), GAE (Gallic acid equivalents), RE (Rutin equivalents), TPC (Total phenolic content), TFC (Total flavanoid content), ABTS (2,4,6-Tris(2-pyridyl)-s-triazine), FRAP (Ferric reducing ability of plasma assay), DPPH (2, 2-diphenyl-1-picrylhydrazyl), and TE (Trolox equivalents).

Compatible solutes. Accumulation of compatible solutes viz. proline (Fig. 9A) and glycine betaine (Fig. 9B) increased considerably in leaves and roots of sorghum genotypes under salt stress. For proline, the percent increase was maximum in SSG 59-3 (50\%) while PC-5 had minimum of $23 \%$. For glycine betaine, the percent increase was maximum in SSG 59-3 (58 \%) while PC-5 had by $23 \%$ at $100 \mathrm{mM}$. In roots, glycine betaine level increased significantly, but the accumulation level was less from leaves in all the genotypes. Salt stress resulted in a significant increase in total soluble sugars (TSS) (Fig. 9C). At $100 \mathrm{mM}$, SSG 59-3 accumulated $52 \%$ TSS as compared to PC-5, where the percent increase was only $31 \%$. A higher concentration of $\mathrm{Na}^{+}$ions had a pronounced effect on TSS, which further increased the total soluble sugar content by 68 \% in SSG 59-3 and 48 \% in PC-5. In roots, the values of total soluble sugar content were less as compared to leaves.
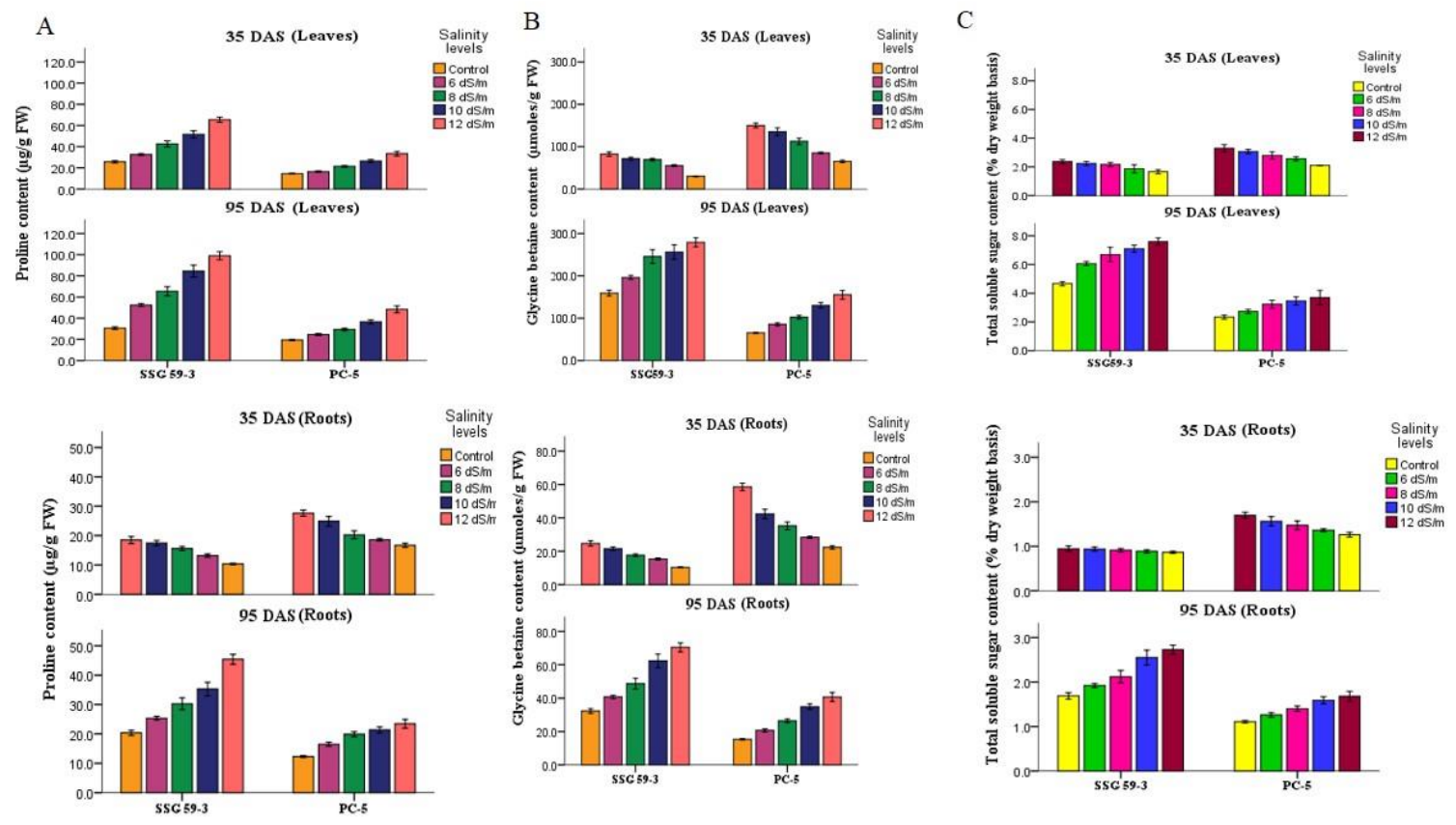

Figure 9 Effect of salt stress on proline (Pro, A), glycine betaine (GB, B), and total soluble carbohydrates (TSC, C) of sorghum genotypes at 35 and 95 DAS. Values are means of at least three replicates and significant differences between means, as determined by Tuckey's test $(P<0.05)$.

Oxidative Stress Markers. Salt stress also leads to higher accumulation of ROS, which disturb cellular redox homeostasis, and result in oxidative damage. $\mathrm{H}_{2} \mathrm{O}_{2}$ content and markers of oxidative damage of cell membranes, i.e., relatives stress index (RSI) and malondialdehyde (MDA) were measured (Fig. 10A). Increase in the $\mathrm{NaCl}$ concentration resulted in a significant increase in the accumulation of $\mathrm{H}_{2} \mathrm{O}_{2}$ content, more particularly in roots than leaves. Following the trend of $\mathrm{H}_{2} \mathrm{O}_{2}, \mathrm{RSI}$ (Fig. 10B), and MDA (Fig. 10C) also increased significantly $(p<0.05)$ in leaves and root, more particularly at $120 \mathrm{mM} \mathrm{NaCl}$ in PC-5. Thus, oxidative stress parametersindicate that root tissues suffered the most from the salinity- induced oxidative stress, followed by leaves. SSG 59-3 accumulated less stress markers due to oxidative damage. 
Polyamines. During plant maturation the, total polyamine concentration remains constant, but under stressed conditions, their level of accumulation enhanced (Fig. 11). A typical chromatogram of benzoylated polyamine standards separated by a C18 reverse phase HPLC column is illustrated in Fig. 12A. The identities of the peaks were confirmed by adding polyamine standards to the extract of the plant tissue (Fig. 12B). Retention times in minutes shown at the tip of each peak are stable and consistently reproducible. Major side products of the benzoyl reaction on the left side of the chromatogram are eluted and separated very clearly from benzoylated polyamines. The naturally occurring amines are putrescine (Put) (Mol. wt. 161.07), spermidine (Spd) (Mol. wt. 145.25), and spermine (Spm) (Mol. wt. 202.34). The amount of individual amine represented at each peak on the chromatogram is $0.05 \mathrm{mM}$. The chromatogram in Figure 2B shows the separation of naturally occurring polyamines from leaf tissue of sorghum plant including the hexanediamine internal standard. Each peak represents the increased levels of Put, Spd, and Spm at 100 $\mathrm{mM} \mathrm{NaCl}$ concentration in sorghum genotypes.

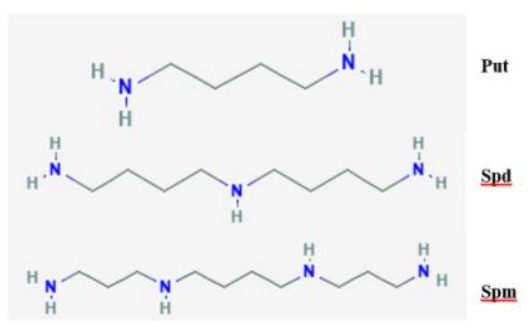

Figure 11 Chemical structures of the polyamines discussed in this study
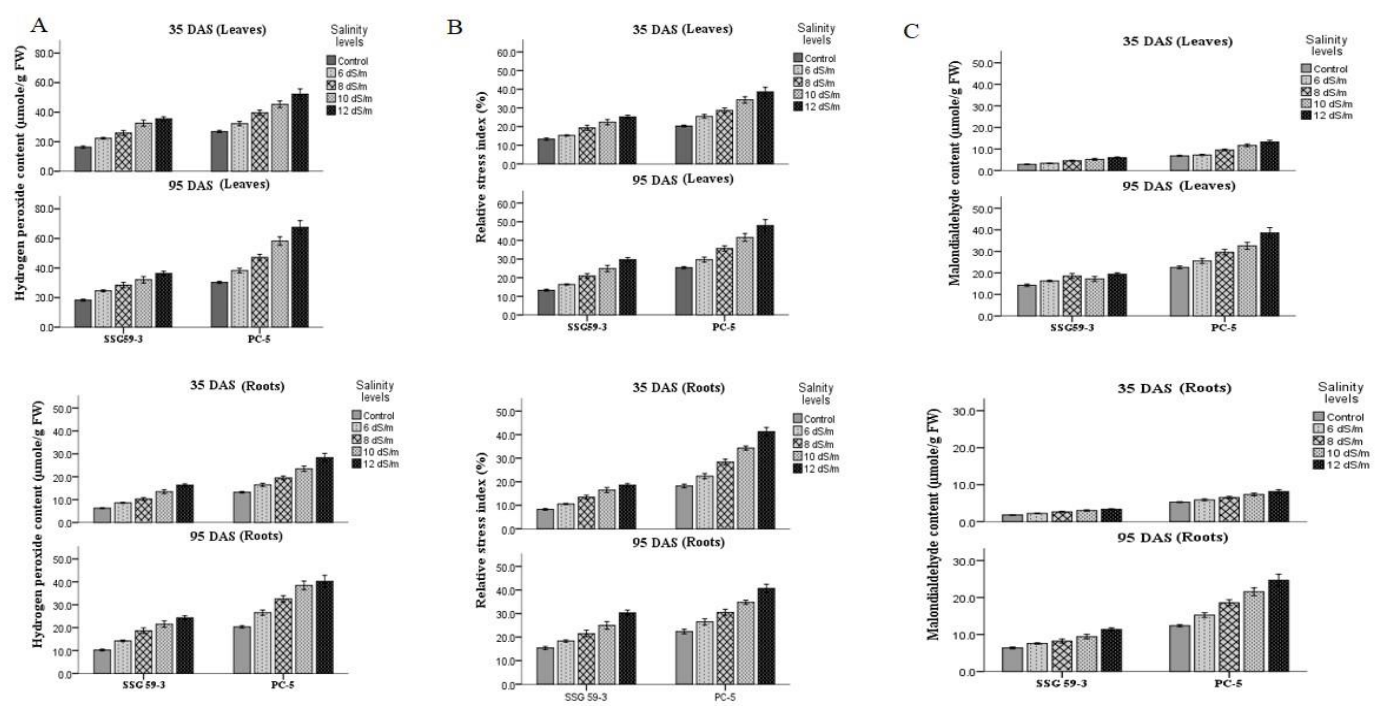

Figure 10 Effect of salt stress on hydrogen peroxide $\left(\mathrm{H}_{2} \mathrm{O}_{2}, A\right)$, relatives stress index $(\mathrm{RSI}, \mathrm{B})$, and malondialdehyde (MDA, C) of sorghum genotypes at 35 and 95 DAS. Values are means of at least three replicates and significant differences between means, as determined by Tuckey's test $(P<0.05)$.

Gene expression analysis of ion transprter genes. Semi-quantitative RT-PCR has now become the most common approach for quantification and comparison of gene expression levels due to its robustness, precision and accuracy. The PCR product using specific primer of ion transporter genes viz. SOS1, SOS2, $\mathrm{NHX}$, and $\mathrm{H}^{+}$-PPase indicated that the appearance of single band (Fig. 13 and 14) and their up regulation during salinity indicated the antioxidative cellular defense mechanism to combat the toxic effects of salt accumulation inside the cytoplasm. In SSG 59-3, the higher expression of SOS1 (Fig. 13A) and SOS2 (Fig. 13B) under high $\mathrm{Na}^{+}$ions indicated its tolerance behavior to exclude the toxic effects of $\mathrm{Na}^{+}$ions, while in 
PC-5, the up-regulation of these genes was lower (Fig. 13A and 13B). The expression was more at 120 $\mathrm{mM} \mathrm{NaCl}$ salt concentration. The expression level of $\mathrm{NHX}$ (Fig. 14A) and $\mathrm{H}^{+}$-PPase (Fig. 14B) peaked at 100 and $120 \mathrm{mM} \mathrm{NaCl}$ salinity. Actin constitutively expressed stably under all salt treatments (Fig. 14C). The higher expression of ion transporter genes under high salinity indicate that SSG 59-3 may be utilized as salt-tolerant crop due to its better genetic and agronomical traits. The detection of salt tolerant genes could be adding a molecular base to the application of identification of salt tolerant genotypes in sorghum.
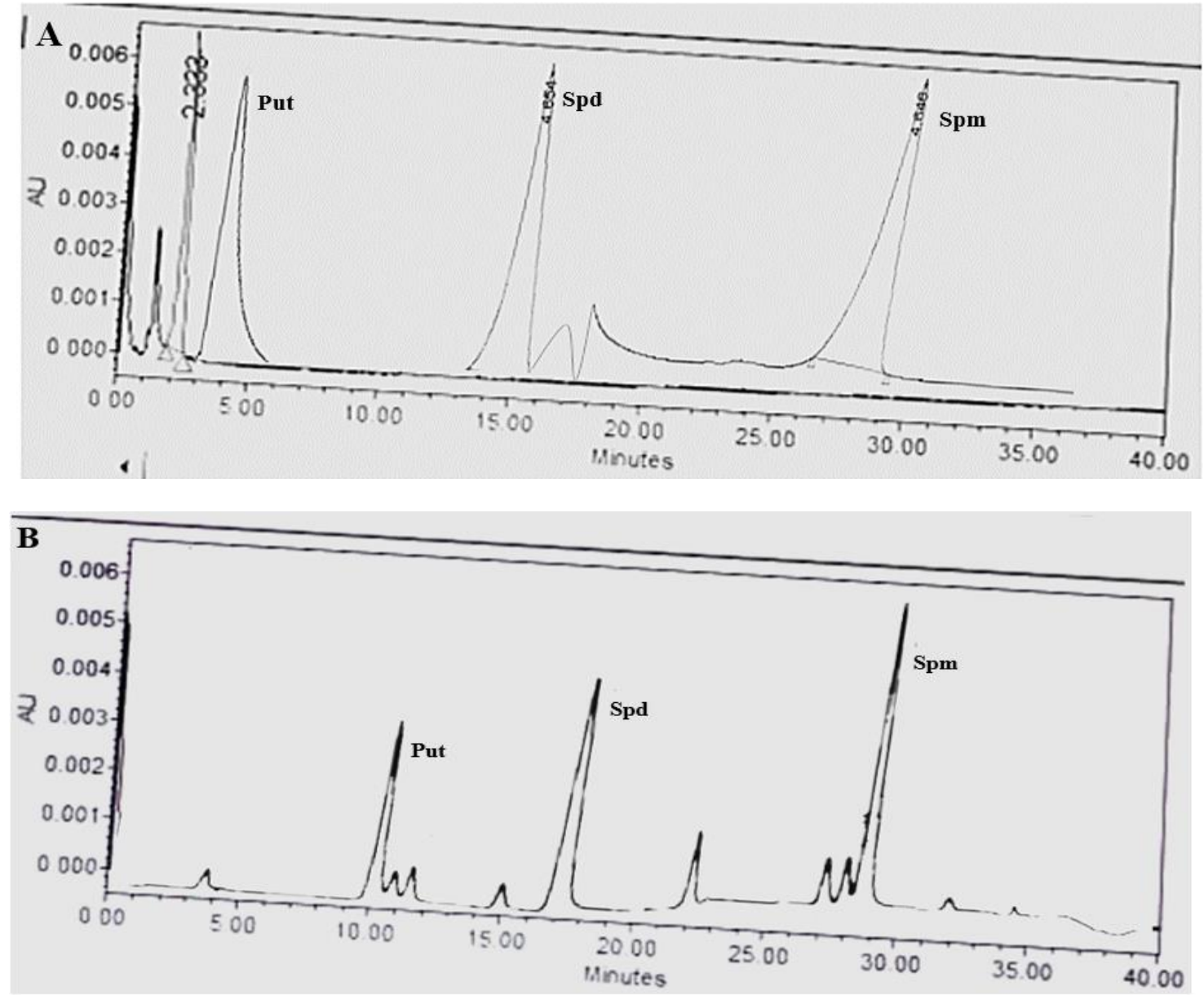

Figure 12 HPLC chromatogram and elusion profile of benzoylated polyamine (A) HPLC of benzoylated polyamine standards; Put, Spd and Spm at $0.05 \mathrm{mM}$ concentration (B) Identification of polyamines in sorghum extracts with each of each Put, Spd and Spm. 

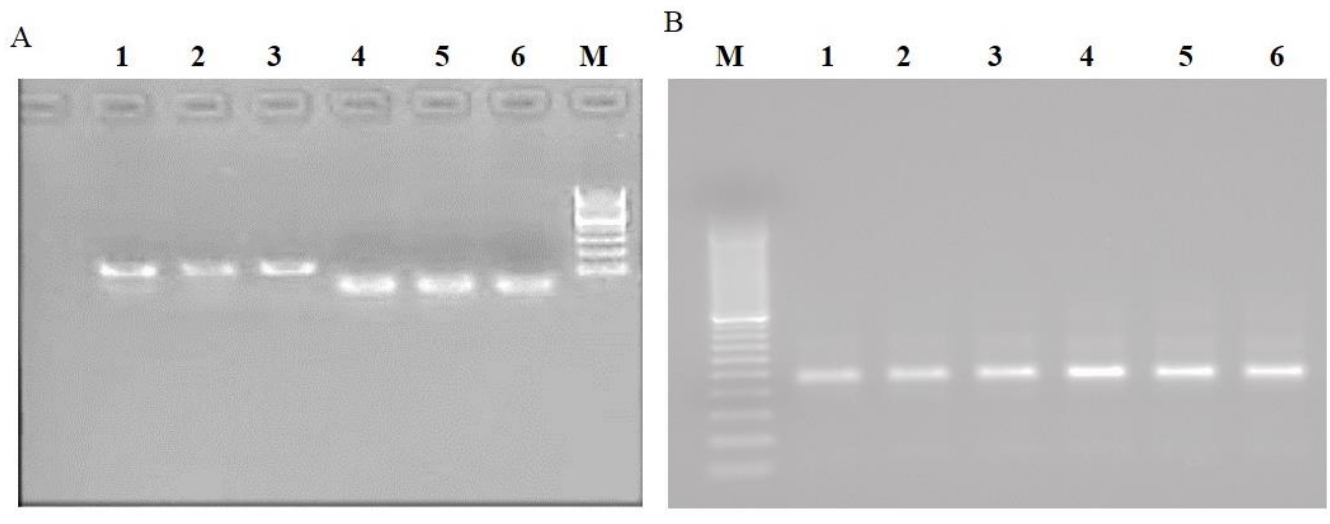

Figure 13 Semi-quantitative RT-PCR analysis of ion transporter genes. (A) salt overly sensitive 1 (SOS1): Lane 1: PC-5 (Control); Lane 2: PC-5 (100 mM NaCl); Lane 3: PC-5 (120 mM NaCl); Lane 4: SSG 59-3 (Control); Lane 5: SSG 59-3 (100 mM NaCl); Lane 6: SSG 59-3 (120 mM NaCl) (B) salt overly sensitive 2 (SOS2): ): Lane 1: PC-5 (Control); Lane 2: PC-5 (100 mM NaCl); Lane 3: PC-5 (120 mM NaCl); Lane 4: SSG 59-3 (Control); Lane 5: SSG 59-3 (100 mM NaCl); Lane 6: SSG 59-3 (120 mM NaCl); M: molecular marker.

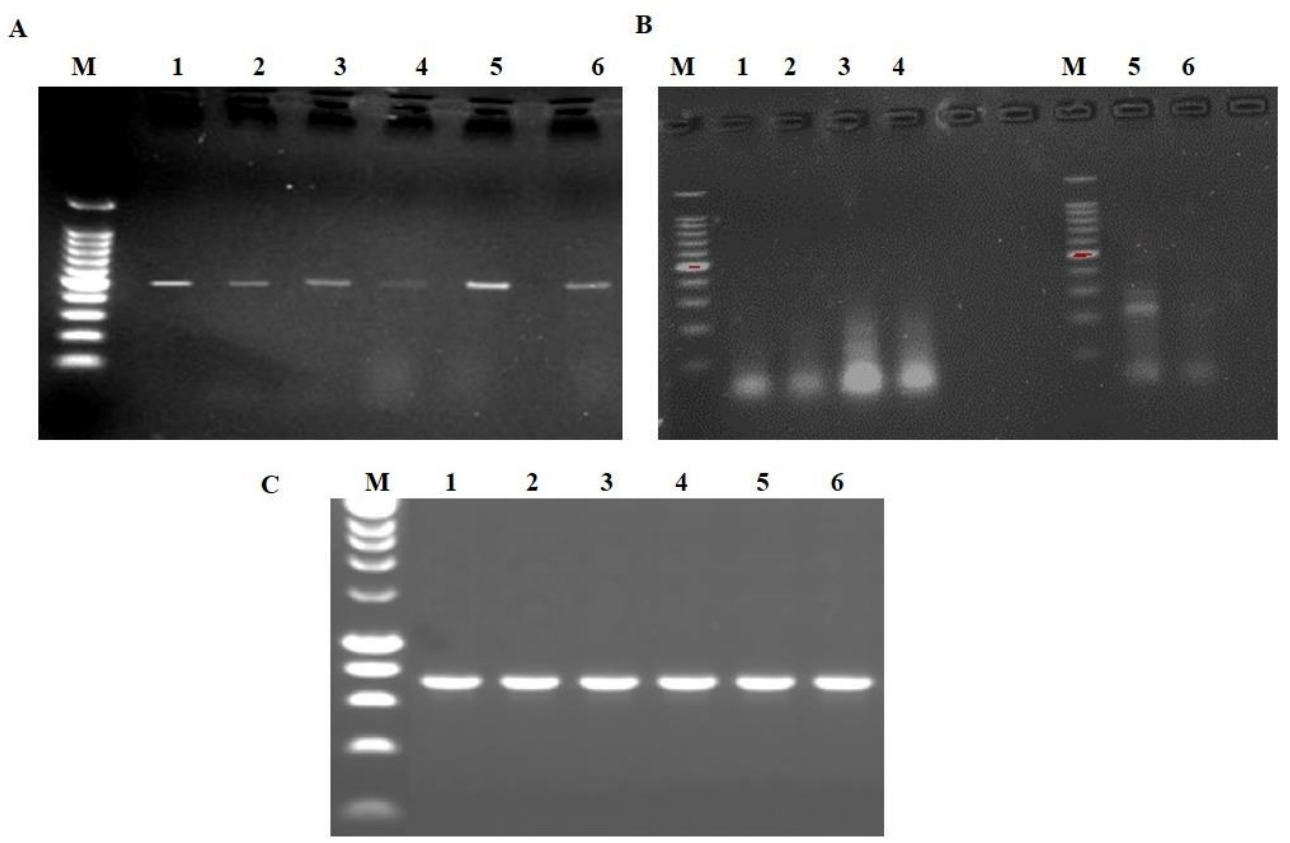

Figure 14 Semi-quantitative RT-PCR analysis of ion transporter genes in sorghum. (A) vacoular pyrophospatase ( $\left.H^{+}-P P a s e\right)$ : Lane 1: SSG 59-3 (120 mM NaCl); Lane 2: SSG 59-3 (100 mM NaCl); Lane 3: SSG 59-3 (Control); Lane 4: PC-5 (Control); Lane 5: PC-5 (100 mM NaCl); Lane 6: PC-5 (120 mM NaCl); (B) sodium proton antiporter (NHX): Lane 1: PC-5 (120 mM NaCl); Lane 2: PC-5 (100 mM NaCl); Lane 3: SSG 59-3 (120 mM NaCl); Lane 4: SSG 59-3 (100 mM NaCl); Lane 5: SSG 59-3 (Control); Lane 6: PC-5 (Control); (C): Actin (act1): constitutive expression of actin under different salinity levels; Lane 1: PC-5 (Control); Lane 2: PC-5 (100 mM NaCl); Lane 3: PC-5 (120 mM NaCl); Lane 4: SSG 59-3 (Control); Lane 5: SSG 59-3 (100 mM NaCl); Lane 6: SSG 59-3 (120 mM NaCl); M: molecular marker. 
Yield traits. SSG 59-3 was found significantly superior in retaining the maximum number of leaves per plant as compared to other genotypes at different salinity levels (Table 2). Plant height decreased significantly with increasing salinity levels in sorghum genotypes at $\mathrm{p}<0.05$ (Table 2). At $35 \mathrm{DAS}$, the percent decline was higher in PC-5 (76.8 \%) while lower in SSG 59-3 (26\%) over their respective controls. The number of tillers per plant was more pronounced at physiological maturity due to increased biomass and dry matter (Table 3). During physiological maturity, the percent decrease in the number of tillers was observed more in PC-5 at 100 and $120 \mathrm{mM}$ i.e., $19 \%$ and $59 \%$, respectively, while in SSG 59-3, the percent decline was less i.e., $8 \%$ and $19 \%$, respectively. At physiological maturity, the harvested seeds showed a higher percentage reduction in seed yield in PC-5 (42 \%) while lower was noted in SSG 59-3 (13\%) (Table 3). SSG 59-3 was found superior in retaining seed yield at different salinity levels.

Table 2. Yield attributing traits in sorghum under salt stress

\begin{tabular}{|c|c|c|c|c|c|c|c|c|}
\hline \multirow{2}{*}{$\begin{array}{c}\text { Stages } \\
\text { Genotypes }\end{array}$} & \multicolumn{4}{|c|}{ Vegetative stage } & \multicolumn{4}{|c|}{ Physiological maturity } \\
\hline & SSG 59-3 & PC 5 & SSG 59-3 & PC 5 & SSG 59-3 & PC 5 & SSG $59-3$ & PC 5 \\
\hline Character & \multicolumn{2}{|c|}{ Plant height a } & \multicolumn{2}{|c|}{$\begin{array}{l}\text { Number of } \\
\text { leaves/plant }\end{array}$} & \multicolumn{2}{|c|}{ Plant height a } & \multicolumn{2}{|c|}{$\begin{array}{l}\text { Number of } \\
\text { leaves/plant }\end{array}$} \\
\hline Control & $77.33 \pm 1.2$ & $67.70 \pm 2.1$ & $10.0 \pm 0.23$ & $6.0 \pm 0.06$ & $190.10 \pm 22.6$ & $154.23 \pm 11.3$ & $13.0 \pm 0.06$ & $8.0 \pm 0.11$ \\
\hline $6 \mathrm{dSm}^{-1}$ & $72.27 \pm 2.3$ & $53.0 \pm 1.1$ & $9.0 \pm 0.45$ & $5.0 \pm 0.11$ & $176.53 \pm 15.6$ & $123.37 \pm 13.2$ & $10.0 \pm 0.11$ & $7.0 \pm 0.10$ \\
\hline $8 \mathrm{dSm}^{-1}$ & $67.80 \pm 2.4$ & $41.60 \pm 1.5$ & $8.0 \pm 0.12$ & $4.0 \pm 0.14$ & $158.63 \pm 14.2$ & $81.43 \pm 13.5$ & $9.0 \pm 0.06$ & $6.0 \pm 0.13$ \\
\hline $10 \mathrm{dSm}^{-1}$ & $57.77 \pm 1.6$ & $34.47 \pm 1.9$ & $7.0 \pm 0.16$ & $4.0 \pm 0.16$ & $145.13 \pm 13.3$ & $64.40 \pm 14.6$ & $8.0 \pm 0.07$ & $6.0 \pm 0.06$ \\
\hline $12 \mathrm{dSm}^{-1}$ & $49.03 \pm 1.9$ & $24.60 \pm 1.4$ & $6.0 \pm 0.21$ & $3.0 \pm 0.09$ & $128.10 \pm 12.6$ & $53.60 \pm 12.8$ & $7.0 \pm 0.09$ & $4.0 \pm 0.09$ \\
\hline
\end{tabular}

C.D. at $5 \%$ level of significance

a Stage $=1.394$, Genotype $=1.394$, Treatment $=2.204$, Stage $\times$ Genotype $=1.972$, Stage $\times$ Treatment $=$ 3.117, Genotype $\times$ Treatment $=3.117$, Stage $\times$ Genotype $\times$ Treatment $=4.409$

b Stage $=0.075$, Genotype $=0.075$, Treatment $=0.119$, Stage $\times$ Genotype $=0.106$, Stage $\times$ Treatment $=$ 0.168 , Genotype $\times$ Treatment $=0.168$, Stage $\times$ Genotype $\times$ Treatment $=0.237$

Table 3. Seed yield and number of tillers traits in sorghum at physiological maturity

\begin{tabular}{|c|c|c|c|c|}
\hline \multirow[b]{2}{*}{ Genotypes } & \multicolumn{4}{|c|}{ Physiological maturity (95DAS) } \\
\hline & SSG 59-3 & PC 5 & SSG 59-3 & PC 5 \\
\hline Character & \multicolumn{2}{|c|}{ Number of tiller/plant ${ }^{a}$} & \multicolumn{2}{|c|}{ Seed yield/plant $(g)^{b}$} \\
\hline Control & $5.03 \pm 0.10$ & $3.0 \pm 0.13$ & $15.25 \pm 0.13$ & $9.56 \pm 0.11$ \\
\hline $6 \mathrm{dSm}^{-1}$ & $4.0 \pm 0.09$ & $2.0 \pm 0.06$ & $13.26 \pm 0.18$ & $7.35 \pm 0.09$ \\
\hline $8 \mathrm{dSm}^{-1}$ & $3.0 \pm 0.04$ & $1.73 \pm 0.10$ & $12.43 \pm 0.16$ & $6.12 \pm 0.04$ \\
\hline $10 \mathrm{dSm}^{-1}$ & $2.63 \pm 0.05$ & $1.33 \pm 0.09$ & $11.32 \pm 0.14$ & $5.48 \pm 0.16$ \\
\hline $12 \mathrm{dSm}^{-1}$ & $2.0 \pm 0.03$ & $0.95 \pm 1.2$ & $9.57 \pm 0.16$ & $3.26 \pm 0.05$ \\
\hline
\end{tabular}

C.D. at $5 \%$ level of significance

${ }^{\mathrm{a}}$ Genotype $=0.082 ;$ Treatment $=0.130 ;$ Genotype $\times$ Treatment $=0.184$

${ }^{\mathrm{b}}$ Genotype $=0.305 ;$ Treatment $=0.193 ;$ Genotype $\times$ Treatment $=0.431$

\section{Discussion}

Soil salinization has emerged as a serious threat affecting crop productivity as well as geographical distribution of crop plants ${ }^{25}$. To contribute to our understanding of the biochemical and 
molecular mechanisms underlying salinity, we exposed sorghum genotypes to four different salinity levels, and compared responses in leaves and roots under two different developmental stages. With the increasing levels of salt stress from control to $120 \mathrm{mM}$, a significant reduction in plant fresh and dry weight was observed among all the genotypes (Fig. 1A and 1B). Increased accumulation of fresh biomass in tolerant genotype might be due to an increase in protoplasmic components and rapid cell division and elongation, leading to the luxury of vegetative growth, resulting in increased production of fresh biomass and dry matter ${ }^{26}$. While the decrease in biomass might be a reason for higher $\mathrm{Na}^{+}$ions, which resulted in delayed physiological maturity of the $\mathrm{crop}^{27}$. The detrimental effect of $\mathrm{NaCl}$ on dry weight may be due to a direct impact on the photosynthetic rate. The decreased root and shoot length (Fig. 1C and 1D) leads to high NDF content, which in turn reduces IVDMD under osmotic stress in sorghum. The decrease in root and shoot length could be due to increased accumulation of $\mathrm{Na}^{+}$ions, which in turn may cause root tip cell damage and decreased essential micronutrient uptake by plants under salt stress ${ }^{28}$.

The physiological characteristics of crop plants might be adversely affected owing to reduced leaf expansion, photosynthetic impairment, premature leaf senescence, and alterations to the protein and pigment structure ${ }^{29}$. The key factors that govern the relationship between plant waters, productivity and growth during salt stress include relative water content, osmotic potentials, stomatal conductance, and total chlorophyll. RWC is regarded as a plant water status indicator. A perusal of the data on RWC (Fig. $2 A$ ) in leaves showed that salt treatments had a progressively decreasing effect in sorghum genotypes. It is also proposed that high RWCs might enable tolerant genotypes conduct more efficiently physiobiological activities under stress than susceptible chickpea genotypes ${ }^{30}$. Osmosis in plant cells can act as a mechanism of osmotic adjustment to decrease the cellular osmotic potential and thus maintain water absorption and turgor. A decrease in osmotic potential $\left(\psi_{s}\right)$ (Fig. 2B) under stress conditions has been proposed to play an important role in osmotic adjustment and plants' survival mechanism under dry conditions ${ }^{31,32}$. The primary causes of an elevated osmotic potential under saline conditions include hydrolysis of biomolecules into smaller molecules such as mono and oligosaccharides, and proline among amino acids etc. Photochemical quantum yield $\left(\mathrm{F}_{\mathrm{v}} / \mathrm{F}_{\mathrm{m}}\right)$ revelations into plant capability for abiotic stress tolerations and how the photosynthetic machinery has been affected under these stressful conditions. ${ }^{33,34}$. In the present investigation, chlorophyll fluorescence $\left(F_{v} / F_{m}\right)$ (Figure 4.15$)$ of leaf reduced with the increasing salinity levels (Fig. $2 \mathrm{C})$. In photosystem II $\left(\mathrm{F}_{\mathrm{v}} / \mathrm{F}_{\mathrm{m}}\right)$, the maximum quantum yield reduced significantly, whereas in saline conditions, non-photochemical quenching ( $q N$ ) in sorghum increased substantially ${ }^{34}$. Values of chlorophyll content decreased with the progression of salt concentration (Fig. 3). Chlorophyll degradation in leaves under high $\mathrm{Na}^{+}$ions may also be accompanied with $\mathrm{ROS}$ generation, resulting in pigment-protein complex instability, chlorophyll oxidation and degeneration of other chloroplastic pigments ${ }^{2}$. A decline in concentration of $\mathrm{K}^{+}$and $\mathrm{Mg}^{2+}$ can lead to the overall drop in chlorophyll concentration under salinity stress concentrations ${ }^{35}$.

Under salt stress, the ratio of $\mathrm{Na}^{+} / \mathrm{K}^{+}$ions in leaves and roots significantly increased in all genotypes (Fig. 4A and 4B). Salt stress maintained abnormally high $\mathrm{Na}^{+} / \mathrm{K}^{+}$ratio, inactivated the enzymes used in the various developmental processes, and inhibited protein synthesis ${ }^{33}$. Another interesting point is that sorghum can also accumulate higher $\mathrm{Na}^{+}$concentration in the roots and limit the transportation of $\mathrm{Na}^{+}$up to shoots under salt stress, which is called salt exclusion ${ }^{36}$, an important salt-tolerance-related process. Growth inhibition in maize organs was correlated linearly with increasing $\mathrm{Na}^{+}$accumulation within tissues ${ }^{9}$.

In the present study, attempts were made to establish a correlation between antioxidative defense mechanism and salinity induced changes in leaves and roots of sorghum genotypes at two growth stages viz. vegetative stage and physiological maturity. During oxidative stress, the excess production of ROS is scavenged by a complex enzymatic antioxidative system which controls ROS production and ultimately protects the plant against oxidative damage ${ }^{37}$. This salinity-induced defense mechanism is differential and mostly dependent on differential activities of antioxidant enzymes, salinity extent, and exposure time ${ }^{38}$. SOD is the most effective intracellular enzymatic antioxidant, ubiquitous in all aerobic organisms and all 
subcellular compartments prone to ROS-mediated oxidative stress ${ }^{21}$. The percent increase was more in tolerant genotype (SSG 59-3) at both stages, suggesting that salt-tolerant genotypes have a better superoxide radical scavenging ability (Fig. 5A). Lee et al. ${ }^{39}$ reported that transgenic tobacco plants overexpressing $\mathrm{Cu} / \mathrm{Zn}-\mathrm{SOD}$ showed tolerance to salt and water stresses. The induction of catalase activity (Fig. 5B) was reported on accumulation of $\mathrm{H}_{2} \mathrm{O}_{2}$ and seemingly consistent with this enzyme's role in scavenging enhanced $\mathrm{H}_{2} \mathrm{O}_{2}$ level ${ }^{40,41}$. Salinity-induced stimulation in POX activity in the present study was more pronounced in tolerant genotypes than in sensitive ones in both the tissues (Fig. 5C), suggesting their possible role inefficient removal of $\mathrm{H}_{2} \mathrm{O}_{2}$ in tolerant genotypes. Bhattacharjee and Mukherjee ${ }^{42}$ reported a gradual decline in POX activity with increasing heat shock and salinity stress in $A$. lividus. Enhanced activity of peroxidase under various stresses was linked to protection from oxidative damage, lignification, and cross-linking of the cell wall. APX and GPX are one of the specific enzymes that scavenge chloroplastic $\mathrm{H}_{2} \mathrm{O}_{2}$ using ascorbate as an electron donor in the first step of the ascorbate-glutathione cycle and is considered the most important plant peroxidases in $\mathrm{H}_{2} \mathrm{O}_{2}$ detoxification ${ }^{43}$. The enhanced activity of APX (Fig. 5D) and GPX (Fig. 6A) concomitant with an enhanced content of ascorbic acid and glutathione may help to quench ROS in SSG 59-3 than PC-5 genotype. GR is essential to recycle GSH in the ascorbateglutathione cycle in an NADPH-dependent reaction. GR activity enhanced significantly in leaves and roots of sorghum genotypes (Fig. 6B). Similarly, higher induction in GR activity in tolerant varieties than sensitive varieties was reported in Macrotyloma uniflorum ${ }^{44}$ and chickpea ${ }^{45}$. A significant interaction effect of MDHAR (Fig. 6C) and DHAR (Fig. 6D) activities implicated notable increases in their activities under all salt in sorghum genotypes. Similar results were also reported in maize ${ }^{9}$, and wheat ${ }^{46,47}$ differing in salt tolerance

Non-enzymatic antioxidants include ascorbic acid, phenolics, glutathione, and carotenoids ${ }^{22,23}$. Glutathione is a major non-protein thiol in plants, which plays a pivotal role in protecting plants from environmental stress. The concentration of total glutathione (GSH+GSSG) (Fig. 7A), GSH (Fig. 7B) and GSSG (Fig. 7C) increased in leaves and roots of sorghum genotypes at 35 and 95 DAS. At the level of organ specificity, GSH level increased in response to high salinity, particularly in roots. This could be ascribed to the increased demand and metabolism of sulfur under stress for antioxidants' biosynthesis such as $\mathrm{GSH}^{48}$. Salt stress resulted in a significant increase in total ascorbic acid content in leaves of sorghum genotypes at both stages (Fig. 8A and 8B). The diminished ascorbate pool under various stresses may be due to changes in glutathione pool that have been implicated in the recycling of ascorbate or failure to maintain ascorbate level may be indicative of an overall decline in the capacity to withstand oxidative stress ${ }^{46}$. The increased absorption of sulfate affects GSH levels in tissues under high salinity 49. The increased content of AsA and GSH, accompanied by the reduced AsA and GSH redox status, indicated the crucial role of the AsA-GSH cycle for scavenging ROS ${ }^{9}$. Reduction in the levels of photosynthetic pigments, including chlorophyll $\mathrm{a}$ and $\mathrm{b}$ and accessory pigments such as carotenoids, on exposure to abiotic stresses have been reported by several researchers ${ }^{50-52}$.

FRAP evaluation measure the capacity of a $\mathrm{Fe}^{3+} /$ tripyridyl-s-triazine complex to be reduced in the presence of an antioxidant. The formation of non-specific radicals is the function of ABTS and DPPH assay. DPPH activity in the red pericarp sorghum was reported to be higher ${ }^{53-56}$. Hence, the present results indicated that sorghum grains with colored pericarp had high antioxidant activities. Significant variations in total phenols, flavonoids and flavanols were observed among different sorghum genotypes (Table 1). This could be due to the absence of tannins, which indicate that red colored pericarp sorghum is of Type I ${ }^{54,57}$.

Plants maintain their cell turgor and osmoregulatory mechanisms by accumulating various compatible solutes such as proline, glycine betaine (GB), polyamines and proteins ${ }^{58,59}$ under different abiotic stresses that decreased the cytoplasmic osmotic potential, enabling water absorption ${ }^{60}$. Proline is considered the only osmolyte, which has been shown to scavenge singlet oxygen and free radicals, including hydroxyl ions, and stabilize proteins, DNA, as well as the membrane ${ }^{61}$. Proline content increased significantly under salt stress in both leaves and roots of sorghum genotypes (Fig. 9A). Glycine betaine 
(GB) is one of the osmoregulatory solutes that naturally accumulates in the plants ${ }^{62}$. Accumulation of glycine betaine increased considerably in leaves and roots of sorghum genotypes because of salt stress (Fig. 9B). More specifically, GB can protect the $\mathrm{O}_{2}$ evolving machinery of chloroplasts when exposed to high $\mathrm{NaCl}$ concentrations ${ }^{63}$. Saneoka et al. ${ }^{64}$ reported that the salt-induced accumulation of betaine and BADH mRNA coincides with ABA in sorghum. Accumulation of soluble carbohydrates increases the resistance against various stresses. Total soluble carbohydrates act as osmolytes inside the cell (Fig. 9D). The imposition of water or salt stress in sorghum has been demonstrated to be accompanied by an increase in the sugar levels of embryos, which may help in osmoregulation under stress conditions ${ }^{65}$.

$\mathrm{H}_{2} \mathrm{O}_{2}$ is a natural plant toxic cellular metabolite; it is a toxic only at high concentrations and causes thylakoid degradation ${ }^{66,67}$. In this study, although $\mathrm{H}_{2} \mathrm{O}_{2}$ accumulation increased during salt stress in tolerant and susceptible genotypes (Fig. 10A), there was a lower ROS level in tolerant genotypes, which might be related to higher antioxidant activity and also higher proline and total soluble sugar content. Forghani et al. ${ }^{68}$ observed that $\mathrm{H}_{2} \mathrm{O}_{2}$ content was about $54 \%$ more in the salt-stressed as compared to control plants. The relative stress index (RSI) in terms of leakage of electrolytes increased significantly in leaves and roots of sorghum genotypes (Fig. 10B). Increased electrolyte leakage from tissues is usually an expression of modification in the physical properties of cell membranes. Malondialdehyde (MDA) is one of the final products of peroxidation of unsaturated fatty acids in phospholipids and is responsible for cell membrane damage. Salt stress-induced higher production of MDA content was reported in present work (Fig. 10B) which is in agreement with those reported by several workers ${ }^{69,70}$. Salt stress-induced membrane lipid peroxidation results in membrane fluidity, leading to enhanced electrolytic leakage in wild type and transgenic lines in sorghum ${ }^{71}$. During stress conditions, the total polyamine concentration enhanced (Fig. 11 and 12). The chromatogram in Figure 12 shows the separation of naturally occurring polyamines (Put, Spd and Spm) from leaf tissue of sorghum plant with their enhanced concentration. At 100 and $120 \mathrm{mM}$ $\mathrm{NaCl}$, their concentration enhanced progressively in SG 59-3 ${ }^{72-74}$.

Analysis of yield components is an essential tool for assessing crop development and productivity ${ }^{75}$. Salt stress significantly reduced the yield attributes and yield among the sorghum genotypes, i.e., plant height, number of leaves/plant (Table 2), number of tillers per plant, and seed yield per plant (Table 3). Reduction in yield attributes was more at a higher level of salt $(120 \mathrm{mM})$ because of the adverse effect on the physiological process and dry matter accumulation and ultimately reduced the plant's seed yield. The reduction in the number of seeds per plant was due to the reduced flower production and fertilization. Seed yield was affected due to pollen sterility, abortion, pollen germination, and in-compatible fertilization, which directly reduced yield attributes and yield under salt stress ${ }^{76}$.

The differential expression of ion transporter genes under different salinity levels indicated their adaptive behavior for $\mathrm{Na}^{+}$ion exclusion (Fig. 15). Salt stress elicits a cytosolic calcium signal ${ }^{77}$. Increased intracellular concentration of $\mathrm{Ca}^{2+}$ ions are sensed by SOS3 which interacts and activates SOS2, a serine/threonine protein kinase. Both SOS2 and SOS3 regulate the expression level of SOS1, a salt tolerance gene which encodes a sodium proton antiporter (NHX) ${ }^{78}$. Co-expression of SOS1 (Fig. 13A) and SOS2 (Fig. 13B) together with NHX (Fig. 14A), dramatically enhance the salt tolerance in SSG 59-3. Expression of a constitutively expressed $\mathrm{H}^{+}$-PPase (Fig. 14B) remains stable at 100 and $120 \mathrm{mM} \mathrm{NaCl}$. Qiu et al. ${ }^{79}$ showed that constitutively active SOS2 kinase could enhance a NHX exchange activity in purified plasma membrane vesicles from wild-type but not sos 1-1 mutant plants ${ }^{80}$. In sos2-2 and sos3-1 mutants ${ }^{81}$, the plasma membrane $N H X$ exchange activity is much lower but can be recovered to near wild-type levels by addition of activated SOS2 in vitro to the membrane vesicle preparations ${ }^{79}$. 


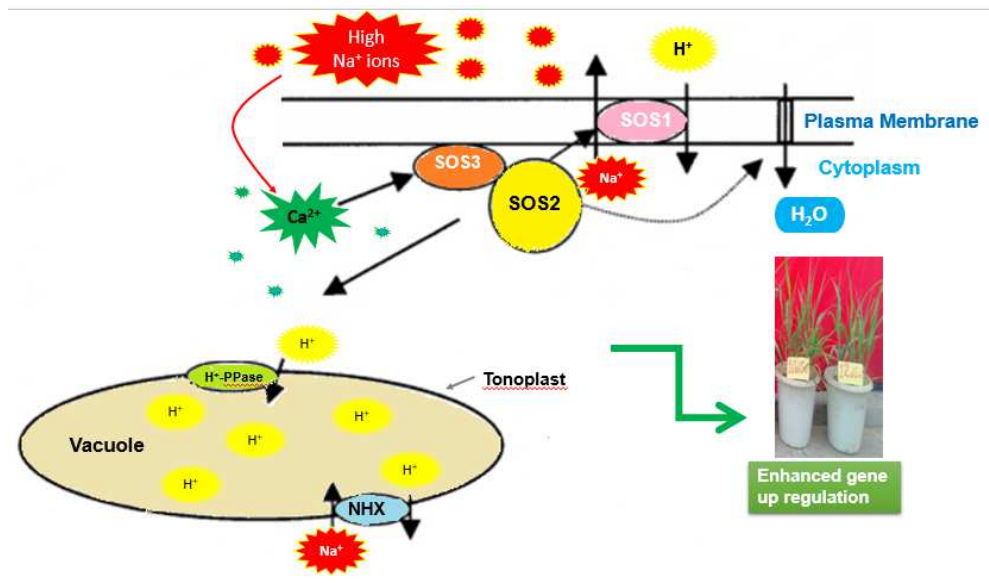

Figure 15 Regulation of $\mathrm{Na}^{+}$and $\mathrm{K}^{+}$ion homeostasis by the SOS pathway. Excess of $\mathrm{Na}^{+}$ions elicits a calcium signaling pathway which activates the SOS1-SOS3 protein kinase complex, which in turn stimulates the SOS1 and sodium proton antiporter (NHX) exchange activity and thus, regulates the expression of genes encoding them.

\section{Conclusion}

Thresholds of sorghum-specific antioxidant defense mechanisms are stimulated at all developmental stages and in all tissues. However, each organ utilizes the most effective and in accordance with the other metabolic networks in that particular organ at its unique age in order to cope with salinity and the associated oxidative stress from the arsenal of alternate antioxidant mechanisms available in sorghum tissue. Deciphering these specific alternatives could help developing more efficient metabolic engineering mechanisms specific to different organs and ages to cope with specific stress conditions. This research clearly establishes SSG 59-3 as a potential sorghum line with naturally occurring antioxidant potential, and highlights the need to further understand and explore the fine-tuning plant sensing and signaling systems. Hence, SSG 59-3 seems physiologically and biochemically promising and may be exploited in plant breeding programs aimed at developing salt-tolerant sorghum genotypes.

\section{Methods}

The experiment was conducted during kharif season (2017-18, 2018-2019, and 2019-20) in the screen house of Department of Biochemistry, CCS Haryana Agricultural University, Hisar, Haryana, India.

Plant material and growth conditions. Seeds of the two sorghum genotypes viz. SSG 59-3 (salttolerant) and PC-5 (salt susceptible) were procured from Forage section, Department of Genetics \& Plant Breeding, CCS Haryana Agricultural University Hisar, India. A screen-house experiment was conducted where sorghum seeds were sown directly in plastic pots lined with polyethylene bags filled with $10 \mathrm{~kg}$ sandy loam soil at $2-3 \mathrm{~cm}$ depth with standard conventional cultivation practices. All pots were rinsed with an equal volume of water and nutrient solution as per the recommended package of practices (POP). The physicochemical properties of the soil used were determined before sowing (Table 4) and the pots were saturated with desired salt levels, i.e., $60,80,100$, and $120 \mathrm{Mm} \mathrm{NaCl}$. Controls were run simultaneously in two genotypes.

Treatments. Saline solutions of required molarity were prepared by mixing $\mathrm{NaCl}, \mathrm{CaCl}_{2} .2 \mathrm{H}_{2} \mathrm{O}, \mathrm{MgCl}_{2} .6 \mathrm{H}_{2} \mathrm{O}$, and $\mathrm{MgSO}_{4} .7 \mathrm{H}_{2} \mathrm{O}$ in the appropriate amount (Table 5). The soil's electrical conductivity was checked at an interval of 15 days and at sampling stage to maintain the desired salt concentration. Three replications of each treatment were taken. 
Raising of the crop. The seeds (10) of uniform size were selected and surface sterilized with $0.01 \%$ mercuric chloride $\left(\mathrm{HgCl}_{2}\right)$ solution to prevent the fungal attack and then thoroughly washed with distilled water and air-dried before sowing. The seeds were sown at a depth of $5 \mathrm{~cm}$ and after seedling emergence, thinning was done up to five seedlings per pot.

The studies are complied with relevant institutional, national, and international guidelines and legislation.

Sampling. Samples were collected at the pre-flowering (35 days after sowing, DAS) (Plate 1) and postflowering (95 days after sowing, DAS) (Plate 2) stage and immediately frozen in liquid nitrogen and stored at $80^{\circ} \mathrm{C}$, for further biochemical and molecular analysis. The morpho-physiological traits were determined from the flag leaf. Dry weight (DW) of the plant organs was measured after drying the tissues for 5 days at $80^{\circ} \mathrm{C}$. Analysis for salt responsive protein profiling and mRNA expression profiling of genes was carried at the early vegetative stage. Data on yield and yield attributes were recorded at the maturity stage.

Table 4. Properties of soil in the pots under screen house experiment

\begin{tabular}{lllllll}
\hline Soil Texture & $\mathrm{EC}(\%)$ & $\mathrm{pH}$ & $\mathrm{OC}(\%)$ & $\mathrm{N}(\mathrm{mg} / \mathrm{kg}$ soil $)$ & $\mathrm{P}(\mathrm{mg} / \mathrm{kg}$ soil $)$ & $\mathrm{K}(\mathrm{mg} / \mathrm{kg} \mathrm{soil})$ \\
\hline Sandy-loam & 0.09 & 7.50 & 0.18 & 86.33 & 3.67 & 165.0 \\
\hline
\end{tabular}

Table 5 Composition of the saline solutions of different molarity

\begin{tabular}{ccccc}
\hline Salts & \multicolumn{4}{c}{ The concentration of salts required (g/litre) } \\
\hline & $\mathbf{6 0} \mathbf{m M}$ & $\mathbf{8 0 ~} \mathbf{~ M M}$ & $\mathbf{1 0 0 ~} \mathbf{~ M M}$ & $\mathbf{1 2 0} \mathbf{~ m M}$ \\
\hline $\mathbf{N a C l}$ & 1.10 & 2.34 & 2.92 & 3.51 \\
\hline $\mathrm{CaCl}_{2} .2 \mathrm{H}_{2} \mathrm{O}$ & 0.661 & 1.09 & 1.38 & 1.66 \\
\hline $\mathrm{MgCl}_{2.6 \mathrm{H}_{2} \mathrm{O}}$ & 0.549 & 0.610 & 0.762 & 0.915 \\
\hline $\mathrm{MgSO}_{4} .7 \mathrm{H}_{2} \mathrm{O}$ & 0.266 & 1.47 & 3.69 & 4.43 \\
\hline
\end{tabular}
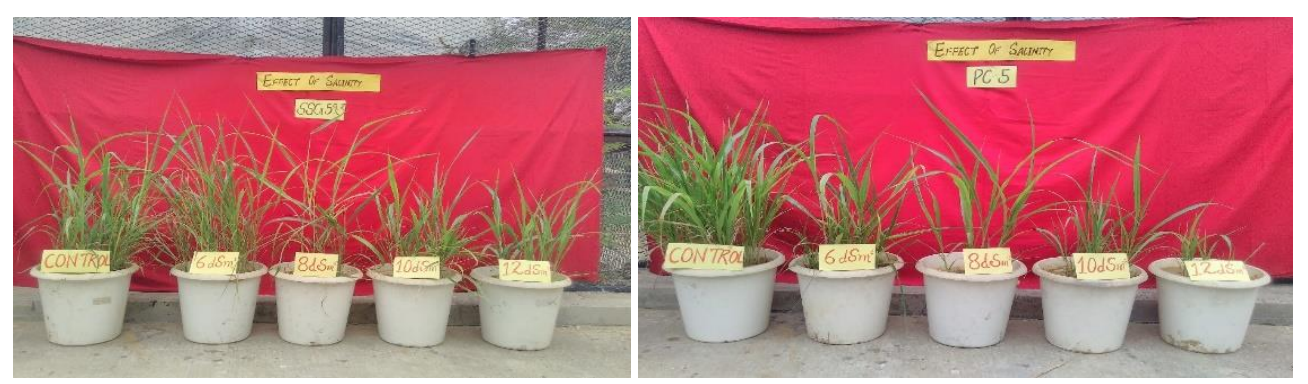

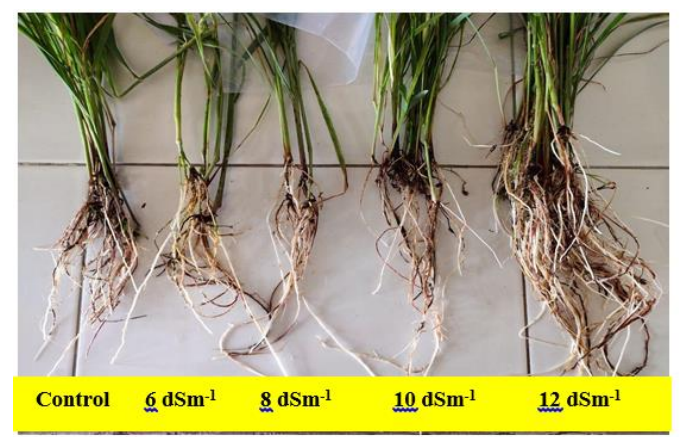

SSG 59-3

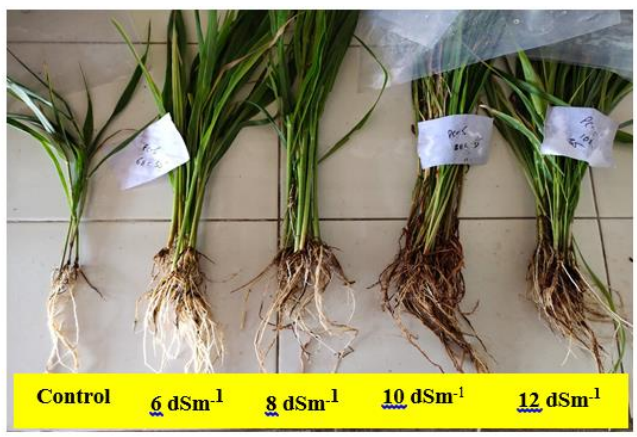

PC-5 
Plate 1: Effect of salt stress (Control, 60, 80, 100, and $120 \mathrm{mM} \mathrm{NaCl}$ ) on growth of sorghum genotypes (SSG 59-3 and PC-5) at vegetative stage (35 DAS)
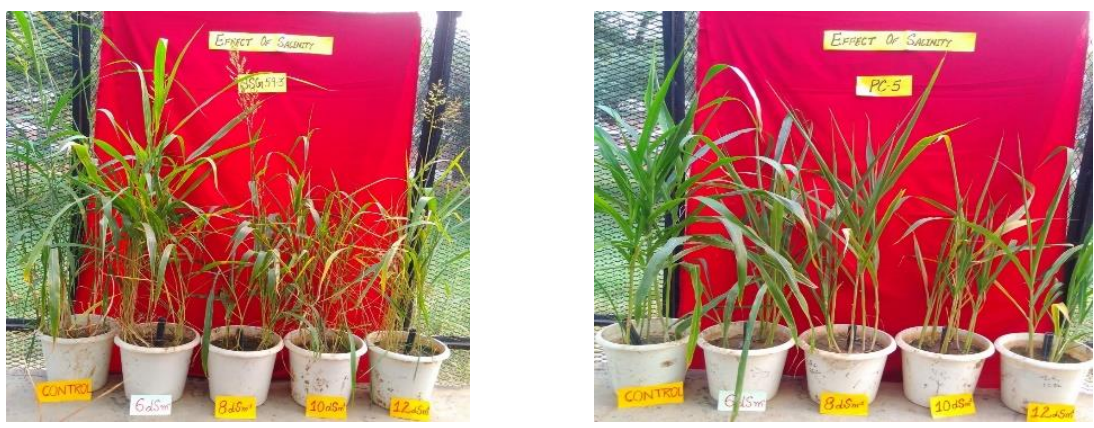

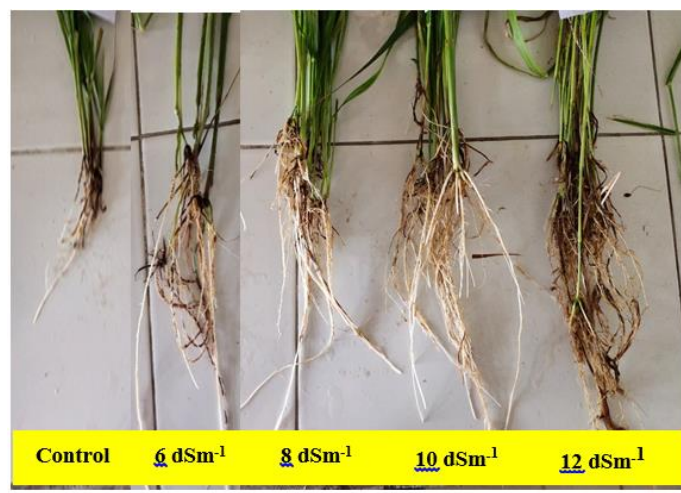

SSG 59-3

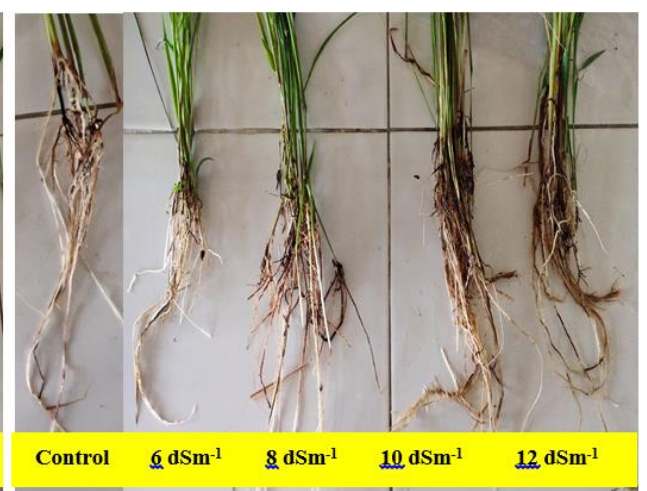

PC-5

Plate 2: Effect of salt stress (Control, $60,80,100$, and $120 \mathrm{mM} \mathrm{NaCl}$ ) on growth of sorghum genotypes (SSG 59-3 and PC-5) at physiological maturity (95 DAS)

Physiological indices. The fresh weight of samples was determined from one whole plant and the sample was kept in a hot air oven at $70{ }^{\circ} \mathrm{C}$ until the constant weight was achieved for determination of dry weight per plant from each replication. Root and shoot length was calculated from the base to the top growing bud at the vegetative stage and from bottom to the topmost portion of plant excluding arrow length, at maturity. RWC was measured from fresh leaf samples, excised, weighed immediately, and placed in distilled water at a constant temperature in diffused light for $6 \mathrm{~h}$. Then, leaf discs were dried in an oven at $80{ }^{\circ} \mathrm{C}$ for $72 \mathrm{~h}$ for dry weight was recorded and calculated as ${ }^{82}$ :

$$
\text { Relative Water Content }(\%)=\frac{\text { Fresh weight }- \text { Dry weight }}{\text { Fully turgid weight }- \text { Dry weight }} \times 100
$$

The osmotic potential (OP) was determined using a psychrometric technique (Model 5199-B vapor Pressure Osmometer, Wescor Inc. Logan, Utah, USA) in the third leaf from the top. The reading (mmole $\mathrm{kg}^{-1}$ ) displayed on osmometer was recorded using osmolarity reference standards of sodium chloride (Wescor Inc, USA). Photochemical quantum yield $\left(F_{v} / F_{m}\right)$ was recorded in intact plants using a chlorophyll fluorometer (OS-30p, Opti-Science, Inc., Hudson, USA) at mid-day. Initial ( $\left.F_{0}\right)$ and maximum ( $\left.F_{m}\right)$ fluorescence were recorded and variable fluorescence $\left(F_{v}\right)$, derived by subtracting $F_{0}$ from $F_{m}$. Chlorophyll stability index (CSI) was estimated as the method describe ${ }^{83}$. Chlorophyll a, chlorophyll band total chlorophyll estimation was done by incubating $50 \mathrm{mg}$ of leaf material in $10 \mathrm{ml}$ of DMSO for $3 \mathrm{~h}$ at $60{ }^{\circ} \mathrm{C}$ and other sets of the same amount of leaf were heated at $32{ }^{\circ} \mathrm{C}$ for one $\mathrm{h}$ in a water bath. After cooling, $10 \mathrm{ml}$ of DMSO was added, and then the absorbance of the solvent was recorded at 663 and $645 \mathrm{~nm}$. The CSI was calculated using 
the formula given as under: CSI $(\%)=1$-[Total chlorophyll of heated samples/ Total chlorophyll of nonheated sample] $\times 100$.

$\mathrm{Na}^{+}: \mathrm{K}^{+}$determination. $\mathrm{Na}^{+}$and $\mathrm{K}^{+}$content was determined in $50 \mathrm{mg}$ of dried and well-ground plant material. Samples were digested in concentrated $\mathrm{H}_{2} \mathrm{SO}_{4} / \mathrm{HClO}_{4}(9: 1)$ and the clear supernatant was analyzed by mass spectrometry (ICP-MS, Finnigan Element XR, Scientific, Bremen, Germany).

Ascorbate-Glutathione pool. SOD, CAT, POX, APX, GR, GPX, MDHAR, and DHAR were determined in an homogenate of $1 \mathrm{~g} \mathrm{(FW)} \mathrm{of} \mathrm{leaf} \mathrm{and} \mathrm{root} \mathrm{tissues,} \mathrm{prepared} \mathrm{in} \mathrm{in} 5 \mathrm{ml}$ of $100 \mathrm{mM}$ sodium phosphate buffer $(\mathrm{pH}$ 7.5) containing $0.25 \% \quad(\mathrm{v} / \mathrm{v})$ Triton X-100, 10\% (w/v) polyvinylpyrrolidone and $1 \mathrm{mM}$ phenylmethylsulfonyl fluoride. SOD (EC 1.15.1.1) activity was determined by measuring the inhibitionof NBT (nitroblue tetrazolium) reduction at $560 \mathrm{~nm}^{84}$. CAT (EC 1.11.1.6) activitywas assayed by monitoring the decomposition of $\mathrm{H}_{2} \mathrm{O}_{2}$ at $240 \mathrm{~nm}{ }^{85}$. POX (E.C. 1.11.1.7) activity was determined by the oxidation of pyrogallol $\left(\varepsilon=2.47 \mathrm{mM}^{-1} \mathrm{~cm}^{-1}\right)^{86}$. APX (EC 1.11.1.11) assay was based on the spectrophotometric monitoring of ascorbic acid oxidation $\left[\varepsilon=2.8 \mathrm{mM} \mathrm{cm}^{-1}\right]^{87}$. GR (EC 1.11.1.9) was assayed by monitoring non-enzymatic oxidation of NADPH $\left[\varepsilon=6.22 \mathrm{mM}^{-1} \mathrm{~cm}^{-1}\right]^{88}$. GR (EC 1.6.4.2) was assayed by monitoring the oxidization one $\mathrm{mM}$ NADPH per $\min \left(\varepsilon=6.22 \mathrm{mM} \mathrm{cm}^{-1}\right){ }^{89}$. MDHAR (EC 1.6.5.4) was assayed spectrophotometrically by following the absorbance decrease at $340 \mathrm{~nm}$ due to NADH oxidation $[\varepsilon=6.2$ $\left.\mathrm{mM}^{-1} \mathrm{~cm}^{-1}\right]^{90}$. The activity of DHAR (EC 1.8.5.1) was measured corresponded to one nmol of ascorbate produced during the reaction $\left[\varepsilon=14 \mathrm{mM}^{-1} \mathrm{~cm}^{-1}\right]^{87}$.

Protein concentration. The soluble protein was extracted by homogenizing $100 \mathrm{mg}$ fresh tissue as per the method of Lowry et al. ${ }^{91}$.

Antioxidant molecules. Ascorbic acid (ASC) was estimated by homogenizing $500 \mathrm{mg}$ of sample tissue in $5 \%(\mathrm{w} / \mathrm{v})$ metaphosphoric acid ${ }^{92}$. The quantity of ascorbic acid was determined at $530 \mathrm{~nm}$ using ascorbic acid's standard curve (10-100 $\mu \mathrm{g})$. The level of oxidized (GSSG), reduced (GSH), and total glutathione (GSH+GSSG) was estimated by homogenizing $1 \mathrm{~g}$ of sample tissue in $5 \%(\mathrm{w} / \mathrm{v})$ sulphosalicylic acid ${ }^{93}$. The reduction rate of 5, 5'- dithiobis-(2-nitrobenzoic acid) [DTNB] was monitored at $412 \mathrm{~nm}$. The carotenoid content in leaves was extracted in DMSO and absorbance was read at 480, 645, and $663 \mathrm{~nm}{ }^{94}$.

Total antioxidant capacity. One hundred milligram fresh plant tissue was homogenized in liquid nitrogen, and extracted in $2 \mathrm{ml}$ of ice-cold $80 \%$ ethanol ${ }^{95}$. Ferric reducing antioxidant power (FRAP) reagent constituting $300 \mathrm{mM}$ acetate buffer ( $\mathrm{pH}$ 3.6), $0.01 \mathrm{mM}$ 2,4,6-tripirydylo-S-triazine (TPTZ)) dissolved in 0.04 $\mathrm{mM} \mathrm{HCl}$ and $20 \mathrm{mM} \mathrm{FeCl}_{3} .6 \mathrm{H}_{2} \mathrm{O}$ was mixed with the ethanolic extract and absorbance was read at $600 \mathrm{~nm}$ using trolox was used as a standard. For DPPH antioxidant activity, a suitable aliquot (3.5 ml) of DPPH solution in methanol was added to $0.1 \mathrm{~mL}$ of sorghum extract followed by incubation period of $40 \mathrm{~min}$ at room temperature in dark, absorbance was recorded at $515 \mathrm{~nm}$ and expressed in milligram per gram Trolox equivalents (TE) ${ }^{96}$. ABTS activity was assayed with slight modifications ${ }^{97}$. The ABTS radical cation solution was prepared by mixing $7 \mathrm{mM}$ ABTS and $2.45 \mathrm{mM}$ potassium persulfate solution followed by incubation of $16 \mathrm{~h}$ at room in the dark. After incubation, the mixture was diluted with buffer $(\mathrm{pH} 7.4)$ and absorbance was read at $734 \mathrm{~nm}$.

Polyphenolic compounds. Extraction was done in $1 \% \mathrm{HCl} / \mathrm{methanol}(\mathrm{v} / \mathrm{v})$ for $2 \mathrm{~h}$ with shaking, centrifuged, and supernatants were pooled. Total phenols were estimated using gallic acid was used as standard for quantification of the samples containing phenolic content and data is expressed as $\mathrm{mg} / \mathrm{g}$ gallic acid equivalents (GAE) ${ }^{98}$. Total flavanoids were estimated using catechin as a standard ${ }^{99}$. o-dihydroxy phenols were quantified using chlorogenic acid as the standard ${ }^{100}$. Flavanols were estimated using rutin as a standard ${ }^{101}$. 
Compatible osmolytes. The proline content in the sample tissue was analyzed by homogenizing $500 \mathrm{mg}$ tissue in $5 \mathrm{ml}$ of $3 \%$ aqueous sulphosalicylic acid, centrifugation at $5000 \mathrm{rpm}$ for $20 \mathrm{~min}$ and extracted using ninhydrin reagent and toluene extraction ${ }^{102}$. The absorbance was read at $520 \mathrm{~nm}$. Glycine-betaine (GB) estimation was done in finely powdered plant material $(500 \mathrm{mg})^{103}$. Dried material was mechanically shaken with deionized water and extract was diluted with $2 \mathrm{~N}$ sulfuric acid (1:1), centrifuged at 10,000 $\times \mathrm{g}$ for $15 \mathrm{~min}$ and absorbance was measured at $365 \mathrm{~nm}$. Total soluble carbohydrates (TSC) were extracted using $2 \%$ phenol and conc. $\mathrm{H}_{2} \mathrm{SO}_{4}$ and the absorbance of solution was measured at $490 \mathrm{~nm}{ }^{104}$.

Oxidative stress markers. Malondialdehyde content was assayed in $250 \mathrm{mg}$ of tissue from control and stressed plants were ground in $2 \mathrm{ml}$ of chilled $1 \%$ TCA and centrifuged at 10,000 rpm for $20 \mathrm{~min}{ }^{105}$. After centrifugation, the supernatant reacted with $20 \%(\mathrm{w} / \mathrm{v})$ trichloroacetic acid (TCA) containing $0.5 \%$ thiobarbituric acid to produce pinkish red chromogen, thiobarbituric acid-malondialdehyde (TBA- MDA). Absorbance was measured at $600 \mathrm{~nm}$ using the extinction coefficient of $155 \mathrm{mM}^{-1} \mathrm{~cm}^{-1}$. Membrane injury index was measured as the percent proportion of ion leakage into the external aqueous medium to the total ion concentration of the stressed tissue as measured by the external medium EC ${ }^{106}$. Two hundred $\mathrm{mg}$ of leaf and root tissues were boiled in de-ionized water at $27^{\circ} \mathrm{C}$ and solution's electrical conductivity (EC) was measured. The membrane injury index was calculated as follows: Membrane injury (\%) = EC $1 / E_{1} C_{2} \times 100$. Hydrogen peroxide $\left(\mathrm{H}_{2} \mathrm{O}_{2}\right)$ concentration was measured by homogenizing one gram of fresh leaf and root tissue in ice-cold $0.1 \mathrm{M}$ phosphate buffer $(\mathrm{pH} \mathrm{7.0)}$ and $40 \mu \mathrm{l}$ was used in the assay based on the peroxidemediated oxidation of $\mathrm{Fe}^{2+}$, followed by reaction of $\mathrm{Fe}^{2+}$ with xylenol orange at $570 \mathrm{~nm}{ }^{107}$.

Polyamines. Poylamines in fresh tissue $(1 \mathrm{~g})$ was homogenized in $5 \mathrm{ml}$ of $5 \%$ cold perchloric acid ${ }^{108}$. The supernatant, containing the free polyamines was frozen at $-20^{\circ} \mathrm{C}$ for further benzoylation reaction using $500 \mu \mathrm{l}$ of extract, $1 \mathrm{ml}$ of $2 \mathrm{~N} \mathrm{NaOH}, 10 \mu \mathrm{l}$ of $99 \%(\mathrm{v} / \mathrm{v})$ benzoyl chloride, incubated for 30 min and then, saturated with $2 \mathrm{ml} \mathrm{NaCl}$. Benzoylated polyamines were extracted with diethyl ether, incubated at $-20^{\circ} \mathrm{C}$ for $1 \mathrm{~h}$ and were separated with the HPLC fitted with $\mathrm{C}_{18}$ ODS 2 analytical column which was pre-equilibrated and run isocratically at a flow rate of $1 \mathrm{ml} \mathrm{min}^{-1}$ with acetonitrile: water $(50: 50 \mathrm{v} / \mathrm{v})$ for $40 \mathrm{~min}$. The injected volume was $10 \mu \mathrm{l}$ and UV- detector was used to measure the absorbance at $224 \mathrm{~nm}$. Polyamines were quantified in the eluent by comparing the integration areas obtained for the samples with those obtained for the standards and the results were express as $\mathrm{nmol} \mathrm{g}^{-1}$ fresh weight of the sample.

Semi-quantitative gene expression by RT-PCR (Sq RT-PCR). Total RNA from seeds at different crossing periods was extracted using Qiagen Plant Total RNA Miniprep Kit (Qiagen, USA). The extracted RNA was quantified using Picodrop (Picodrop Ltd, Cambridge UK). The total RNA concentration was determined by absorbance at $260 \mathrm{~nm}$, and the A260:280 ratio in the range of 1.8-2.0 was used for further analysis. Singlestranded cDNA was synthesized from the purified mRNA using an iScript cDNA synthesis kit (Bio-Rad Laboratories, USA). The experiment was performed in three biological replicates and five technical triplicates. In semi-quantitative RT-PCR analysis, $5 \mu$ of cDNA, $0.2 \mu \mathrm{M}$ of forward and reverse primer, and $12 \mu \mathrm{l}$ of SybrGreen master mix (Bio-Rad Laboratories, USA) with a reaction volume of $25 \mu \mathrm{l}$ were used. The first step includes initial denaturation at $94^{\circ} \mathrm{C}$ for $3 \mathrm{~min}$, followed by 30 cycles of denaturation at $94^{\circ} \mathrm{C}$ for $30 \mathrm{~s}$. The second step of annealing at $57^{\circ} \mathrm{C}$ for $45 \mathrm{~s}$ and the last step includes extension at $72^{\circ} \mathrm{C}$ for 60 $\mathrm{s}$ and a final extension at $72^{\circ} \mathrm{C}$ for 10 min withhold at $4^{\circ} \mathrm{C}$ in a thermocycler (Labnet MultiGene ${ }^{\mathrm{TM}}$ Mini PCR Thermal Cycler, Merck). The PCR product was analyzed on agarose gel ( $1.5 \%)$ containing $0.5 \mu \mathrm{g} / \mathrm{ml}$ SYBR Safe DNA Gel Stain (Thermo Fisher Scientific Inc., USA) Intensity of bands was quantified using image $\mathrm{J}$ $1.51 \mathrm{~K}$ (http://imagej.nih.gov/ii) densitometric software.

Primer designing. Primer-BLAST software from NCBI was used for designing primers for the genes viz. salt overly sensitive 1 (SOS1), salt overly sensitive 2 (SOS2), sodium proton antiporter (NHX), and vacuolar proton pyrophosphatase $\left(H^{+}-P P a s e\right)$ (Table 6$)$. For normalizing the data, actin (Act1) gene was used as an internal control. The primers were then custom synthesized from Sigma. 
Table 6. List of primers

\begin{tabular}{|c|c|c|c|c|c|}
\hline Gene & Accession No. & Primers & Sequence (5'-3') & $\begin{array}{l}\text { Product } \\
\text { size }\end{array}$ & $\mathbf{T}_{\mathbf{m}}$ \\
\hline \multirow{2}{*}{ SOS1 } & \multirow{2}{*}{ XM_015763865.2 } & Forward & GGCTCAAGGCCAACTGGTAT & \multirow{2}{*}{$607 \mathrm{bp}$} & \multirow[t]{2}{*}{$60^{\circ} \mathrm{C}$} \\
\hline & & Reverse & TTTCGGGCCTCCCTATCTCA & & \\
\hline \multirow{2}{*}{ sos2 } & \multirow{2}{*}{ KP330207.1 } & Forward & TGCATCAGTACTGTGGCTGG & \multirow{2}{*}{$889 \mathrm{bp}$} & \multirow[t]{2}{*}{$60^{\circ} \mathrm{C}$} \\
\hline & & Reverse & ATTTAGAAGCCGCACACGGA & & \\
\hline \multirow{2}{*}{$N H X$} & \multirow{2}{*}{ EU482408.2 } & Forward & CGATGGGTGAACGAGTCCAT & \multirow{2}{*}{$617 \mathrm{bp}$} & \multirow{2}{*}{$\begin{array}{c}58.5^{\circ} \\
C\end{array}$} \\
\hline & & Reverse & GTTGCAAAAGTATGTCTGGCA & & \\
\hline \multirow{2}{*}{$\mathrm{H}^{+}$-PPase } & \multirow{2}{*}{ GQ469975.1 } & Forward & CACCTCTCTGGTATCTGGTTTC & \multirow{2}{*}{$629 \mathrm{bp}$} & \multirow{2}{*}{$62^{\circ} \mathrm{C}$} \\
\hline & & Reverse & GTGCGGGCTCAATTTCTTTC & & \\
\hline \multirow[b]{2}{*}{ Act 1} & \multirow{2}{*}{ XM_021463392.1 } & Forward & CAACTGGGACGATATGGAGAAG & \multirow[b]{2}{*}{$571 \mathrm{bp}$} & \multirow[b]{2}{*}{$62^{\circ} \mathrm{C}$} \\
\hline & & Reverse & AATGAAGGATGGCTGGAAGAG & & \\
\hline
\end{tabular}

Yield components. Plant height was measured from the base to the topmost leaves at vegetative stage and from the bottom to the top tip of the plant at maturity, including arrow length and expressed in centimeters $(\mathrm{cm})$. The number of leaves per plant were expressed as the mean of simply counted leaves from each replication. The number of tillers per plant were expressed as the mean of counted tillers number from each replication. The seed yield per plant $(\mathrm{g})$ was recorded from seed weight from each plant.

Statistical analysis. The data was expressed as Mean \pm SD (three replicates each). Two-way ANOVA was conducted to check the significance of main effects (genotypes, salinity and stage) and their interaction on growth indices. Significant differences between the means of parameters $(n=8)$ were determined by using the Tuckey test at $5 \%$ level $(P \leq 0.05)$. Statistical analysis was performed using SPSS v25.0 software (SPSS for Windows, Chicago, IL, USA).

\section{References}

1. Zhang, X., Yao, Y., Li, X., Zhang, L. \& Fan, S. Transcriptomic analysis identifies novel genes and pathways for salt stress responses in Suaeda salsa leaves. Sci. Rep. 10, 1-12 (2020).

2. Punia, H. et al. Discerning morpho-physiological and quality traits contributing to salinity tolerance acquisition in sorghum [Sorghum bicolor (L.) Moench]. South African J. Bot. (2020).

3. Corwin, D. L. \& Scudiero, E. Review of soil salinity assessment for agriculture across multiple scales using proximal and/or remote sensors. in Advances in Agronomy vol. 158 1-130 (Elsevier, 2019).

4. Munns, R., Passioura, J. B., Colmer, T. D. \& Byrt, C. S. Osmotic adjustment and energy limitations to plant growth in saline soil. New Phytol. 225, 1091-1096 (2020).

5. Shokat, S. \& Großkinsky, D. K. Tackling Salinity in Sustainable Agriculture-What Developing Countries May Learn from Approaches of the Developed World. Sustainability 11, 4558 (2019).

6. Abreu, I. A. et al. Coping with abiotic stress: proteome changes for crop improvement. J. Proteomics 93, 145168 (2013).

7. Chawla, S., Jain, S. \& Jain, V. Salinity induced oxidative stress and antioxidant system in salt-tolerant and saltsensitive cultivars of rice (O ryza sativa L.). J. plant Biochem. Biotechnol. 22, 27-34 (2013).

8. Punia, H. et al. Proteome dynamics and transcriptome profiling in sorghum [Sorghum bicolor (L.) Moench] under salt stress. 3 Biotech 10, 412 (2020).

9. AbdElgawad, $\mathrm{H}$. et al. High salinity induces different oxidative stress and antioxidant responses in maize seedlings organs. Front. Plant Sci. 7, 276 (2016).

10. Deinlein, U. et al. Plant salt-tolerance mechanisms. Trends Plant Sci. 19, 371-379 (2014).

11. Punia, H. et al. Solar Radiation and Nitrogen Use Efficiency for Sustainable Agriculture. in Resources Use Efficiency in Agriculture 177-212 (Springer, 2020).

12. Malik, A. et al. Biostimulant-Treated Seedlings under Sustainable Agriculture: A Global Perspective Facing Climate Change. Agronomy 11, 14 (2020).

13. Venkateswaran, K., Elangovan, M. \& Sivaraj, N. Origin, domestication and diffusion of Sorghum bicolor. in Breeding Sorghum for diverse end uses 15-31 (Elsevier, 2019).

14. USDA-Agricultural Research Service, N. P. G. S. Germplasm Resources Information Network (GRINTaxonomy). (2019).

15. Wang, Y.-H., Upadhyaya, H. D. \& Kole, C. Genetics, genomics and breeding of sorghum. (CRC Press, 2014). 
16. Punia, H., Tokas, J., Malik, A., Satpal \& Sangwan, S. Characterization of phenolic compounds and antioxidant activity in sorghum [Sorghum bicolor (L.) Moench] grains. Cereal Res. Commun. (2021) doi:10.1007/s42976020-00118-w.

17. Punia, H., Tokas, J., Malik, A. \& Kumar, N. Enzymes as nanoadditives: a promising alternative for biofuel production. in Nanomaterials 631-662 (Elsevier, 2021).

18. Munns, R. \& Gilliham, M. Salinity tolerance of crops-what is the cost? New Phytol. 208, 668-673 (2015).

19. Kotula, L. et al. Oxygen deficiency and salinity affect cell-specific ion concentrations in adventitious roots of barley (H ordeum vulgare). New Phytol. 208, 1114-1125 (2015).

20. Goche, T. et al. Comparative physiological and root proteome analyses of two sorghum varieties responding to water limitation. Sci. Rep. 10, 1-18 (2020).

21. Gill, S. S. \& Tuteja, N. Reactive oxygen species and antioxidant machinery in abiotic stress tolerance in crop plants. Plant Physiol. Biochem. 48, 909-930 (2010).

22. Gupta, B. \& Huang, B. Mechanism of salinity tolerance in plants: physiological, biochemical, and molecular characterization. Int. J. Genomics 2014, (2014).

23. Talbi, S. et al. Drought tolerance in a Saharian plant Oudneya africana: role of antioxidant defences. Environ. Exp. Bot. 111, 114-126 (2015).

24. Kravchik, M. \& Bernstein, N. Effects of salinity on the transcriptome of growing maize leaf cells point at cellage specificity in the involvement of the antioxidative response in cell growth restriction. BMC Genomics 14, $1-13$ (2013).

25. Shabala, S., Bose, J. \& Hedrich, R. Salt bladders: do they matter? Trends Plant Sci. 19, 687-691 (2014).

26. Satpal, B. S., Duhan, U. N., Joshi, A. S., Godara, S. A. \& Arya, S. Neelam. 2015: Response of yield, quality and economics of single cut forage sorghum genotypes to different nitrogen and phosphorus levels. Forage Res 41, 170-175.

27. McConnell, J. S., Francis, P. B., Stark, C. R. \& Glover, R. E. Plant responses of ultra narrow row cotton to nitrogen fertilization. J. Plant Nutr. 31, 1005-1017 (2008).

28. Gill, R. A. et al. Chromium-induced physio-chemical and ultrastructural changes in four cultivars of Brassica napus L. Chemosphere 120, 154-164 (2015).

29. Menconi, M., Sgherri, C. L. M., Pinzino, C. \& Navari-Lzzo, F. Activated oxygen production and detoxification in wheat plants subjected to a water deficit programme. J. Exp. Bot. 46, 1123-1130 (1995).

30. Patel, P. K., Hemantaranjan, A., Sarma, B. K. \& Radha, S. Growth and antioxidant system under drought stress in chickpea (Cicer arietinum L.) as sustained by salicylic acid. J. Stress Physiol. Biochem. 7, (2011).

31. Siddique, M. R. B., Hamid, A. \& Islam, M. S. Drought stress effects on water relations of wheat. Bot. Bull. Acad. Sin. 41, (2000).

32. Sairam, R. K., Srivastava, G. C. \& Saxena, D. C. Increased antioxidant activity under elevated temperatures: a mechanism of heat stress tolerance in wheat genotypes. Biol. Plant. 43, 245-251 (2000).

33. Yang, Z., Li, J.-L., Liu, L.-N., Xie, Q. \& Sui, N. Photosynthetic regulation under salt stress and salt-tolerance mechanism of sweet sorghum. Front. Plant Sci. 10, 1722 (2020).

34. Netondo, G. W., Onyango, J. C. \& Beck, E. Sorghum and salinity: II. Gas exchange and chlorophyll fluorescence of sorghum under salt stress. Crop Sci. 44, 806-811 (2004).

35. Aftab, T., Khan, M. M. A., da Silva, J. A. T., Idrees, M. \& Naeem, M. Role of salicylic acid in promoting salt stress tolerance and enhanced artemisinin production in Artemisia annua L. J. Plant Growth Regul. 30, 425435 (2011).

36. Dai, L. Y., Zhang, L. J., Jiang, S. J. \& Yin, K. De. Saline and alkaline stress genotypic tolerance in sweet sorghum is linked to sodium distribution. Acta Agric. Scand. Sect. B-Soil Plant Sci. 64, 471-481 (2014).

37. Ashraf, U. et al. Lead toxicity in rice: effects, mechanisms, and mitigation strategies-a mini review. Environ. Sci. Pollut. Res. 22, 18318-18332 (2015).

38. $\mathrm{Li}, \mathrm{Y}$. et al. Osa-miR398b boosts $\mathrm{H} 2 \mathrm{O} 2$ production and rice blast disease-resistance via multiple superoxide dismutases. New Phytol. 222, 1507-1522 (2019).

39. Lee, Y.-P. et al. Enhanced tolerance to oxidative stress in transgenic tobacco plants expressing three antioxidant enzymes in chloroplasts. Plant Cell Rep. 26, 591-598 (2007).

40. Gupta, S. \& Gupta, N. K. High temperature induced antioxidative defense mechanism in seedlings of contrasting wheat genotypes. Indian J. Plant Physiol. 10, 73 (2005).

41. Pal, M., Singh, D. K., Rao, L. S. \& Singh, K. P. Photosynthetic characteristics and activity of antioxidant enzymes in salinity tolerant and sensitive rice cultivars. Indian J. Plant Physiol 9, 407-412 (2004).

42. BHATTACHARJEE, S. \& Mukherjee, A. K. Heat and salinity induced oxidative stress and changes in protein profile in Amaranthus lividus L. Indian J. plant Physiol. 11, 41-47 (2006).

43. de Azevedo Neto, A. D., Prisco, J. T., Enéas-Filho, J., de Abreu, C. E. B. \& Gomes-Filho, E. Effect of salt stress on antioxidative enzymes and lipid peroxidation in leaves and roots of salt-tolerant and salt-sensitive maize genotypes. Environ. Exp. Bot. 56, 87-94 (2006).

44. Murthy, S. M., Devaraj, V. R., Anitha, P. \& Tejavathi, D. H. Studies on the activities of antioxidant enzymes under induced drought stress in in vivo and in vitro plants of Macrotyloma uniflorum (Lam.) Verdc. Recent Res. Sci. Technol. 4, 34-37 (2012). 
45. Randhawa, N. \& Kaur, J. Antioxidant responses of Chickpea genotypes exposed to moisture stress. Int. J. Adv. Res. 3, 950-955 (2015).

46. Sairam, R. K., Rao, K. V. \& Srivastava, G. C. Differential response of wheat genotypes to long term salinity stress in relation to oxidative stress, antioxidant activity and osmolyte concentration. Plant Sci. 163, 1037-1046 (2002).

47. Zeeshan, M., Lu, M., Sehar, S., Holford, P. \& Wu, F. Comparison of biochemical, anatomical, morphological, and physiological responses to salinity stress in wheat and barley genotypes deferring in salinity tolerance. Agronomy 10, 127 (2020).

48. Gill, S. S. et al. Glutathione and glutathione reductase: a boon in disguise for plant abiotic stress defense operations. Plant Physiol. Biochem. 70, 204-212 (2013).

49. Cao, M. et al. Sulfate availability affects $A B A$ levels and germination response to $A B A$ and salt stress in $A$ rabidopsis thaliana. Plant J. 77, 604-615 (2014).

50. Salama, A. Z., Lazova, G. N., Stoinova, Z. G., Popova, L. P. \& El-Fouly, M. M. Effect of zinc deficiency on photosynthesis in chick-pea and maize plants. Comptes Rendus l'Academie Bulg. des Sci. 55, 3-65 (2002).

51. Ngo, T. \& Zhao, Y. Retaining green pigments on thermally processed peels-on green pears. J. Food Sci. 70, C568-C574 (2005).

52. Lau, T. S. L., Eno, E., Goldstein, G., Smith, C. \& Christopher, D. A. Ambient levels of UV-B in Hawaii combined with nutrient deficiency decrease photosynthesis in near-isogenic maize lines varying in leaf flavonoids: Flavonoids decrease photoinhibition in plants exposed to UV-B. Photosynthetica 44, 394-403 (2006).

53. Dykes, L., Rooney, L. W., Waniska, R. D. \& Rooney, W. L. Phenolic compounds and antioxidant activity of sorghum grains of varying genotypes. J. Agric. Food Chem. 53, 6813-6818 (2005).

54. Rao, S. et al. Characterization of phenolic compounds and antioxidant activity in sorghum grains. J. Cereal Sci. 84, 103-111 (2018).

55. Shen, S. et al. Phenolic compositions and antioxidant activities differ significantly among sorghum grains with different applications. Molecules 23, 1203 (2018).

56. Wu, G. et al. Growth temperature and genotype both play important roles in sorghum grain phenolic composition. Sci. Rep. 6, 1-10 (2016).

57. Khoddami, A., Truong, H. H., Liu, S. Y., Roberts, T. H. \& Selle, P. H. Concentrations of specific phenolic compounds in six red sorghums influence nutrient utilisation in broiler chickens. Anim. Feed Sci. Technol. 210, 190-199 (2015)

58. Qureshi, M. I., Abdin, M. Z., Ahmad, J. \& lqbal, M. Effect of long-term salinity on cellular antioxidants, compatible solute and fatty acid profile of Sweet Annie (Artemisia annua L.). Phytochemistry 95, 215-223 (2013).

59. Anjum, S. A. et al. Morphological, physiological and biochemical responses of plants to drought stress. African J. Agric. Res. 6, 2026-2032 (2011).

60. Pottosin, I., Bonales-Alatorre, E. \& Shabala, S. Choline but not its derivative betaine blocks slow vacuolar channels in the halophyte Chenopodium quinoa: Implications for salinity stress responses. FEBS Lett. 588, 3918-3923 (2014).

61. Matysik, J., Alia, Bhalu, B. \& Mohanty, P. Molecular mechanisms of quenching of reactive oxygen species by proline under stress in plants. Curr. Sci. 525-532 (2002).

62. Arafa, A. A., Khafagy, M. A. \& El-Banna, M. F. The effect of glycinebetaine or ascorbic acid on the salt-stress induced damages in sorghum plant cells. Int. J. Bot. (2007).

63. Murata, N., Mohanty, P. S., Hayashi, H. \& Papageorgiou, G. C. Glycinebetaine stabilizes the association of extrinsic proteins with the photosynthetic oxygen-evolving complex. FEBS Lett. 296, 187-189 (1992).

64. Saneoka, H., Ishiguro, S. \& Moghaieb, R. E. A. Effect of salinity and abscisic acid on accumulation of glycinebetaine and betaine aldehyde dehydrogenase mRNA in Sorghum leaves (Sorghum bicolor). J. Plant Physiol. 158, 853-859 (2001).

65. Gill, P. K., Sharma, A. D., Singh, P. \& Bhullar, S. S. Changes in germination, growth and soluble sugar contents of Sorghum bicolor (L.) Moench seeds under various abiotic stresses. Plant Growth Regul. 40, 157-162 (2003).

66. Bailly, C., El-Maarouf-Bouteau, H. \& Corbineau, F. From intracellular signaling networks to cell death: the dual role of reactive oxygen species in seed physiology. C. R. Biol. 331, 806-814 (2008).

67. Acosta-Motos, J. R. et al. Towards a sustainable agriculture: Strategies involving phytoprotectants against salt stress. Agronomy 10, 194 (2020).

68. Forghani, A. H., Almodares, A. \& Ehsanpour, A. A. The role of gibberellic acid and paclobutrazol on oxidative stress responses induced by in vitro salt stress in sweet sorghum. Russ. J. Plant Physiol. 67, 555-563 (2020).

69. Selote, D. S. \& Khanna-Chopra, R. Drought-induced spikelet sterility is associated with an inefficient antioxidant defence in rice panicles. Physiol. Plant. 121, 462-471 (2004).

70. Sharma, P. \& Dubey, R. S. Drought induces oxidative stress and enhances the activities of antioxidant enzymes in growing rice seedlings. Plant Growth Regul. 46, 209-221 (2005).

71. Reddy, P. S. et al. Proline over-accumulation alleviates salt stress and protects photosynthetic and antioxidant enzyme activities in transgenic sorghum [Sorghum bicolor (L.) Moench]. Plant Physiol. Biochem. 94, 104-113 (2015).

72. Flores, H. E. \& Galston, A. W. Analysis of polyamines in higher plants by high performance liquid 
chromatography. Plant Physiol. 69, 701-706 (1982).

73. Fraga, M. F., Rodríguez, R. \& Cañal, M. J. Reinvigoration of Pinus radiata is associated with partial recovery of juvenile-like polyamine concentrations. Tree Physiol. 23, 205-209 (2003).

74. Slocum, R. D., Flores, H. E., Galston, A. W. \& Weinstein, L. H. Improved method for HPLC analysis of polyamines, agmatine and aromatic monoamines in plant tissue. Plant Physiol. 89, 512-517 (1989).

75. Punia, H., Madan, S., Malik, A. \& Sethi, S. K. Stability analysis for quality attributes in durum wheat (Triticum durum L.) genotypes. Bangladesh J. Bot. 48, 967-972 (2019).

76. Hussain, H. A. et al. Interactive effects of drought and heat stresses on morpho-physiological attributes, yield, nutrient uptake and oxidative status in maize hybrids. Sci. Rep. 9, 1-12 (2019).

77. Knight, H., Trewavas, A. J. \& Knight, M. R. Cold calcium signaling in Arabidopsis involves two cellular pools and a change in calcium signature after acclimation. Plant Cell 8, 489-503 (1996).

78. Shi, H., Ishitani, M., Kim, C. \& Zhu, J.-K. The Arabidopsis thaliana salt tolerance gene SOS1 encodes a putative $\mathrm{Na}+/ \mathrm{H}+$ antiporter. Proc. Natl. Acad. Sci. 97, 6896-6901 (2000).

79. Qiu, Q. S., Guo, Y., Dietrich, M. A., Schumaker, K. S. \& Zhu, J. K. Characterization of the plasma membrane $\mathrm{Na}+/ \mathrm{H}+$ exchanger in Arabidopsis thaliana. in The 12th International Workshop Plant Membrane Biology, Madison 235 (University of Wisconsin, 2001).

80. Wu, S.-J., Ding, L. \& Zhu, J.-K. SOS1, a genetic locus essential for salt tolerance and potassium acquisition. Plant Cell 8, 617-627 (1996).

81. Zhu, J.-K., Liu, J. \& Xiong, L. Genetic analysis of salt tolerance in Arabidopsis: evidence for a critical role of potassium nutrition. Plant Cell 10, 1181-1191 (1998).

82. Barrs, H. D. \& Weatherley, P. E. A re-examination of the relative turgidity technique for estimating water deficits in leaves. Aust. J. Biol. Sci. 15, 413-428 (1962).

83. MURPHY, K. S. Modifications of the technique for determination of chlorophyll stability index in relation to studies of drought resistance in rice. Curr. Sci. 31, 470-471 (1962).

84. Beauchamp, C. \& Fridovich, I. Superoxide dismutase: improved assays and an assay applicable to acrylamide gels. Anal. Biochem. 44, 276-287 (1971).

85. Aebi, H. [13] Catalase in vitro. Methods Enzymol. 105, 121-126 (1984).

86. Kumar, K. B. \& Khan, P. A. Peroxidase and polyphenol oxidase in excised ragi (Eleusine corocana cv PR 202) leaves during senescence. Indian J. Exp. Biol. 20, 412-416 (1982).

87. Nakano, Y. \& Asada, K. Hydrogen peroxide is scavenged by ascorbate-specific peroxidase in spinach chloroplasts. Plant cell Physiol. 22, 867-880 (1981).

88. Halliwell, B. \& Foyer, C. H. Properties and physiological function of a glutathione reductase purified from spinach leaves by affinity chromatography. Planta 139, 9-17 (1978).

89. Nagalakshmi, N. \& Prasad, M. N. V. Responses of glutathione cycle enzymes and glutathione metabolism to copper stress in Scenedesmus bijugatus. Plant Sci. 160, 291-299 (2001).

90. Hossain, M. A., Nakano, Y. \& Asada, K. Monodehydroascorbate reductase in spinach chloroplasts and its participation in regeneration of ascorbate for scavenging hydrogen peroxide. Plant cell Physiol. 25, 385-395 (1984).

91. Lowry, O. H., Rosebrough, N. J., Farr, A. L. \& Randall, R. J. Protein measurement with the Folin phenol reagent. J. Biol. Chem. 193, 265-275 (1951).

92. Mukherjee, S. P. \& Choudhuri, M. A. Implications of water stress-induced changes in the levels of endogenous ascorbic acid and hydrogen peroxide in Vigna seedlings. Physiol. Plant. 58, 166-170 (1983).

93. Smith, I. K. Stimulation of glutathione synthesis in photorespiring plants by catalase inhibitors. Plant Physiol. 79, 1044-1047 (1985).

94. Wellburn, A. R. \& Lichtenthaler, H. Formulae and program to determine total carotenoids and chlorophylls a and $b$ of leaf extracts in different solvents. in Advances in photosynthesis research 9-12 (Springer, 1984).

95. Benzie, I. F. F. \& Strain, J. J. [2] Ferric reducing/antioxidant power assay: direct measure of total antioxidant activity of biological fluids and modified version for simultaneous measurement of total antioxidant power and ascorbic acid concentration. in Methods in enzymology vol. 299 15-27 (Elsevier, 1999).

96. Sompong, R., Siebenhandl-Ehn, S., Linsberger-Martin, G. \& Berghofer, E. Physicochemical and antioxidative properties of red and black rice varieties from Thailand, China and Sri Lanka. Food Chem. 124, 132-140 (2011).

97. Re, R. et al. Antioxidant activity applying an improved ABTS radical cation decolorization assay. Free Radic. Biol. Med. 26, 1231-1237 (1999).

98. Swain, T. \& Hillis, W. E. The phenolic constituents of Prunus domestica. I.-The quantitative analysis of phenolic constituents. J. Sci. Food Agric. 10, 63-68 (1959).

99. Delcour, J. A. \& Varebeke, D. J. de. A new colourimetric assay for flavanoids in pilsner beers. J. Inst. Brew. 91, 37-40 (1985).

100. Johnson, G. \& Schaal, L. A. Relation of chlorogenic acid to scab resistance in potatoes. Science (80-. ). 115, 627-629 (1952).

101. Balbaa, S. I., Zaki, A. Y. \& El Shamy, A. M. Total Flavonoid and Rutin Content of the Different Organs of Sophora japonica L. J. Assoc. Off. Anal. Chem. 57, 752-755 (1974). 
102. Bates, L. S., Waldren, R. P. \& Teare, I. D. Rapid determination of free proline for water-stress studies. Plant Soil 39, 205-207 (1973).

103. Grieve, C. M. \& Grattan, S. R. Rapid assay for determination of water soluble quaternary ammonium compounds. Plant Soil 70, 303-307 (1983).

104. Dubois, M., Gilles, K. A., Hamilton, J. K., Rebers, P. A. t \& Smith, F. Colorimetric method for determination of sugars and related substances. Anal. Chem. 28, 350-356 (1956).

105. Heath, R. L. \& Packer, L. Photoperoxidation in isolated chloroplasts: II. Role of electron transfer. Arch. Biochem. Biophys. 125, 850-857 (1968).

106. Sullivan, C. Y. Selection for drought and heat tolerance in grain sorghum. Stress Physiol. Crop plants (1979).

107. Sinha, A. K. Colorimetric assay of catalase. Anal. Biochem. 47, 389-394 (1972).

108. Malik, A. U. \& Singh, Z. Endogenous free polyamines of mangos in relation to development and ripening. J. Am. Soc. Hortic. Sci. 129, 280-286 (2004).

\section{Acknowledgement}

First Author Ms. Himani is thankful to the Department of Science \& Technology, SERB and CII under the Prime Minister's Fellowship Scheme for Doctoral Research for providing financial assistance to carry out this research work. Authors are thankful to Forage Section, Department of Genetics \& Plant Breeding, CCS $\mathrm{HAU}$, Hisar for providing the seeds of sorghum genotypes and CCS HAU, Hisar for providing the necessary facilities and support to carry out the research.

\section{Author Contributing Statement}

All authors contributed to the study conception and design. Material preparation, data collection and analysis were performed by H.P. and A.M. J.T., N.K. and S.Y. check the final draft and reviewed the manuscript. Satpal provided the sorghum seeds. All the authors read and approved the final manuscript.

\section{Conflict of Interest}

The authors declare that there is no conflict of interests regarding the publication of this paper. 
Figures

$\mathrm{A}^{-} \mathrm{B}$
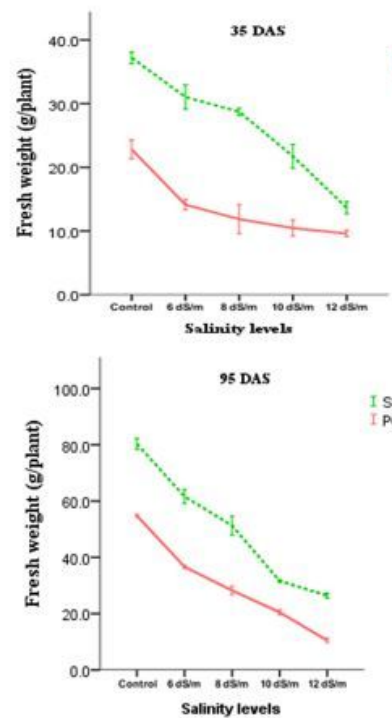
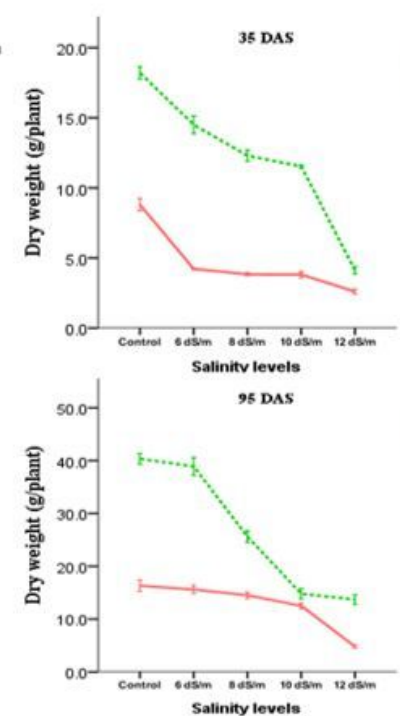

$\mathrm{C}$
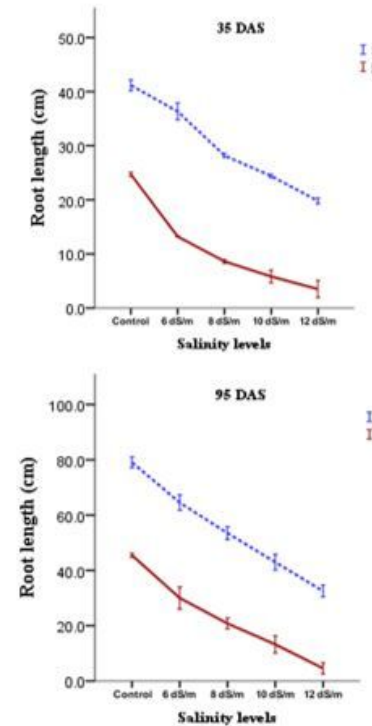

$\mathrm{D}$
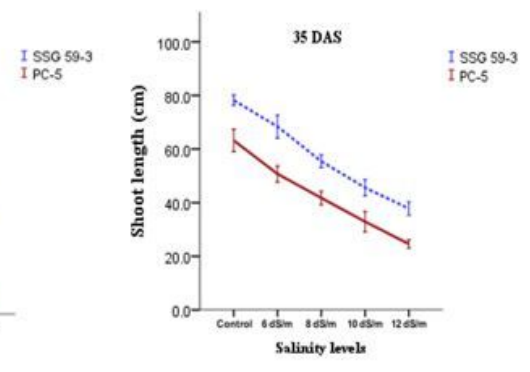

SsG 59-3

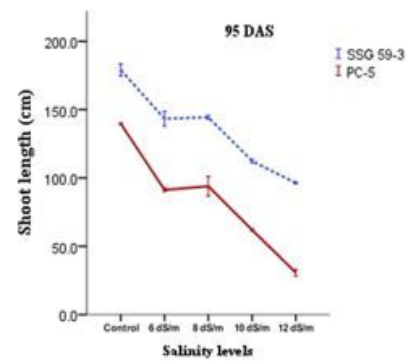

Figure 1

Effect of salt stress on fresh weight (A), dry weight (B), Root length (C), and shoot length (D) of sorghum genotypes at 35 and 95 DAS. Values are means of at least three replicates and significant differences between means, as determined by Tuckey's test $(P<0.05)$.

A
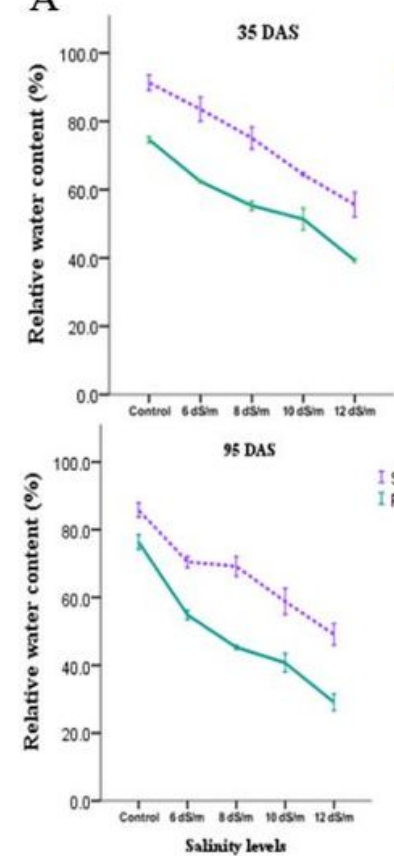

B
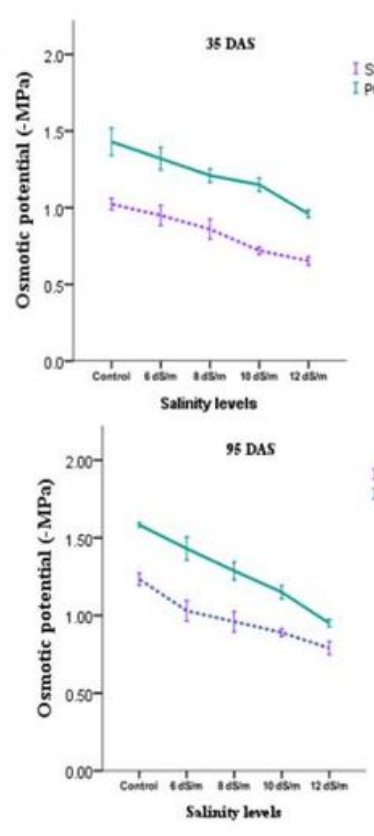

$\mathrm{C}$

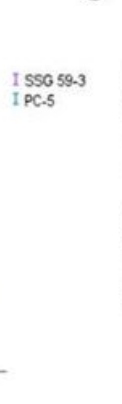

ssa $59-3$

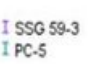

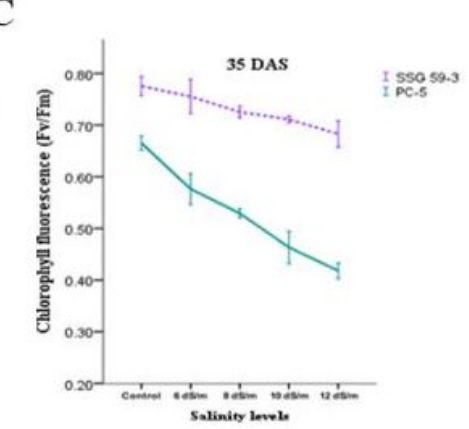

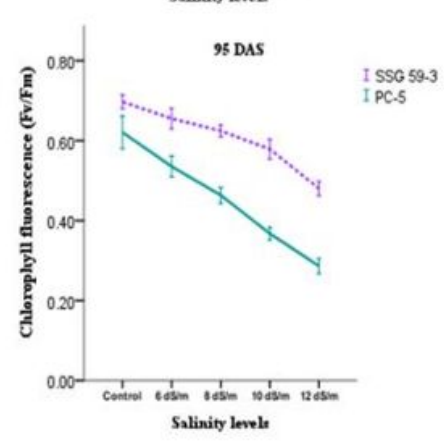

D
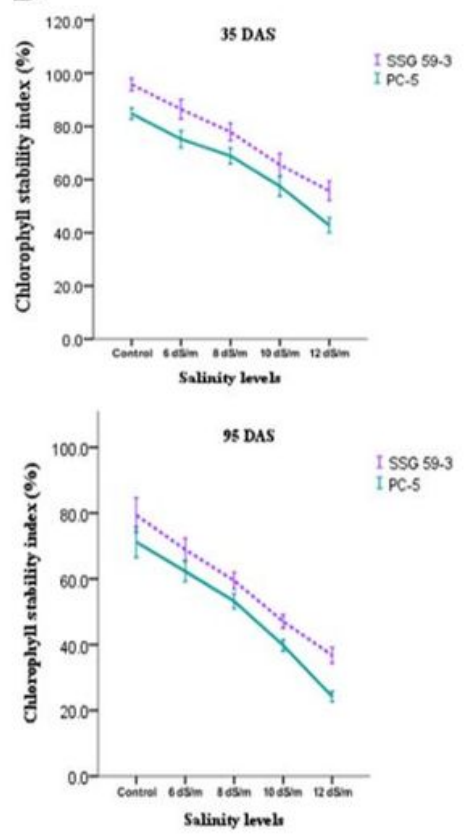

Figure 2 
Effect of salt stress on relative water content (A), osmotic potential (B), chlorophyll fluorescence (C), and chlorophyll stability index (D) of sorghum genotypes at 35 and 95 DAS. Values are means of at least three replicates and significant differences between means, as determined by Tuckey's test $(P<0.05)$.

A
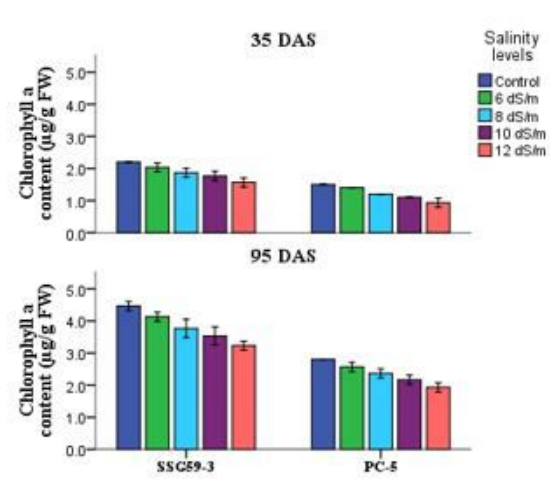

$\mathrm{B}$
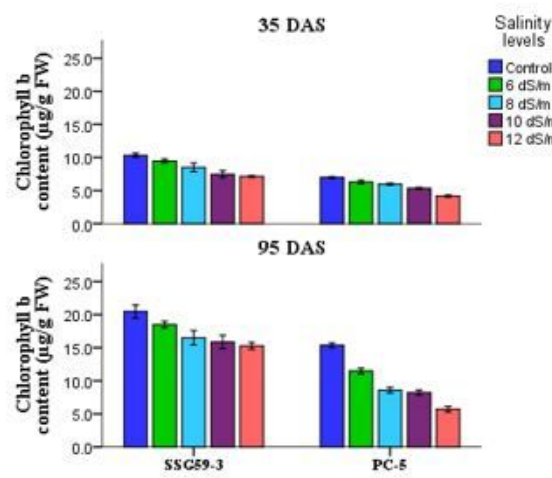

$\mathrm{C}$
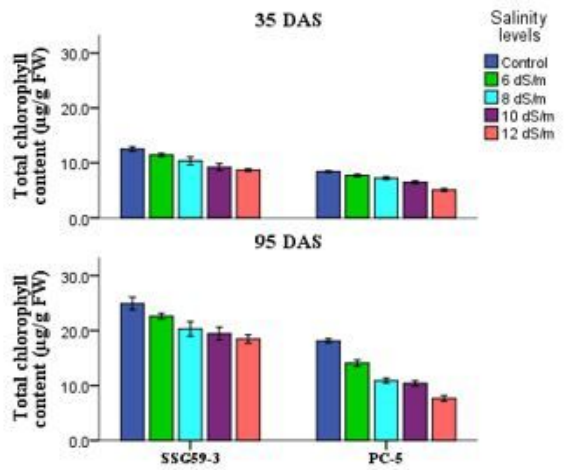

\section{Figure 3}

Effect of salt stress on chlorophyll a (A), chlorophyll B (B), and total chlorophyll (C) of sorghum genotypes at 35 and 95 DAS. Values are means of at least three replicates and significant differences between means, as determined by Tuckey's test $(P<0.05)$.

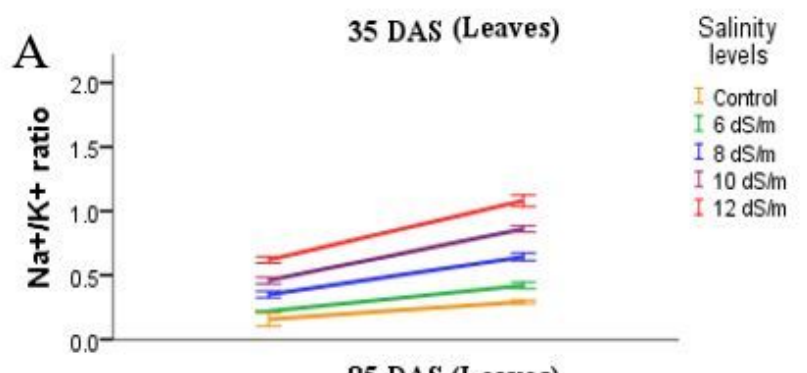

95 DAS (L eaves)

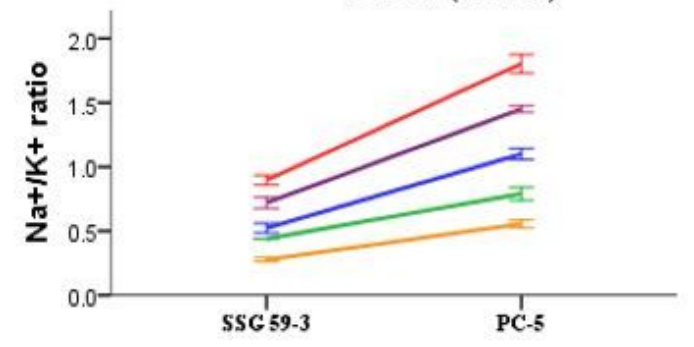

$\mathrm{B}$
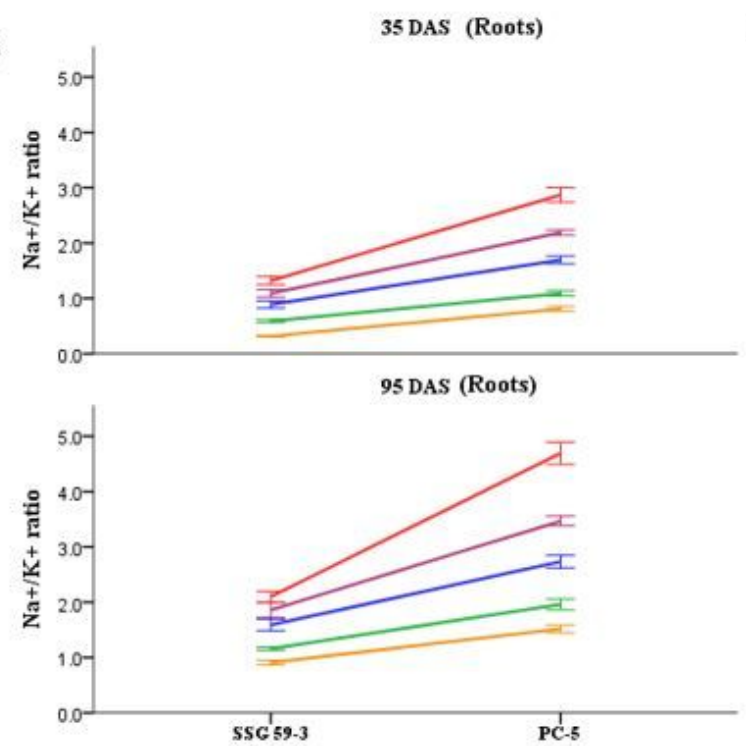

Salinitylevels I control

I $8 \mathrm{dSim}$

$12 \mathrm{dStm}$

\section{Figure 4}

Effect of salt stress on $\mathrm{Na}+\mathrm{K}+$ in leaves $(\mathrm{A})$, and $\mathrm{Na}+\mathrm{K}+$ in roots $(\mathrm{B})$ of sorghum genotypes at 35 and 95 DAS. Values are means of at least three replicates and significant differences between means, as determined by Tuckey's test $(P<0.05)$. 
A
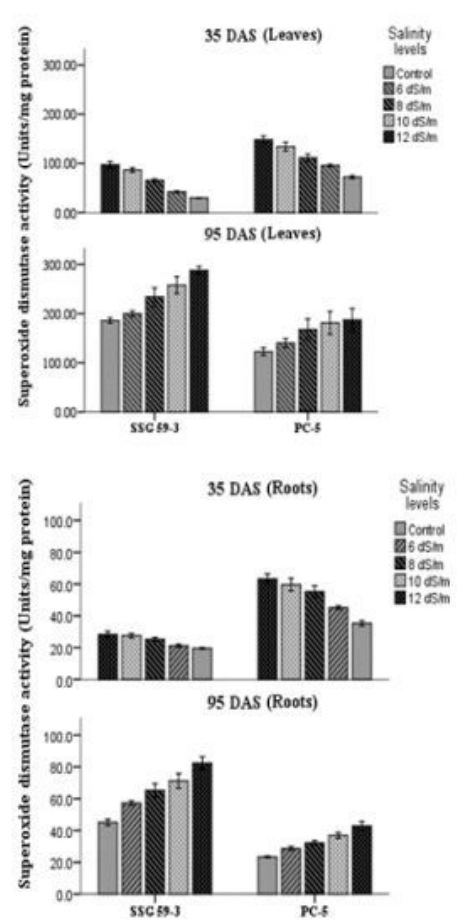

B
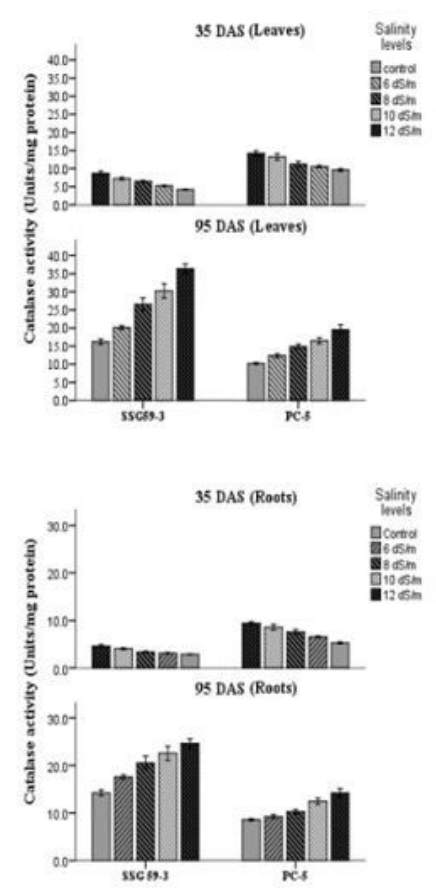

$\mathrm{C}$
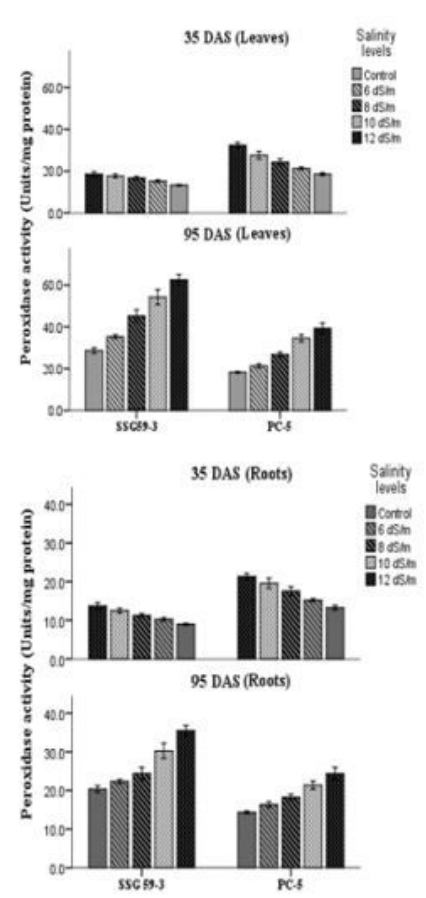

$\mathrm{D}$
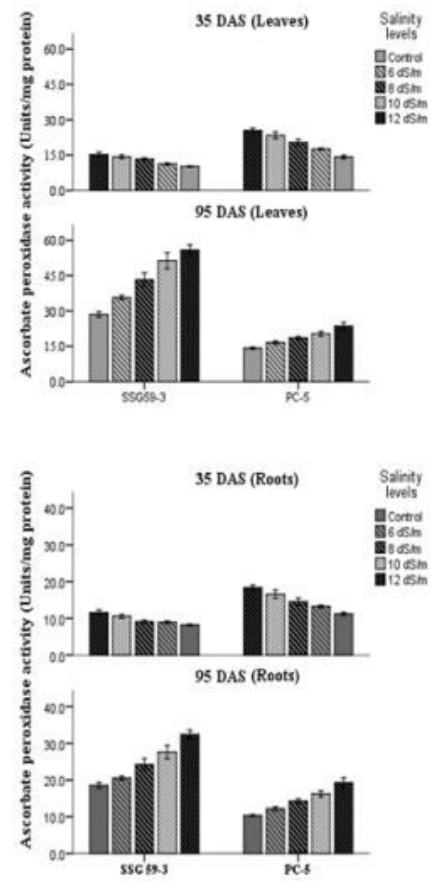

Figure 5

Effect of salt stress on superoxide dismutase (SOD, A), catalase (CAT, B), peroxidase (POX, C), and ascorbate peroxidase (APX, D) of sorghum genotypes at 35 and 95 DAS. Values are means of at least three replicates and significant differences between means, as determined by Tuckey's test $(P<0.05)$. 
A
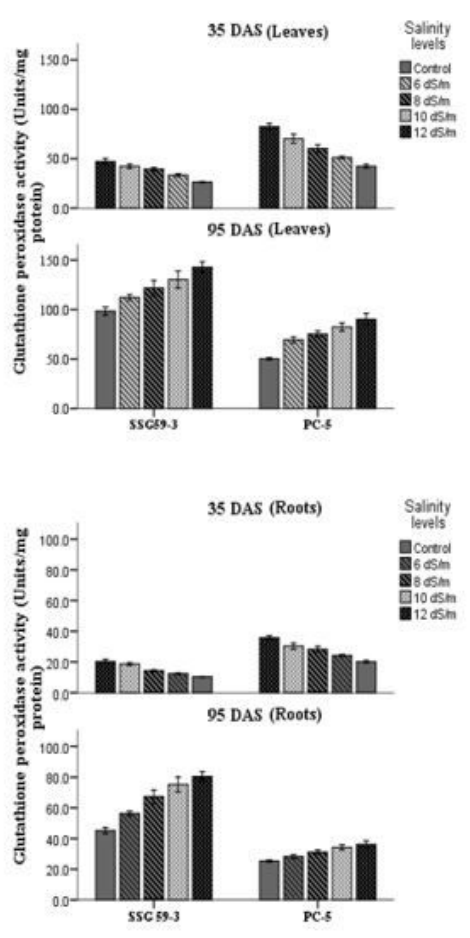

B
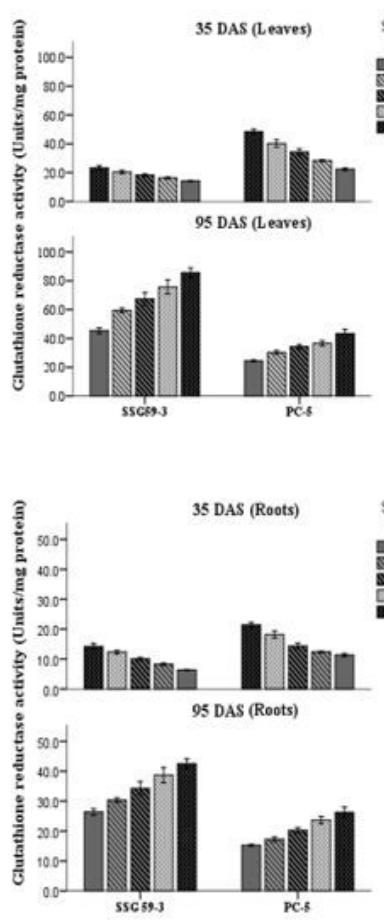
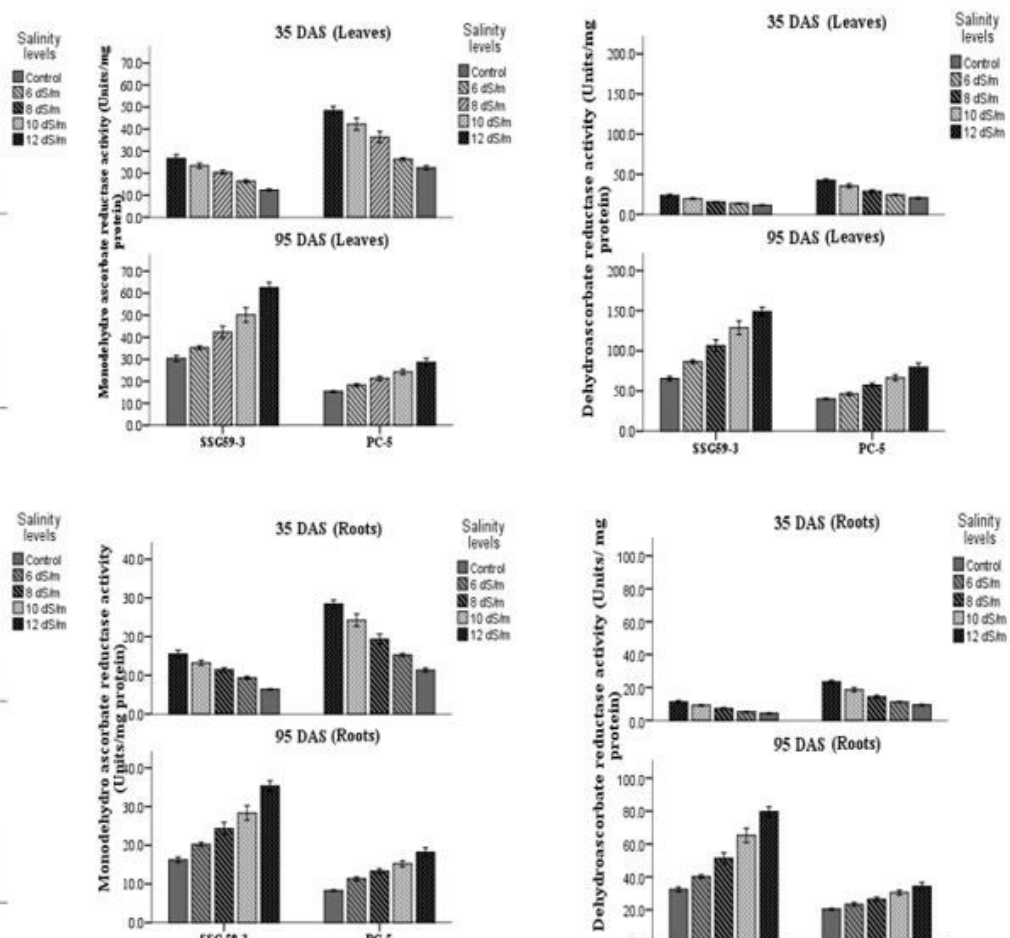

$\mathrm{C}$

$\mathrm{D}$

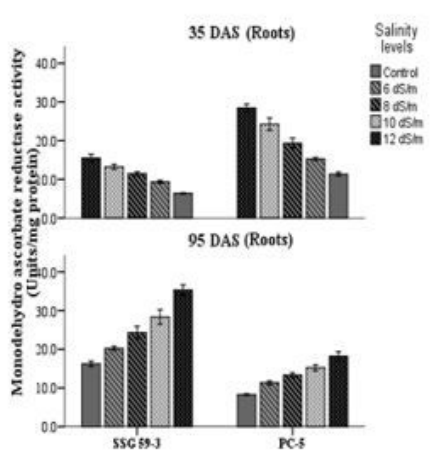

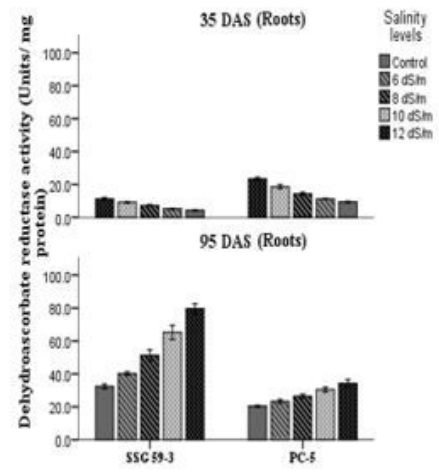

Figure 6

Effect of salt stress on glutathione peroxidase (GPX, A), glutathione reductase (GR, B), monodehydroascorbate reductase (MDHAR, C), and dehydroascorbate reductase (DHAR, D) of sorghum genotypes at 35 and 95 DAS. Values are means of at least three replicates and significant differences between means, as determined by Tuckey's test $(P<0.05)$. 

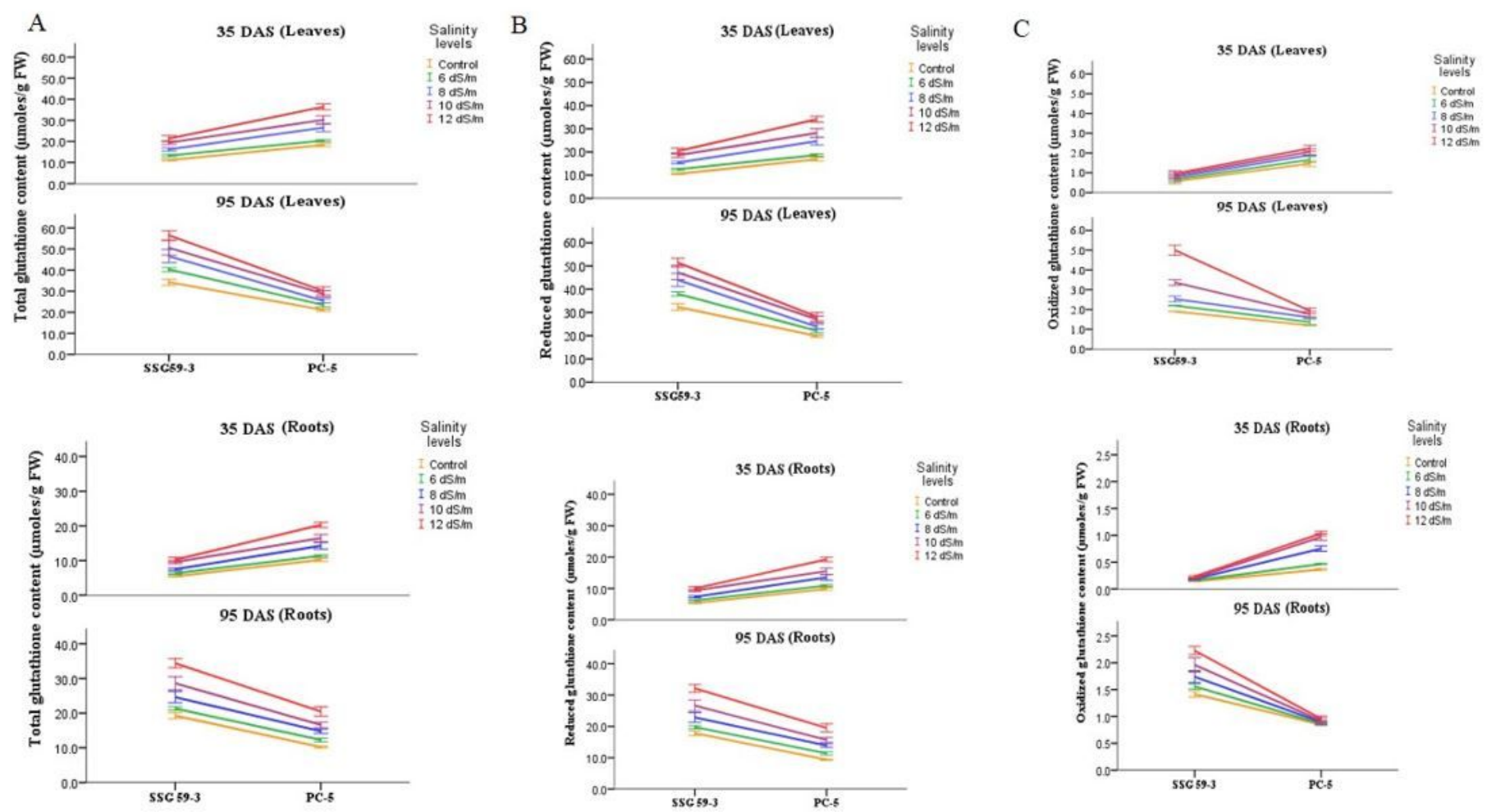

Figure 7

Effect of salt stress on total glutathione $(A)$, reduced glutathione $(G S H, B)$, and oxidized glutathione (GSSG, C) of sorghum genotypes at 35 and 95 DAS. Values are means of at least three replicates and significant differences between means, as determined by Tuckey's test $(P<0.05)$.
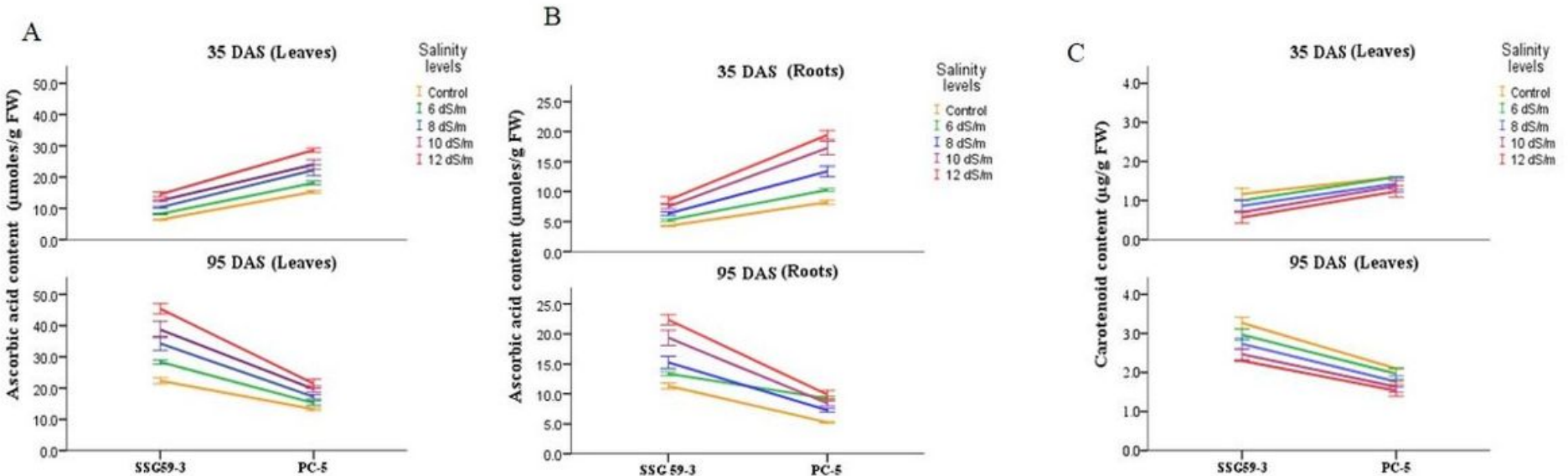

Figure 8

Effect of salt stress on ascorbic acid (ASC, A and B) and carotenoids (B) of sorghum genotypes at 35 and 95 DAS. Values are means of at least three replicates and significant differences between means, as determined by Tuckey's test $(P<0.05)$. 

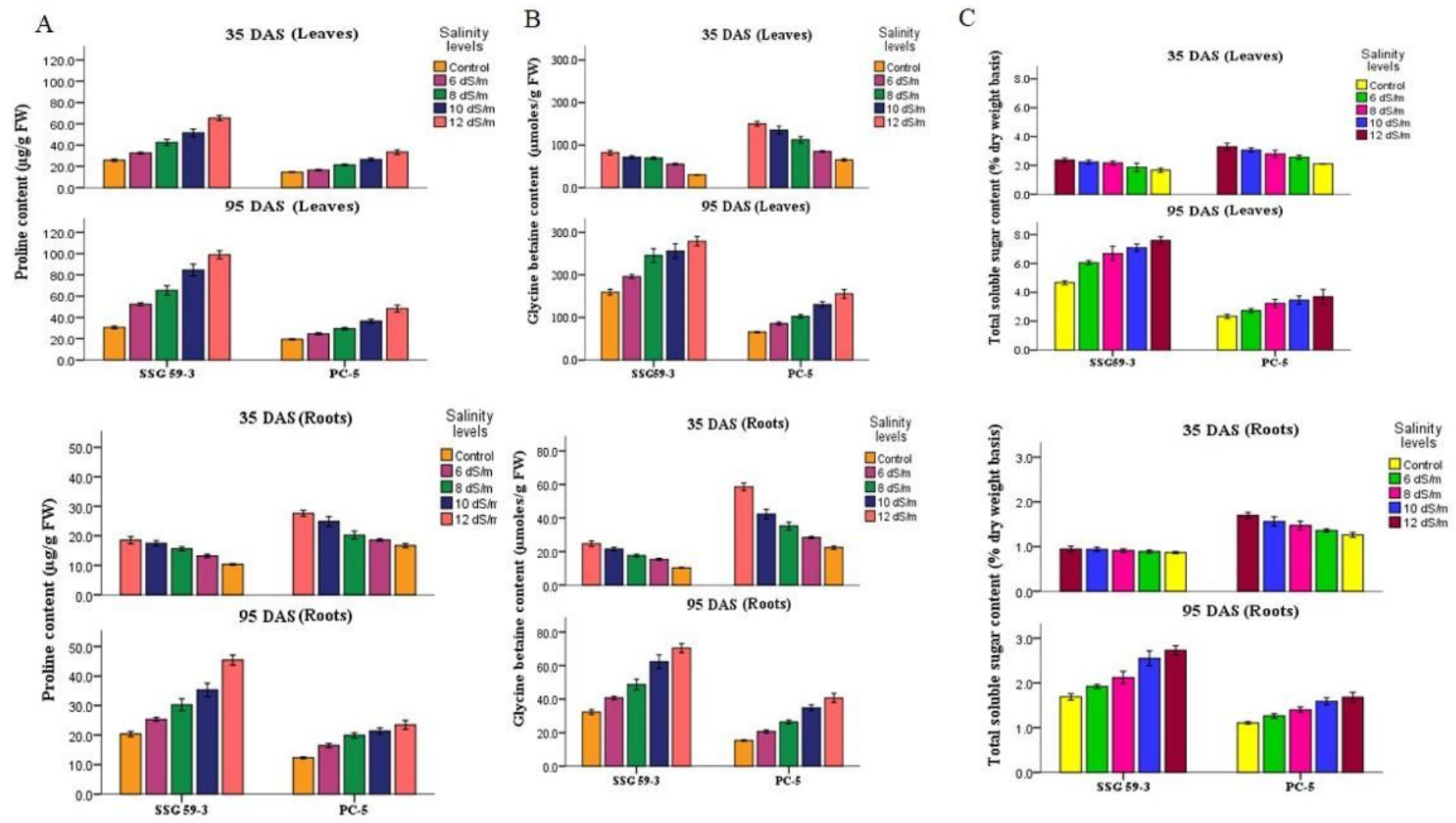

Figure 9

Effect of salt stress on proline (Pro, A), glycine betaine (GB, B), and total soluble carbohydrates (TSC, C) of sorghum genotypes at 35 and 95 DAS. Values are means of at least three replicates and significant differences between means, as determined by Tuckey's test $(P<0.05)$.
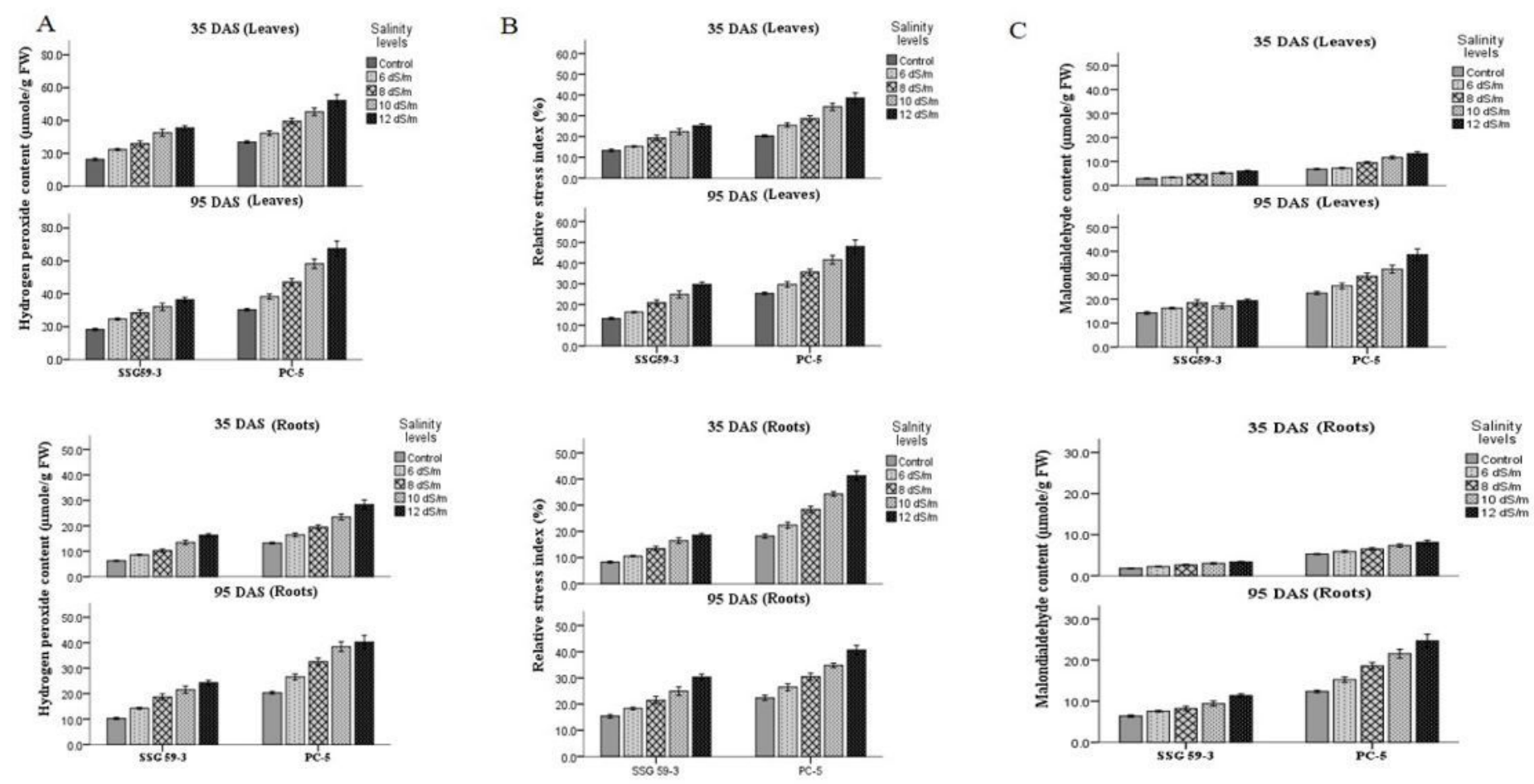
Figure 10

Effect of salt stress on hydrogen peroxide $(\mathrm{H} 2 \mathrm{O} 2, A)$, relatives stress index (RSI, $B)$, and malondialdehyde (MDA, C) of sorghum genotypes at 35 and 95 DAS. Values are means of at least three replicates and significant differences between means, as determined by Tuckey's test $(P<0.05)$.

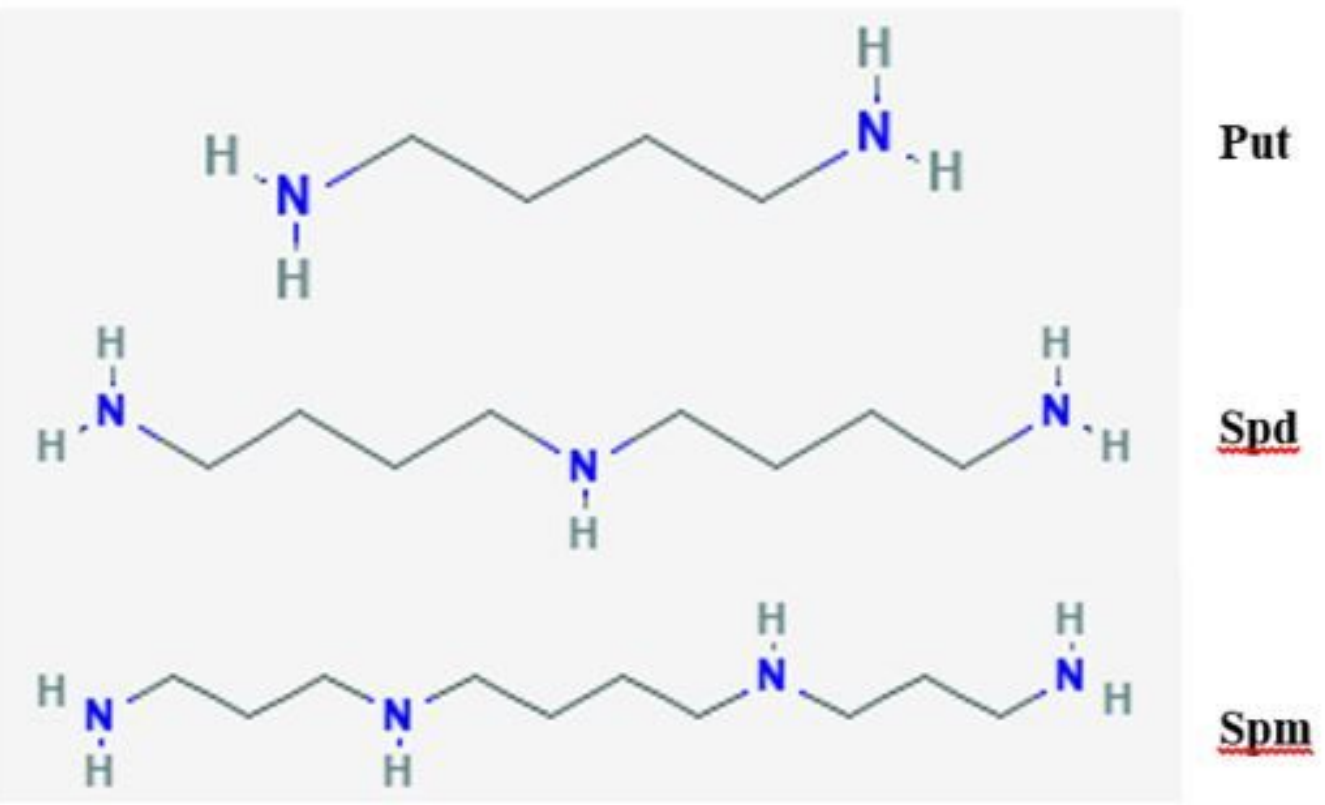

Figure 11

Chemical structures of the polyamines discussed in this study 

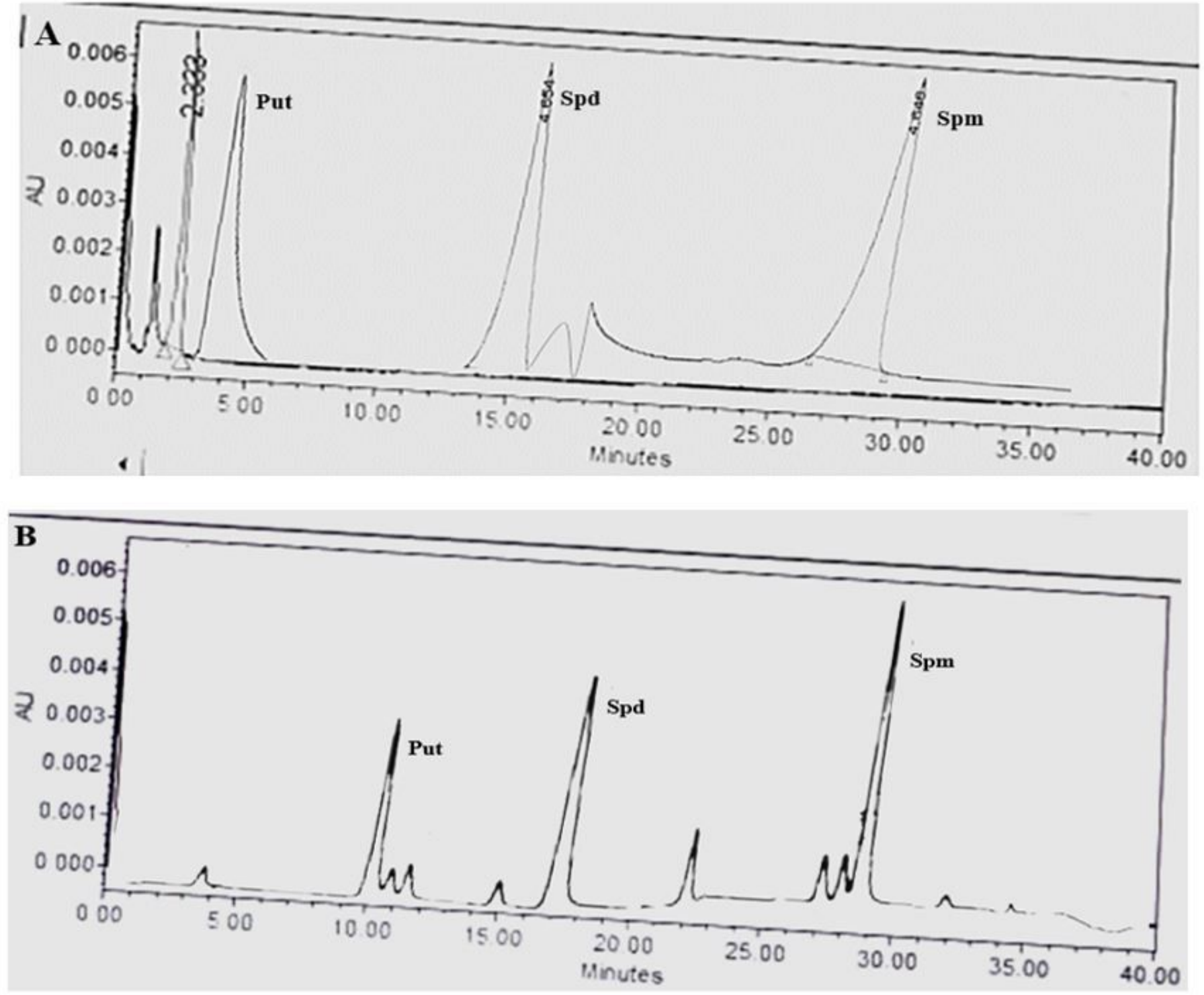

Figure 12

HPLC chromatogram and elusion profile of benzoylated polyamine (A) HPLC of benzoylated polyamine standards; Put, Spd and Spm at $0.05 \mathrm{mM}$ concentration (B) Identification of polyamines in sorghum extracts with each of each Put, Spd and Spm. 


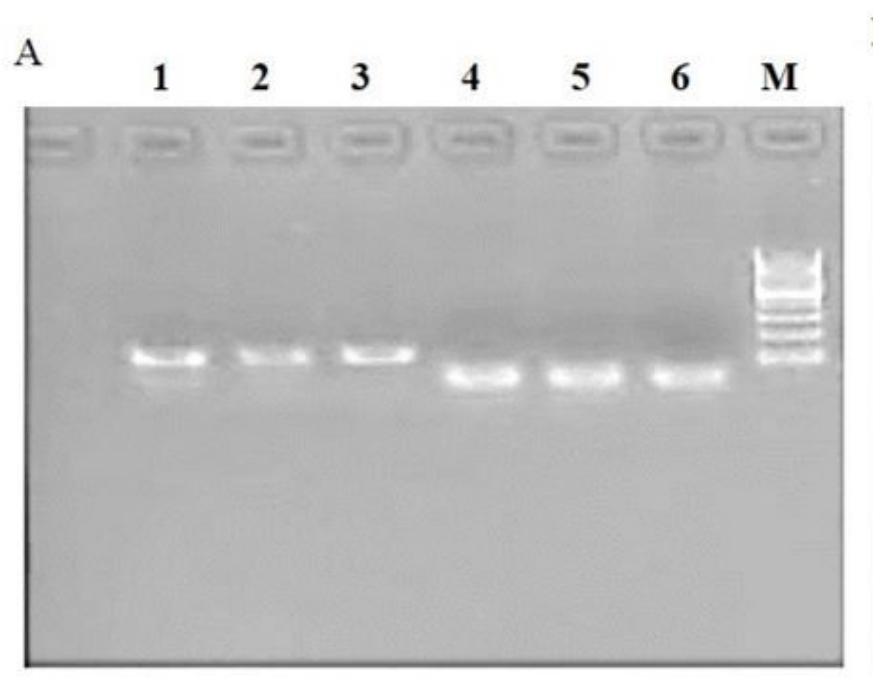

B

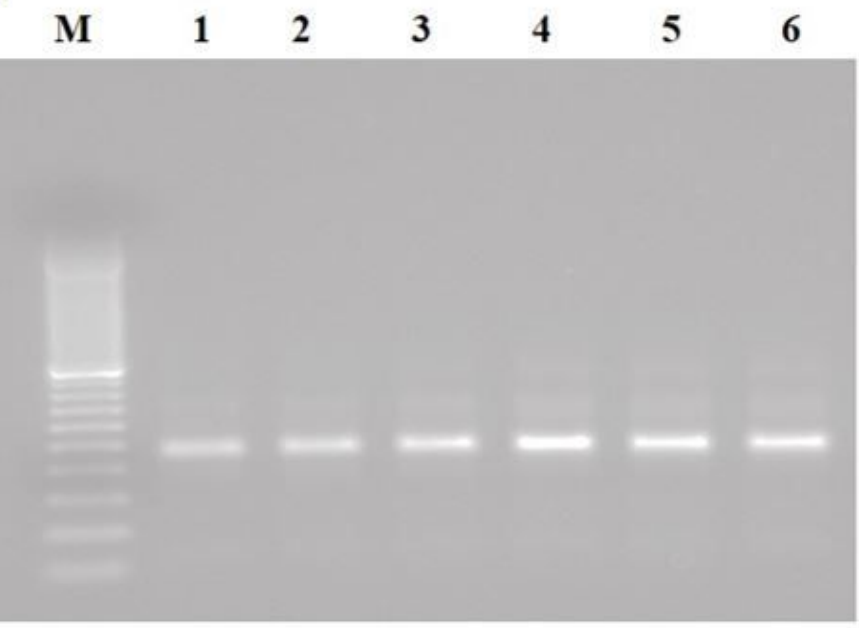

\section{Figure 13}

Semi-quantitative RT-PCR analysis of ion transporter genes. (A) salt overly sensitive 1 (SOS1): Lane 1: PC5 (Control); Lane 2: PC-5 (100 mM NaCl); Lane 3: PC-5 (120 mM NaCl); Lane 4: SSG 59-3 (Control); Lane 5: SSG 59-3 (100 mM NaCl); Lane 6: SSG 59-3 (120 mM NaCl) (B) salt overly sensitive 2 (SOS2): ): Lane 1: PC-5 (Control); Lane 2: PC-5 (100 mM NaCl); Lane 3: PC-5 (120 mM NaCl); Lane 4: SSG 59-3 (Control); Lane 5: SSG 59-3 (100 mM NaCl); Lane 6: SSG 59-3 (120 mM NaCl); M: molecular marker. 
A

B
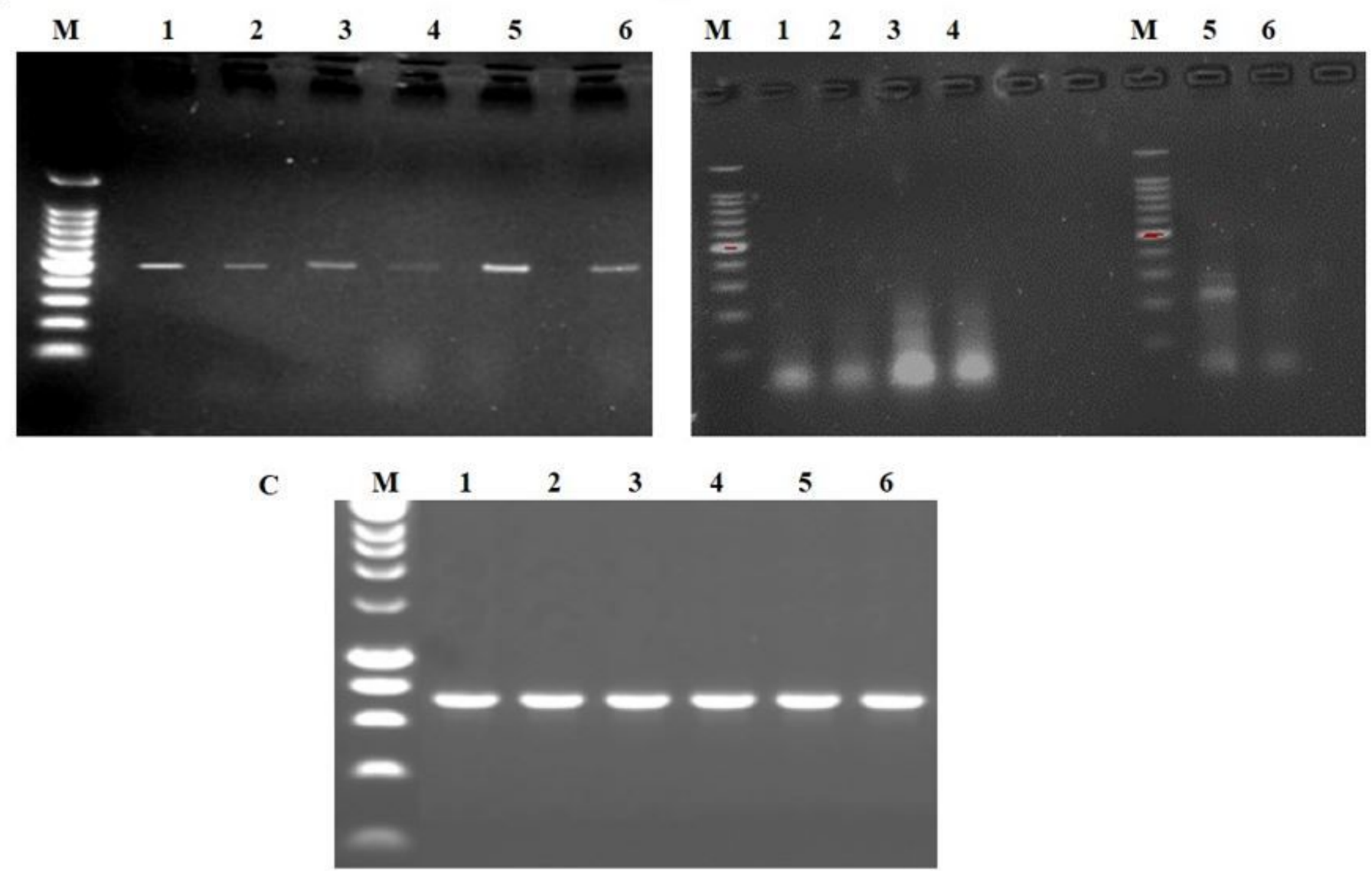

\section{Figure 14}

Semi-quantitative RT-PCR analysis of ion transporter genes in sorghum. (A) vacoular pyrophospatase (H+-PPase): Lane 1: SSG 59-3 (120 mM NaCl); Lane 2: SSG 59-3 (100 mM NaCl); Lane 3: SSG 59-3 (Control); Lane 4: PC-5 (Control); Lane 5: PC-5 (100 mM NaCl); Lane 6: PC-5 (120 mM NaCl); (B) sodium proton antiporter (NHX): Lane 1: PC-5 (120 mM NaCl); Lane 2: PC-5 (100 mM NaCl); Lane 3: SSG 59-3 (120 mM NaCl); Lane 4: SSG 59-3 (100 mM NaCl); Lane 5: SSG 59-3 (Control); Lane 6: PC-5 (Control); (C): Actin (act1): constitutive expression of actin under different salinity levels; Lane 1: PC-5 (Control); Lane 2: PC-5 (100 mM NaCl); Lane 3: PC-5 (120 mM NaCl); Lane 4: SSG 59-3 (Control); Lane 5: SSG 59-3 (100 mM NaCl); Lane 6: SSG 59-3 (120 mM NaCl); M: molecular marker. 


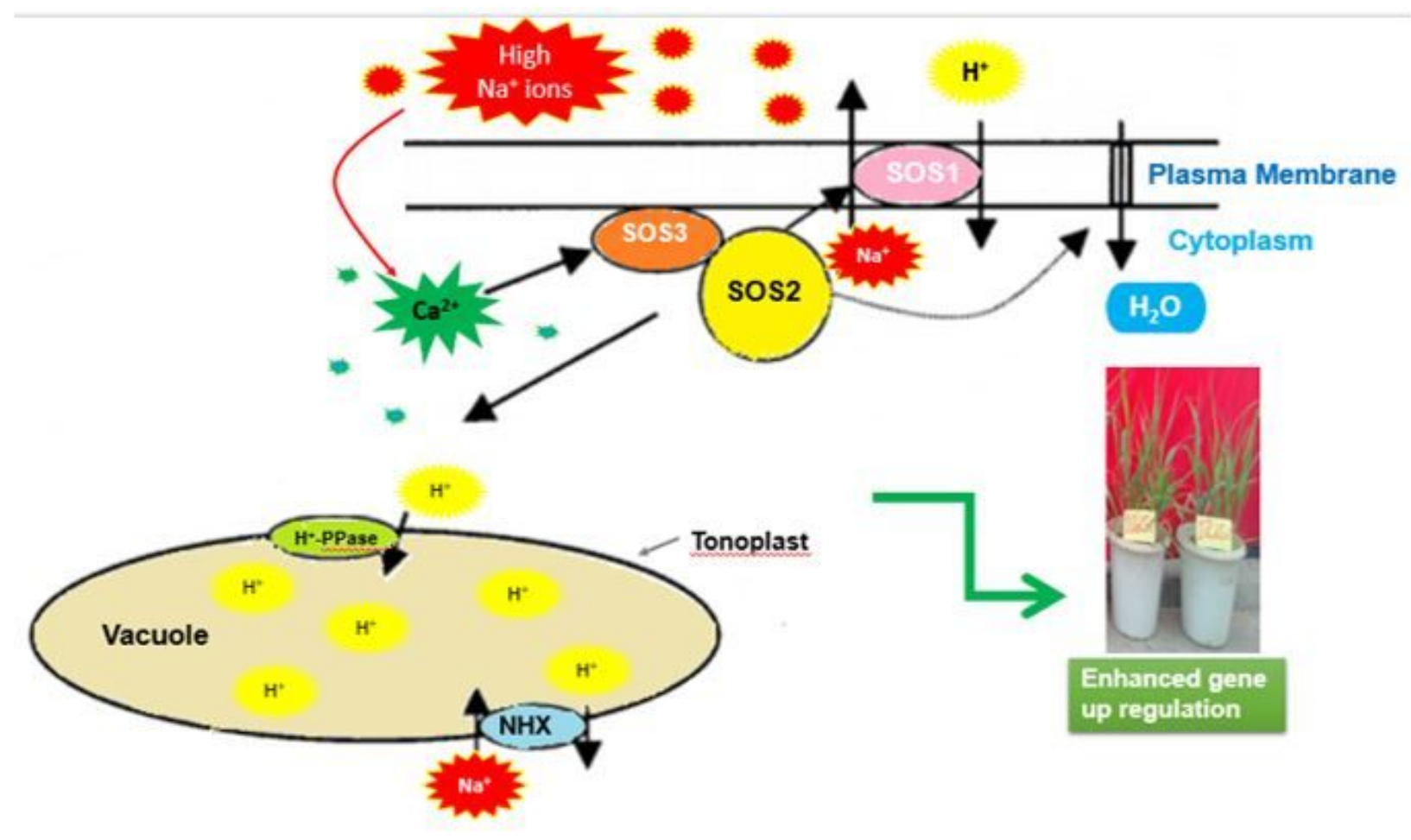

Figure 15

Regulation of $\mathrm{Na}+$ and $\mathrm{K}+$ ion homeostasis by the SOS pathway. Excess of $\mathrm{Na}+$ ions elicits a calcium signaling pathway which activates the SOS1-SOS3 protein kinase complex, which in turn stimulates the SOS1 and sodium proton antiporter (NHX) exchange activity and thus, regulates the expression of genes encoding them.

\section{Supplementary Files}

This is a list of supplementary files associated with this preprint. Click to download.

- ga.jpg

- ps1.jpg

- ps2.jpg 